Departamento de Química Instituto de

Tecnología Química (UPV / CSIC)
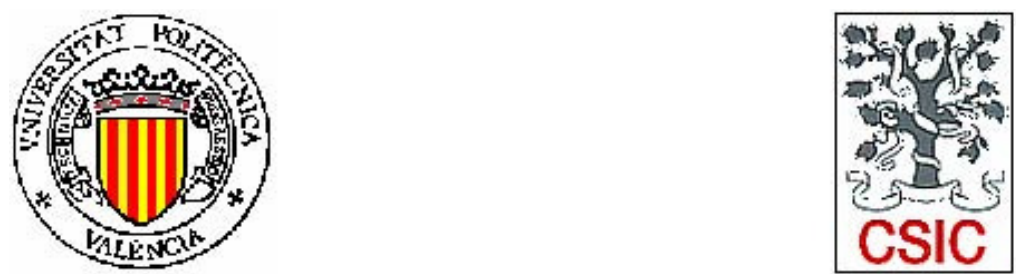

\title{
INTERACCIONES FÁRMACO-PROTEÍNA EN ESTADOS EXCITADOS
}

\section{TESIS DOCTORAL}

\section{Presentada por:}

Carlos Javier Bueno Alejo

\section{Dirigida por:}

Dr. Miguel A. Miranda Alonso

Dra. M. Consuelo Jiménez Molero 

Departamento de Química Instituto de Tecnología Química (UPV / CSIC)
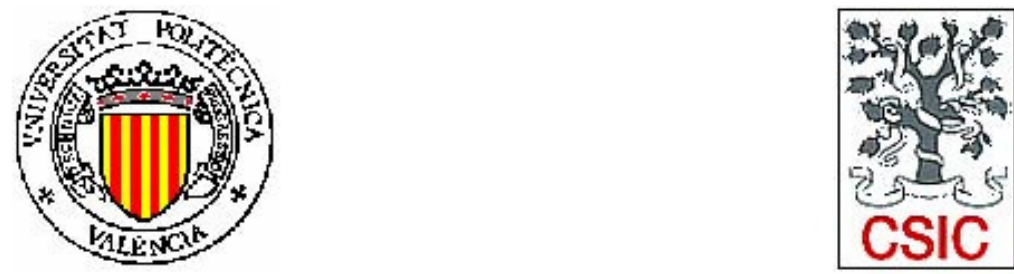

\title{
INTERACCIONES FÁRMACO-PROTEÍNA EN ESTADOS EXCITADOS
}

\section{TESIS DOCTORAL}

\author{
Presentada por: \\ Carlos Javier Bueno Alejo \\ Dirigida por: \\ Dr. Miguel A. Miranda Alonso \\ Dra. M. Consuelo Jiménez Molero
}

Valencia, Noviembre 2009 

D. MIGUEL ÁNGEL MIRANDA ALONSO, Catedrático de Química de la Universidad Politécnica de Valencia, y Dña. MARIA CONSUELO JIMÉNEZ MOLERO, Profesora Titular de Universidad de la Universidad Politécnica de Valencia,

CERTIFICAN: Que la presente tesis doctoral, titulada: "Interacciones Fármaco-Proteína en estados excitados", ha sido desarrollada por CARLOS JAVIER BUENO ALEJO, bajo su dirección, en el Departamento de Química-Instituto de Tecnología Química (UPV/CSIC) de la Universidad Politécnica de Valencia.

D. Miguel A. Miranda Alonso Dña. M. Consuelo Jiménez Molero 

Creer es muy monótono; la duda es apasionante.

Oscar Wilde 

A mi familia 



\section{Agradecimientos}

En cuatro años da tiempo a conocer a mucha gente que de una u otra manera influye en tu vida. Si escribiera el nombre de todos los que me han ayudado en este tiempo tendría que añadir otro tomo a la tesis y, sinceramente, con uno es más que suficiente. Me limitaré a decir que ha sido una época maravillosa que jamás olvidaré, sobre todo por la gente que he conocido y que han hecho posible que, aun estando lejos de casa, me sintiera como en familia. Por esto, quiero agradecer a todas esas personas el apoyo recibido.

Entre ellas, me gustaría destacar a mis directores de tesis que tanta paciencia han tenido conmigo. Gracias por confiar en mí para este proyecto y por apoyarme cada vez que lo necesitaba.

A todos los compañeros del departamento, ITQ e ICMol con los que he compartido tan buenos momentos, tanto dentro como fuera del laboratorio (aunque los mejores sean los de fuera). Gracias por esos ratos de cerveceo en el Max que tan bien venían cuando salíamos del laboratorio después de un día duro (que los ha habido). O por esas comidas de los viernes en casa del tío Manolo y la tía Rosa, que tan bien me han cuidado durante estos cuatro años.

Por supuesto, a mis compañeros de piso, que me han aguantado a lo largo de este tiempo y con los que he compartido grandes ratos de cerveza y futbol tanto en casa como en "El Pato".

A toda la gente conocida en los congresos, algunos de los cuales han pasado a la categoría de amigos y con los cuales, aún en la distancia, he podido contar cuando los he necesitado.

A todos ¡MUCHAS GRACIAS! 

Abreviaturas y símbolos 



$\begin{array}{ll}\text { AA } & \text { Ácido araquidónico } \\ \text { AAG } & \text { a-glicoproteína ácida humana } \\ \text { a.a. } & \text { Aminoácido } \\ \text { AINE } & \text { Antiinflamatorio no esteroideo } \\ \text { Arg } & \text { Arginina } \\ \text { AS } & \text { Albúmina sérica } \\ \text { ASB } & \text { Albúmina sérica bovina } \\ \text { ASC } & \text { Albúmina sérica de conejo } \\ \text { ASCe } & \text { Albúmina sérica de cerdo } \\ \text { ASH } & \text { Albúmina sérica humana } \\ \text { ASO } & \text { Albúmina sérica de oveja } \\ \text { ASP } & \text { Albúmina sérica de perro } \\ \text { ASR } & \text { Albúmina sérica rata } \\ \text { ATP } & \text { Adenosina trifosfato } \\ \text { BP } & \text { Bifenilo } \\ \text { BZP } & \text { Benzofenona } \\ \text { CD }{ }_{3} \text { OD } & \text { Metanol deuterado } \\ \text { CDCl } & \text { Cloroformo deuterado } \\ \text { COX } & \text { Ciclooxigenasa } \\ \text { CPF } & \text { Carprofeno } \\ \delta & \text { Desplazamiento químico } \\ \text { D.O. } & \text { Densidad óptica } \\ \text { DCM } & \text { Diclorometano } \\ \text { DMSO } & \text { Dimetilsulfóxido } \\ \text { F } & \text { Fluorescencia } \\ \text { FBP } & \text { Flurbiprofeno } \\ \text { FBPMe } & \text { Éster metílico del flurbiprofeno } \\ \text { FBPGluc } & \text { Glucurónido del flurbiprofeno } \\ \text { FDL } & \text { Fotólisis de destello láser } \\ \phi_{F} & \text { Rendimiento cuántico de fluorescencia } \\ \phi_{T} & \text { Rendimiento cuántico de triplete } \\ \text { IBP } & \text { lbuprofeno } \\ \text { IR } & \text { Infrarrojo } \\ \boldsymbol{J} & \text { Constante de acoplamiento } \\ \text { KPF } & \text { Ketoprofeno } \\ \text { LAS } & \text { Amano AS Lipasa } \\ \text { LP } & \text { Lipoproteína } \\ & \end{array}$




$\begin{array}{ll}\text { LTs } & \text { Leucotrienos } \\ \text { Lys } & \text { Lisina } \\ \text { MeCN } & \text { Acetonitrilo } \\ \text { MeOH } & \text { Metanol } \\ \text { NPX } & \text { Naproxeno } \\ \text { PBS } & \text { Disolución tampón de fosfato } \\ \text { PGs } & \text { Prostaglandinas } \\ \text { Phe } & \text { Fenilalanina } \\ \text { PLE } & \text { Estereasa de hígado porcina } \\ \text { Ppm } & \text { Partes por millón } \\ \text { RMN-13C } & \text { Resonancia magnética nuclear de carbono } \\ \text { RMN-1H } & \text { Resonancia magnética nuclear de hidrógeno } \\ \text { RTE } & \text { Retrotransferencia electrónica } \\ \text { S } & \text { Singlete } \\ \text { Ser } & \text { Serina } \\ \text { T } & \text { Triplete } \\ \text { TNF } & \text { Factor de necrosis tumoral } \\ \text { Trp } & \text { Triptófano } \\ \tau & \text { Tiempo de vida de triplete } \\ \text { TXs } & \text { Tromboxanos } \\ \text { Tyr } & \text { Tirosina } \\ \text { u.a. } & \text { Unidades arbitrarias } \\ \text { UV } & \text { Ultravioleta } \\ \text { UV-vis } & \text { Ultravioleta visible } \\ \text { Val } & \text { Valina } \\ & \end{array}$


INDICE 

Parte I: Proteínas..........................................................

1.1. Aspectos generales...............................................

1.2. Tipos de proteínas..................................................4

1.2.1. Albúmina sérica..........................................

1.2.1.1. Función de la albúmina sérica....................9

1.2.1.2. Estructura general de la albúmina..............10

1.2.1.3. Interacción con sustratos............................12

1.2.2. a-Glicoproteína ácida humana..............................18

1.2.2.1. Función de la $\alpha$-glicoproteína ácida.............18

1.2.2.2. Estructura de la a-glicoproteína ácida..........20

1.2.2.3. Interacción con sustratos...........................21

1.2.3. Uridino difosfoglucuronosiltransferasa .........23

Parte II: Antiinflamatorios no esteroideos....................24

1.3. Perspectiva histórica............................................24

1.4. Actividad farmacológica de las AINES.......................25

1.4.1. Prostaglandinas: inflamación y dolor.............26

1.4.2. Mecanismo de acción de los AINES...............28

1.4.3. Los AINES como inhibidores de COX...........29

1.5. Ácidos 2-arilpropiónicos...........................................30

Parte III: Metabolismo................................................ 32 
1.6. Aspectos generales

1.7. Metabolismo de fármacos: Farmacocinética

y farmacodinámica .34

1.7.1. Metabolismo del Flurbiprofeno. 36

Parte IV: Aspectos generales

1.8. Fotólisis de Destello Láser. 40

1.9. Antecedentes bibliográficos inmediatos 41

1.10. Referencias bibliográficas. .44

Capítulo 2. Objetivos

2.1. Objetivos generales .55

Capítulo 3. Estudio de las interacciones entre FBP, FBPGluc y FBPMe y albúminas séricas de distintas especies

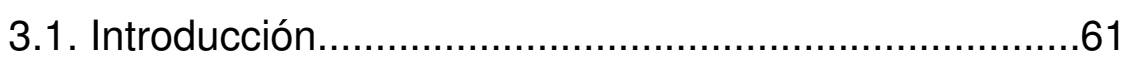

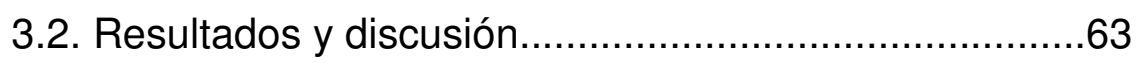

3.2.1. Datos fotofísicos de FBPGluc..........................63

3.2.2. Sistemas FBP/AS...........................................64

3.2.3. Sistemas FBPGluc/ASs................................71

3.2.5. Sistemas FBPMe/AS...................................... 80

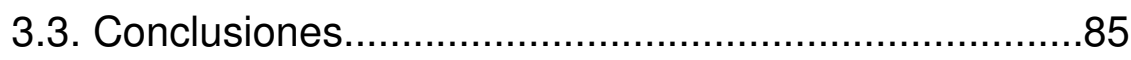

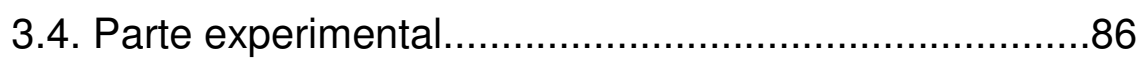

3.4.1. Materiales y disolventes...................................86 
3.4.2. Procedimiento experimental para la síntesis de (2S)-

y (2R)-FBPGluc. .86

3.4.3. Datos espectroscópicos de los intermedios sintéticos .87

3.4.4. Fotólisis de destello laser. .88

3.5. Referencias bibliográficas. .90

Capítulo 4. Estudio de la actividad glucuronidasa de albúminas séricas

4.1. Introducción 95

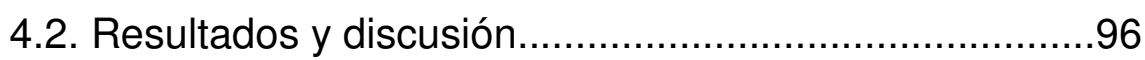

4.2.1. Hidrólisis de FBPGluc en ASH..........................96

4.2.2. Hidrólisis de FBPGluc en otras ASs.................100

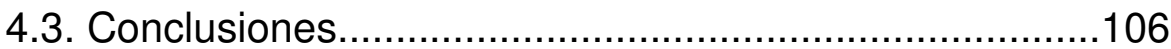

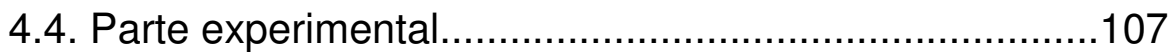

4.4.1. Materiales y disolventes..................................107

4.4.2. Fotólisis de destello laser.................................107

4.4.3. Procedimiento para el ajuste de la

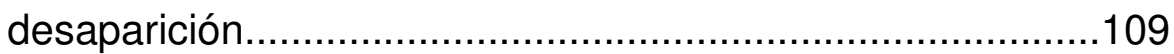

4.5. Referencias bibliográficas............................................111

Capítulo 5. Determinación de la distribución de ligandos en sistemas binarios ASH/AAG

5.1. Introducción.

5.1. Resultados y discusión. 


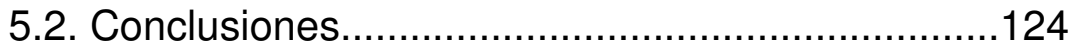

5.3. Parte experimental...............................................124

5.3.1. Materiales y disolventes...........................124

5.3.2. Fotólisis de destello laser..........................124

5.4. Referencias bibliográficas.....................................126

Capitulo 6. Determinación de la composición enantiomérica en mezclas de enantiómeros

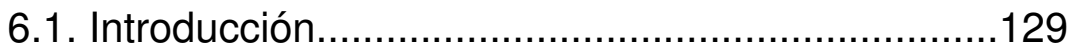

6.2. Resultados y discusión.........................................131

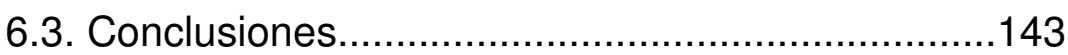

6.4. Parte experimental..............................................144

6.4.1. Materiales y disolventes...........................144

6.4.2. General....................................................144

6.5. Referencias bibliográficas....................................146

Capítulo 7. Instrumentación

7.1. Instrumentación general.........................................151

7.2. Instrumentación fotoquímica...................................151

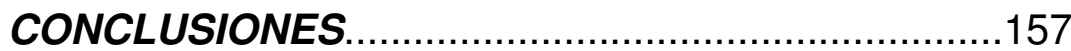

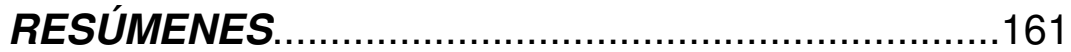

ANEXO I. Contribución a congresos.............................173

ANEXO II. Publicaciones................................................177 



\section{Parte I: Proteínas}

\subsection{Aspectos generales}

Las proteínas son macromoléculas muy abundantes en los organismos vivos. Son biomoléculas muy diversas y versátiles que cumplen con diversas funciones vitales, pudiendo actuar como enzimas, hormonas, anticuerpos, receptores o como vehículo de transporte de diversas sustancias, tanto endógenas como exógenas. ${ }^{1}$

Desde el punto de vista de su estructura, las proteínas pueden ser consideradas como polímeros formados por aminoácidos. Constan de cuatro niveles estructurales: estructura primaria, secundaria, terciaria y cuaternaria. La estructura primaria viene determinada por la secuencia de aminoácidos que forman parte de la cadena. La estructura secundaria ocurre cuando la secuencia de aminoácidos adquiere una disposición espacial estable, que viene dada por el plegamiento de la cadena polipeptídica debido a enlaces de hidrógeno. La estructura terciaria de las proteínas da información sobre la disposición espacial de la estructura secundaria de un polipéptido al plegarse sobre si misma, originando una estructura globular. Las interacciones que tienen lugar en la estructura terciaria son puentes disulfuro, enlaces de hidrógeno, interacciones iónicas e interacciones hidrófobas. La estructura cuaternaria viene dada por la disposición espacial de las distintas cadenas polipeptídicas de una proteína multimérica, es decir, compuesta por varios péptidos. Tanto la interacción entre los aminoácidos de la cadena polipeptídica, como la disposición geométrica que adoptan conducen a la formación del sitio de unión o centro activo, el cual constituye una cavidad donde tiene lugar la interacción específica entre sustratos de distinta naturaleza y la proteína. Es, por 
tanto, donde la proteína desarrolla sus funciones propias. ${ }^{2}$ El centro activo está formado por las cadenas laterales de los residuos de aminoácido específicos que forman parte del mismo, lo que le confiere una disposición tridimensional particular distinta al resto de la proteína. ${ }^{3}$

Generalmente, las interacciones más significativas que tienen lugar entre un sustrato y los aminoácidos del centro activo de la proteína son de naturaleza iónica, por enlace de hidrógeno o tipo van der Waals.

En la Figura 1.1 se muestra de forma esquemática la interacción entre un sustrato y el sitio de unión de la proteína.

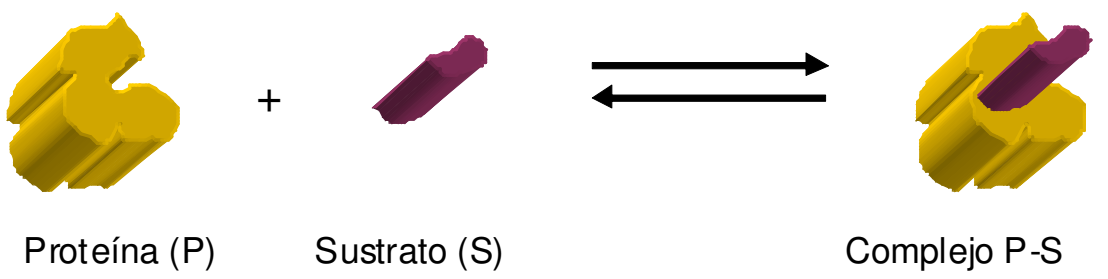

Figura 1.1. Esquema de la formación de un complejo proteína-sustrato (P-S).

\subsection{Tipos de proteínas}

Las proteínas pueden interaccionar con una gran variedad de sustratos, como iones metálicos, vitaminas, ácidos grasos, fármacos, etc. Las proteínas que son susceptibles de interaccionar con fármacos forman parte de las denominadas dianas farmacológicas. Entre ellas se encuentran, los receptores, algunas enzimas y las proteínas transportadoras. ${ }^{4}$ 
Los receptores farmacológicos son moléculas, generalmente de naturaleza proteica, que se encuentran en la membrana celular o intracelularmente, en las que el fármaco desarrolla su acción al interaccionar en el centro activo de éstas. Las interacciones que tienen lugar entre el fármaco y el receptor son generalmente lábiles y reversibles. Se pueden considerar cuatro tipos de receptores: receptores asociados a canales iónicos, receptores asociados a proteínas $\mathrm{G}$, receptores con actividad enzimática intrínseca y receptores que regulan la transcripción génica. Mediante la combinación química del fármaco con el receptor, éste último sufre un cambio configuracional que origina una respuesta funcional en la célula, que es, en definitiva, resultado del efecto farmacológico, como por ejemplo la contracción o relajación de un músculo, el aumento o la inhibición de la secreción de una glándula, la apertura o el bloqueo de un canal iónico, las variaciones del metabolismo celular, la activación de enzimas y proteínas intracelulares o inhibición de las mismas. Algunos fármacos actúan modificando reacciones celulares que son desarrolladas enzimáticamente por interacción del fármaco sobre dichos receptores. Entre éstos, se pueden destacar la fosfolipasa A2 (inhibida por glucocorticoides), la ciclooxigenasa (inhibida por AINES), etc.

Las enzimas son biocatalizadores de naturaleza proteica. ${ }^{7,8}$ Todas las reacciones químicas del metabolismo celular se realizan gracias a la acción de estos catalizadores, cuya función principal es la de incrementar la velocidad de los procesos químicos, actuando sobre un sustrato de forma específica y enormemente eficiente. Las enzimas son fundamentales, ya que las funciones vitales de cualquier célula serían imposibles de mantener si las reacciones que ocurren en ella fueran demasiado lentas. ${ }^{8}$ Ejemplos de enzimas son los citocromos 
P450 (fase 1) o la uridino difosfoglucuronosiltranferasa, UDPGT, (fase 2). En lo que se refiere a los fármacos, su metabolismo tiene lugar por vía enzimática mediante dos tipos de reacciones que frecuentemente son secuenciales y que se conocen como las reacciones de fase 1 y de fase 2. Las reacciones de fase 1 suelen consistir en oxidaciones reducciones o hidrólisis. Estas reacciones suelen introducir en la estructura del fármaco un grupo reactivo que lo convierte en más activo químicamente. Las reacciones de fase 2 suelen ser reacciones de conjugación que, por regla general, inactivan el fármaco y favorecen su eliminación del organismo. En términos generales, estas reacciones actúan sobre el grupo reactivo introducido en las reacciones de fase 1 añadiendo un sustituyente mayor. Los más habituales son el glucuronilo (más frecuente y que forma el glucurónido resultante), el sulfato, etc. El metabolito final es poco liposoluble y se favorece por tanto la eliminación renal o biliar.

> Las proteínas transportadoras son aquellas que proporcionan un medio de transporte, bien en el plasma o a través de la membrana celular, a aquellos sustratos que interaccionan en el centro activo de ésta. Como ejemplos de proteínas transportadoras se pueden citar las lipoproteínas, que son las encargadas de transportar las grasas por todo el organismo, las albúminas séricas, ${ }^{5}$ que son proteínas plasmáticas que actúan como vehículo de diversos agentes, tanto endógenos (ácidos grasos, hormonas, enzimas) como exógenos (fármacos) y la $\alpha$ glicoproteína ácida, ${ }^{6}$ que es otra proteína plasmática que, entre otras funciones, se encarga del transporte de fármacos básicos o neutros por el organismo. 
En la Figura 1.2 se muestran algunos ejemplos de las proteínas descritas.

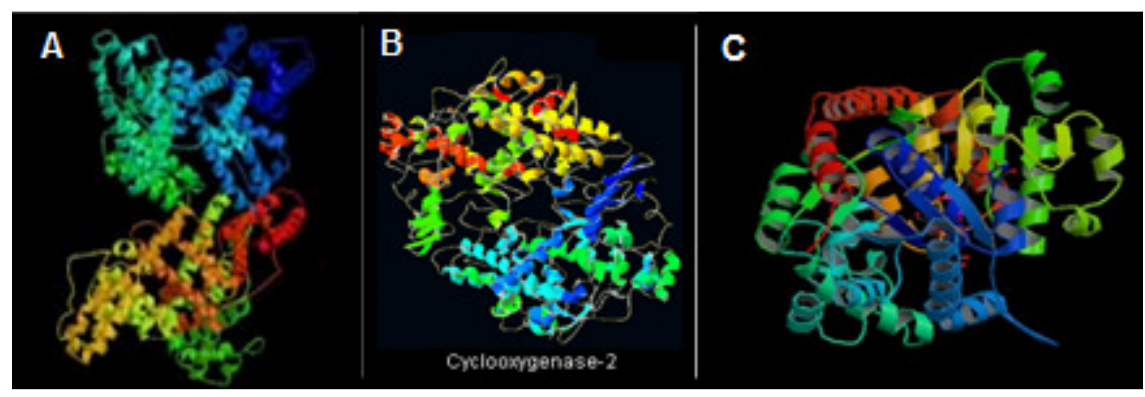

Figura 1.2. A) Ciclooxigenasa-2 (receptor farmacológico). B) uridino difosfoglucuronosiltranferasa (enzima). C) Albúmina sérica humana (proteína transportadora).

\subsubsection{Albúmina Sérica (AS)}

La albúmina sérica humana ( $\mathrm{ASH})$, junto con la hemoglobina, es probablemente una de las primeras proteínas del cuerpo humano que llamó la atención de los investigadores. Son muchas sus aplicaciones, tanto en medicina clínica como en investigación básica. El físico griego Hipócrates de Cos ya indica en sus Aforismos que la aparición de espuma en la orina es debida, con toda probabilidad, a la presencia de un exceso de albúmina, indicativo de una dolencia crónica en el riñón. En 1837, H. Ancell cita en sus lecturas que "la albúmina es sin duda una de las proteínas más importantes en los animales, ya que no sólo se encuentra en la sangre sino también en la exhalación de ciertas superficies, en diversos fluidos celulares (como en tejidos y en los ojos) y en muchos otros fluidos animales".

La albúmina sérica se encuentra presente en todas las especies animales. Se puede extraer de bovinos (ASB), ratas (ASR), conejos 
(ASC), cerdos (ASCe), perros (ASP), humanos ASH), etc. Muchas de estas albúminas se han usado para estudios de interacción con fármacos y de farmacocinética en lugar de $\mathrm{ASH}$, basándose en la alta similitud encontrada en las secuencias de aminoácidos de otras especies respecto a la humana. Sin embargo, diferentes estudios han puesto de manifiesto diferencias en cuanto a la unión de varios fármacos y metabolitos a albúminas de diferentes especies. A modo de ejemplo se puede citar el caso de la bilirrubina, que presenta diferentes grados de unión según interaccione con una u otra albúmina, como se aprecia en los datos de desactivación de la fluorescencia en presencia de ASCe, ASP, ASO y ASR. ${ }^{9-12}$ Estas diferencias muestran la importancia de extender los estudios de farmacocinética y farmacodinámica a albúminas de otras especies distintas a la humana. La estructura de algunas de estas albúminas se muestra en la Figura 1.3.
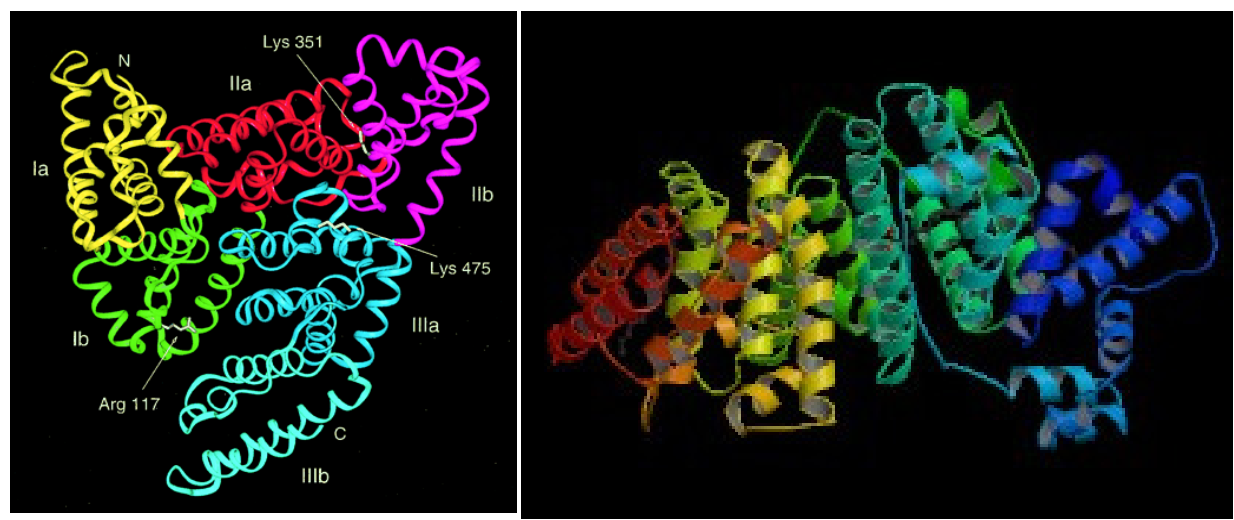

Figura 1.3. Estructura de la albúmina sérica humana (izquierda) y de la albúmina sérica bovina (derecha). 


\subsubsection{Función de la albúmina sérica}

La albúmina sérica es una proteína que se sintetiza en el hígado. Está presente en prácticamente todos los tejidos pero sobre todo en la piel y los músculos (entre los dos acumulan el $80 \%$ de albúmina extravascular). Puede encontrarse en cualquier fluido corporal, como por ejemplo en el fluido vítreo y acuoso ocular, en el sudor, en las lágrimas, saliva y sangre donde es la proteína transportadora más abundante (3.5-4 g en $100 \mathrm{ml})$.

La AS ayuda a mantener el pH y la presión osmótica en la sangre. ${ }^{13}$ Su principal función es actuar como vehículo de transporte y distribución de sustancias endógenas y exógenas en la sangre. Ejemplo de ello es el transporte de fármacos (influyendo, así, en la farmacocinética y distribución de éstos), de ácidos grasos aniónicos de cadena larga, ácidos biliares, hormonas, vitaminas, etc. ${ }^{14}$

La interacción de sustratos con AS puede originar un incremento en la solubilidad de éstos en la sangre (como es el caso de los ácidos grasos), así como una disminución de su toxicidad o una protección frente a la oxidación (como es el caso del daño peroxidativo al ácido linoléico). ${ }^{15}$

La albúmina actúa, en ocasiones, como almacén de ciertas toxinas, como cuando transporta la bilirrubina hasta el hígado para su excreción biliar. También es capaz de interaccionar con toxinas exógenas, haciendo que sean menos nocivas para el organismo (como la interacción de $A S$ con la aflatoxina $G_{1}$ cancerígena), que es transportada hasta el hígado para su destrucción. ${ }^{16}$

En ocasiones, la albúmina presenta actividad enzimática cuando interacciona con moléculas pequeñas. Posee actividad enolasa, y también es capaz de actuar como tioesterasa (ya que posee un grupo 
sulfhidrilo libre por el residuo de aminoácido cisteina-34), pudiendo llevar a cabo un importante proceso clínico como es la degradación de disulfuram. ${ }^{16,17}$ También presenta actividad esterasa en uno de sus múltiples sitios de unión, debido probablemente a la proximidad de la arginina-410 y la tirosina-411, pudiendo producir la hidrólisis de ácidos grasos. La actividad esterasa de AS es útil desde un punto de vista clínico-farmacéutico, ya que es importante en el proceso de activación de pro-fármacos, como es el caso del medoxomil olmesartan, que se transforma al fármaco activo olmesartan. ${ }^{21}$ También es de destacar su actividad glucuronidasa, mediante la cual se produce la hidrólisis del glucurónido de algunos fármacos, como carprofeno, naproxeno, flurbiprofeno o ketoprofeno. ${ }^{19,20}$

\subsubsection{Estructura general de la albúmina}

La albúmina consiste en una cadena polipeptídica simple sin grupos prostéticos u otros aditivos, con una masa molecular aproximada de $67 \mathrm{KDa}$. Contiene 9 logos dobles formados por 17 puentes disulfuro, que envuelven a los residuos de cisteína adyacentes. Estos se pueden agrupar en tres dominios homólogos (dominio I, II y III), en los cuales pueden interaccionar sustratos de distinta naturaleza. Cada uno de estos dominios contiene 2 logos y está separado de los contiguos por otro logo. Así pues, en cada dominio hay dos subdominios A y B. Por tanto, en las albúminas existe un amplio y variado número de sitios de unión donde los sustratos pueden interaccionar. ${ }^{5}$ En la Figura 1.4 se muestran los principales dominios de unión de la albúmina sérica humana así como ejemplos de fármacos que se unen a cada sitio de unión. 


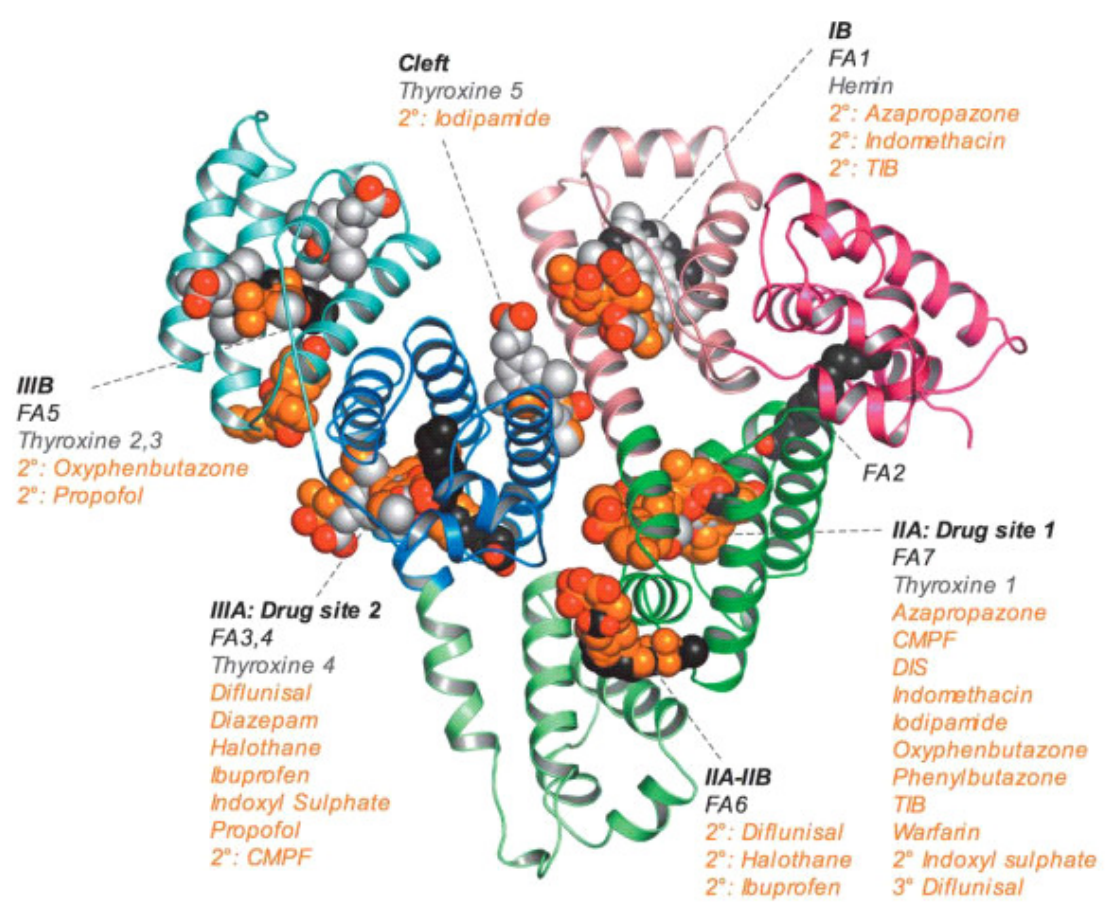

Figura 1.4. Representación de los dominios I, II y III en ASH.

La albúmina sérica humana es una proteína globular que constituye alrededor del $60 \%$ del total de proteína en la sangre. Posee una masa molecular promedio de 66500 Da y consta de 585 aminoácidos, entre los cuales se forman un total de 17 puentes disulfuro; existe un tiol libre (Cys-34) y un único triptófano (Trp-214). ${ }^{22}$ Según análisis cristalográficos a partir de difracción de rayos- $X$, la cadena polipeptídica se dobla formando una hélice de dimensiones aproximadas de $80 \times 80 \times 30 \AA$, con cerca del $67 \%$ de hélice-a, un 10\% de giro $\beta$ y un $23 \%$ de cadena extendida. ${ }^{13,23,24}$ Recientes estudios 
proponen que la conformación global de ASH en disolución neutra es muy similar a la observada en la forma cristalina. ${ }^{25}$

Las albúminas de las otras especies estudiadas presentan una similitud en la secuencia peptídica del $70-80 \%$ respecto a la humana. El número de aminoácidos que la forman es de 583 para la albúmina sérica de bovino (ASB), de cerdo (ASCe) y de oveja (ASO) y de 584 para la de perro (ASP), de conejo (ASC) y de rata (ASR). También existen diferencias en cuanto al número de triptófanos presentes. Mientras ASP, ASC y ASR contienen un único residuo de triptófano (al igual que $\mathrm{ASH}$ ), las otras albúminas mencionadas contienen dos.

Todas estas AS son muy similares. En general, las diferencias estructurales que se pueden observar entre ellas se derivan de la sustitución de ciertos aminoácidos hidrofóbicos por otro tipo de aminoácidos también hidrofóbicos, en lugar de otros de naturaleza polar.

\subsubsection{Interacción con sustratos}

Las albúminas son proteínas flexibles que pueden adaptar su estructura para interaccionar con una gran variedad de sustratos en sus distintos sitios de unión. Entre los compuestos con mayor grado de unión se encuentran aniones orgánicos hidrofóbicos como ácidos grasos de cadena larga, bilirrubina, etc. Esta interacción puede generar cambios en la albúmina que provoquen un aumento en su estabilidad, una mayor afinidad hacia otros sustratos, etc. ${ }^{15}$

Como se ha indicado anteriormente, la albúmina tiene gran afinidad por ácidos grasos, aminoácidos, algunos metabolitos como la 
bilirrubina, y por fármacos, entre los que se encuentran los antiinflamatorios no esteroideos (AINES).

\section{* Interacción con fármacos}

El estudio de la interacción fármaco/AS es importante para conocer la biodistribución, el metabolismo, la eliminación y el efecto farmacológico de éstos en el organismo.

Los AINES presentan un alto grado de unión con la albúmina, en muchos casos el 99\%. ${ }^{15}$ La naturaleza de estas interacciones es de tipo electrostático, por puente de hidrógeno, puente salino o de tipo van der Waals; el proceso, que generalmente es reversible, tiene unas constantes de asociación que oscilan entre $10^{4}$ y $10^{6} \mathrm{M}^{-1}$. En otras ocasiones, las interacciones entre AS y fármacos son irreversibles. Esto se da con ciertos tipos de metabolitos de los fármacos, y es más pronunciada con algunos de aquellos que tienen tendencia a formar glucurónidos. ${ }^{15}$ También puede darse con fármacos que posean un grupo tiol capaz de unirse covalentemente con el residuo de aminoácido cisteína de la posición $34 .{ }^{26}$ Este hecho es importante porque se puede alterar el destino metabólico del fármaco en cuestión, y porque puede cambiar tanto las propiedades estructurales como funcionales de la proteína. Estos aductos podrían causar efectos tóxicos, como hipersensibilidad y toxicidad hepática y renal aguda.

Aunque las albúminas séricas poseen varios dominios de unión con sustratos, se sigue aceptando por consenso la existencia de dos sitios específicos de unión o centros activos para moléculas orgánicas pequeñas. Estos sitios de unión específicos fueron designados por Sudlow como sitio I (o sitio de unión de la warfarina) y sitio II (o sitio de 
unión del diazepán). ${ }^{27}$ En la Tabla 1.1 se muestran algunas características de los dos principales sitios de unión de ASH.

Tabla 1.1. Características de los dos principales sitios de unión de ASH.

\begin{tabular}{|c|c|l|}
\hline $\begin{array}{c}\text { Sitio de unión } \\
\begin{array}{c}\text { Sustratos } \\
\text { específicos }\end{array}\end{array}$ & Warfarina, dansilamida. & $\begin{array}{l}\text { Sitio II } \\
\text { Dansilsarcosina, } \\
\text { diazepán. }\end{array}$ \\
\hline $\begin{array}{c}\text { Otros sustratos } \\
\text { afines }\end{array}$ & $\begin{array}{c}\text { ésteres de los ácidos } \\
\text { 2-arilpropiónicos }\end{array}$ & $\begin{array}{c}\text { ácidos 2- } \\
\text { arilpropiónicos }\end{array}$ \\
\hline $\begin{array}{c}\text { Residuos de a.a. } \\
\text { presentes }\end{array}$ & Trp 214, Arg 218 & His 146, Lys 194, Arg \\
410, Tyr 411
\end{tabular}

El sitio I se encuentra situado en el subdominio IIA. ${ }^{22}$ Las interacciones predominantes son de tipo hidrofóbicas. ${ }^{28}$ Ejemplos de sustratos con gran afinidad por el sitio I son warfarina, indometacina, fenilbutazona, etc. También es conocido que los ésteres de los ácidos 2-arilpropiónicos interaccionan preferentemente en este sitio de unión. ${ }^{29}$ Algunas evidencias sugieren que el sitio I es flexible y de gran tamaño (moléculas grandes, como la bilirrubina, interaccionan en él). Esto puede ocasionar que sea más difícil observar estereoselectividad en la interacción con los sustratos. Los aminoácidos que tienen mayor relevancia para la interacción con fármacos son Trp-214 y Arg-218.

El sitio II está situado en el subdominio IIIA y es de menor tamaño y menos flexible que el sitio I. $^{22}$ Por esta razón, se cree que las interacciones estereoselectivas se pueden observar en mayor grado en este sitio de unión. El ejemplo clásico se observa con el L-triptófano, cuya afinidad por el sitio II es 100 veces mayor que la del isómero D. Las interacciones que predominan son de tipo puente de hidrógeno y 
electrostáticas. ${ }^{28}$ Los sustratos que suelen unirse al sitio II son ácidos carboxílicos aromáticos, como los AINES de la familia de los ácidos 2arilpropiónicos. Los aminoácidos Arg-410 y Tyr-411 desempeñan un papel importante en la interacción con ligandos. ${ }^{22}$

En la Figura 1.5 se muestran los sitios de unión I y II de la ASH.
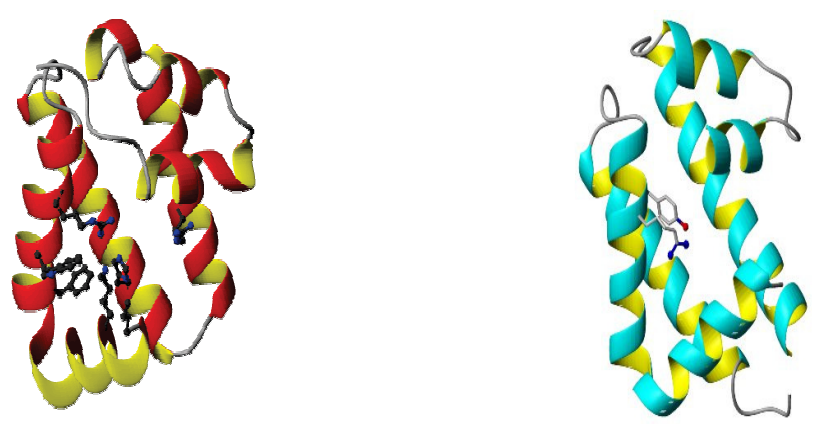

Figura 1.5. Sitio I (izquierda) y sitio II (derecha) de ASH.

Como se ha indicado anteriormente, esta clasificación realizada por Sudlow no engloba todos los sitios de unión específicos de alta afinidad que posee la albúmina para interaccionar con los fármacos. Como ejemplo, el propofol interacciona tanto en el sitio II (subdominio IIIA) como en el subdominio IIIB. ${ }^{30}$

\section{* Interacción con ácidos grasos}

Los ácidos grasos de cadena larga $\left(\mathrm{C}_{16}-\mathrm{C}_{20}\right)$ son intermedios cruciales en el metabolismo lipídico. Se requieren para la síntesis de la membrana lipídica, de hormonas, y son una importante fuente de energía. Son altamente insolubles en el plasma sanguíneo, pero gracias a su interacción con la albúmina sérica aumenta su solubilidad, 
favoreciéndose así el transporte desde el hígado al riñón, de ahí al músculo y finalmente al tejido adiposo. ${ }^{5}$

Las albúminas séricas poseen un gran número de sitios de unión con ácidos grasos de distinto tamaño de cadena. Existen hasta siete sitios de unión distintos que pueden ser ocupados por este tipo de moléculas. Las interacciones que se dan son por puente salino o puente de hidrógeno entre el carboxilato del ácido graso y los residuos de aminoácido presentes en el centro de unión. También se observan interacciones hidrofóbicas entre la cadena lateral del ácido graso y el medio que le rodea. ${ }^{31}$ Los ácidos grasos de cadena media $\left(\mathrm{C}_{6}-\mathrm{C}_{14}\right)$ interaccionan casi exclusivamente en el sitio II, mientras que los de cadena mayor lo hacen en el sitio I o en otros dominios de unión de la albúmina ${ }^{32}$ por lo que se pueden usar para desplazamiento de fármaos de su sitio de unión.

\section{* Interacciones competitivas}

Se pueden considerar dos tipos de interacciones competitivas: competición de varios sustratos por un mismo sitio de unión en la albúmina, y competición de la albúmina con otra proteína (por ejemplo a-glicoproteína ácida) por la unión de un mismo sustrato.

Debido a la flexibilidad de la albúmina y a que ésta posee un número limitado de sitios de unión de alta afinidad con los sustratos, la unión, por ejemplo, de un fármaco o de un ácido graso a AS puede generar cambios en su estructura que pueden influir en la unión de nuevos fármacos. ${ }^{32,33}$ Esta alteración es importante porque se puede modificar la distribución y eliminación de un fármaco, pudiendo modular sus efectos terapéuticos. Este riesgo es mayor cuando dos o más fármacos compiten por el mismo sitio de unión (o cuando un ácido graso 
desplaza al fármaco de su sitio de unión). En algunos casos, esta competición entre dos ligandos por el mismo sitio puede generar un aumento en la concentración del fármaco desplazado, que pasa a encontrarse libre en el medio. Sin embargo, en otras ocasiones se produce un desplazamiento del fármaco desde el sitio de mayor afinidad a otro de menor afinidad, sin sacarlo fuera de la proteína. Esto ocurre en la unión competitiva entre ibuprofeno y carprofeno, donde este último desplaza al ibuprofeno de su sitio II, de mayor afinidad, al sitio I, de menor afinidad. $^{34}$

Puesto que la actividad farmacológica depende de la concentración de fármaco como forma libre en el medio, el desplazamiento a la sangre del fármaco previamente unido a AS incrementaría la concentración libre de éste, produciendo un aumento de su actividad, que podría, incluso, generar toxicidad. Los desplazamientos desde el sitio de mayor afinidad a otro de menor afinidad son importantes para aquellos fármacos que interaccionan fuertemente con la proteína y de los que sólo se requiere una pequeña concentración libre para causar su efecto farmacológico. ${ }^{35}$ Por esta razón es importante conocer los mecanismos de las interacciones competitivas entre fármacos, ya que deben tenerse en cuenta a la hora, por ejemplo, de calcular la dosis que se debe suministrar de un fármaco durante la administración simultánea de otro.

Como ya se mencionó anteriormente, en el organismo existen principalmente tres proteínas transportadoras: albumina sérica, $\alpha$ glicoproteína ácida (AAG) y lipoproteína (LP). ASH es la principal proteína transportadora para fármacos y moléculas pequeñas, pero no la única. AAG también se encarga del transporte de fármacos, y en algunos casos, como en moléculas básicas o neutras, es la principal encargada. El que ambas proteínas sean capaces de transportar el 
mismo sustrato, unido al hecho de que en determinadas enfermedades (como en procesos inflamatorios) la concentración de ASH disminuya a la vez que aumenta la de AAG, muestran la importancia del estudio de interacción de esos fármacos con ambas proteínas presentes simultáneamente en el medio.

\subsection{2. a-Glicoproteína ácida humana}

La a-glicoproteina ácida es una de las proteínas plasmáticas sintetizadas en el hígado que normalmente es segregada por los hepatocitos, aunque, a diferencia de ASH, también puede ser expresada en tejidos extrahepáticos, como células endoteliales o macrófagos alveolares. También puede ser sintetizada por otros tejidos en respuesta a procesos inflamatorios.

\subsubsection{Función de la a-glicoproteína ácida humana}

La AAG se encuentra presente en casi todos los tejidos y fluidos biológicos como el plasma, jugos gástricos, líquido sinovial, etc. ${ }^{36}$ Su vida media es de aproximadamente 5 dias y su eliminación renal es baja. ${ }^{37-40}$

Su función biológica no está totalmente definida. Sin embargo, se conocen muchos procesos donde su participación es importante.

Parece que AAG, en las células endoteliales, es un componente importante de la barrera capilar, lo cual es esencial para la selectividad de carga capilar. ${ }^{41}$ 


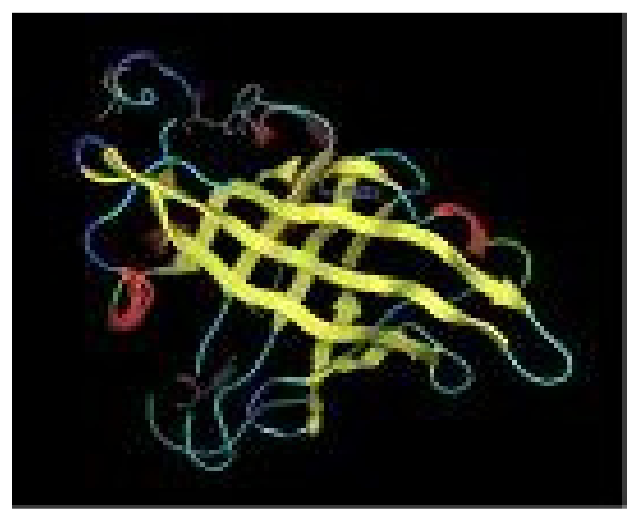

Figura 1.6. Estructura de la $\alpha$-glicoproteína ácida

También puede servir como agente protector en infecciones y contra toxinas, por unión a lectinas tóxicas, ${ }^{42}$ endotoxinas ${ }^{43}$ y lipopolisacáridos bacteriales. ${ }^{43}$ Inhibe la adherencia de Mycoplasma pneumonia a los macrofagos alveolares, ${ }^{44}$ así como la replicación del rotavirus SA-II actuando directamente sobre la partícula de virus. ${ }^{45}$

Aunque AAG estimula a las células mononucleares y los macrófagos para secretar factor- $\alpha$ de necrosis de tumores (TNF- $\alpha$ ), ${ }^{46}$ también inhibe la apoptosis inducida por TNF de hepatocitos ${ }^{47}$ y proporciona protección contra otros efectos tóxicos de la TNF. ${ }^{48}$

Posee además actividad inmunosupresiva, demostrada en pacientes con cancer, ${ }^{49}$ que puede deberse a interacciónes electrostáticas entre los grupos de ácidos siálicos de AAG y fosfolípidos. ${ }^{50}$

Pero su principal función es como proteína transportadora. Debido a sus propiedades físico-químicas, AAG se une principalmente a compuestos básicos o neutros de origen tanto endógeno como exógeno, aunque también es capaz de transportar fármacos ácidos. 


\subsubsection{Estructura de la a-glicoproteína ácida humana}

La a-glicoproteína ácida humana es una proteína con 44 KDa de peso molecular que está cargada negativamente con un pKa de 2.6, y punto isoeléctrico de 2.7, debido fundamentalmente a un alto contenido de ácido siálico (11\%) en su parte carbohidratada. ${ }^{51}$ Ha sido cristalizada como sal de $\mathrm{Pb}^{2+}$ en forma de bipirámide hexagonal. ${ }^{53}$ La proteína consiste en una sola cadena polipeptídica con 183 aminoácidos y dos puentes disulfuros. Medidas de dicroísmo circular indican que, en disolución acuosa, en su mayor parte está formada por láminas- $\beta .^{55,56}$ La AAG es una de las proteínas más glicosiladas con aproximadamente un $45 \%$ de de su masa total formada por carbohidratos. ${ }^{52}$

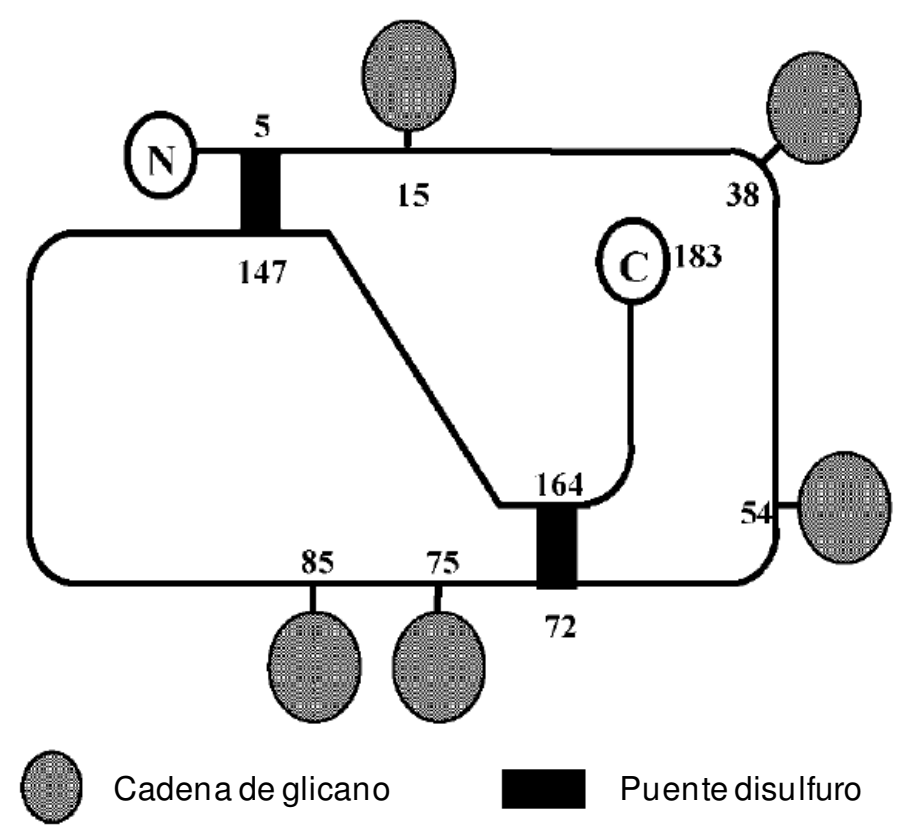

Figura 1.7. Esquema de la cadena polipeptídica de AAG

El rol biológico de la parte oligosacárida se muestra fundamentalmente en eventos de fase aguda, ${ }^{54}$ y parece no intervenir 
en los procesos de unión a AAG. ${ }^{57,58}$ Contiene 3 residuos triptófano (en posiciones 25, 122 y 160) de los cuales los dos últimos están implicados en la unión con fármacos. Atendiendo a diferentes pruebas de desplazamiento se podría decir que AAG contiene un solo sitio de unión grande y flexible para la mayoría de fármacos y moléculas pequeñas. Es un sitio grande donde solapan las zonas de alta afinidad para fármacos básicos, donde el principal aminoácido involucrado es Trp160, con la de los ácidos, y neutros, en los que intervienen His97, Try91, Arg105, (estos para ácidos) y Trp122 (neutros).

\subsubsection{Interacción con sustratos}

Se han descrito hasta 7 sitios de unión para AAG. Sin embargo, solo uno de ellos es de alta afinidad y es el encargado de transportar a la gran mayoría de moléculas que interaccionan con $A A G$, ya sean básicas, neutras o ácidas (Figura 1.8). El resto de sitios son de baja afinidad y su influencia en la función de transporte de sustratos se considera despreciable.

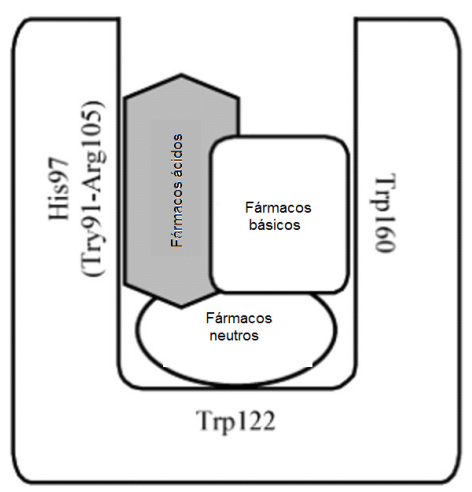

Figura 1.8. Estructura del sitio de unión para fármacos en $A A G$ 
Dipiridamol, un inhibidor de agregación plaquetaria, fue el primer fármaco no esteroideo cuya unión a AAG fue descrita. ${ }^{59}$ Desde entonces se han determinado los parámetros de unión a esta proteína para un gran número de fármacos.

Como ya se mencionó anteriormente, AAG transporta principalmente moléculas básicas y neutras como tamoxifen ${ }^{60} 0$ propanolol. ${ }^{61}$ De hecho, es la principal proteína plasmática para el transporte de la mayoría de estas moléculas tanto endógenas como exógenas. Por ejemplo, la relación de afinidad en la unión AAG/ASH para la quinidina es de $18^{66}$ y para la tioridacina es de $1000 .{ }^{67}$

Además, se encarga de transportar hormonas como la heparina o la serotonina, ${ }^{60}$ además de esteroides endógenos como el cortisol. ${ }^{63}$

También es capaz de unirse a moléculas ácidas para su transporte como fenobartital ${ }^{64} 0$ ácido retinoico. ${ }^{65}$

Aunque generalmente se asume que en el plasma los fármacos ácidos se unen principalmente a $A S H$, la unión de estos a $A A G$ puede contribuir significativamente a la concentración total de fármaco unido a las proteínas plasmáticas, sobre todo en determinadas condiciones fisiológicas o patológicas donde disminuye la concentración de ASH y aumenta la de AAG, como ocurre precisamente en los procesos inflamatorios.

Otro aspecto a tener en cuenta es el efecto de la interacción de dos fármacos con afinidad por AAG que puede tener implicaciones clínicas importantes. Un fármaco que tenga mayor afinidad por AAG puede desplazar a otro con menor afinidad, y de esa manera, aumentar la cantidad de fármaco libre en plasma. Por ejemplo, la bupivacaina desplaza a la lidocaina ${ }^{68}$ del sitio de unión de AAG. Si se administran los dos anestésicos locales a la vez podría liberarse lidocaina aumentando el riesgo de toxicidad. Por otro lado, esta interacción por 
desplazamiento puede ayudar a potenciar la eficacia de un fármaco, como es el caso del antifolato CB3717, que es potenciado por la coadministración intencionada de dipiridamol, ${ }^{69}$ ya que este último desplaza al antifolato del sitio de unión de AAG incrementando de esta manera la concentración de fármaco libre.

Asimismo, es de esperar que algunos fármacos desplacen sustancias endógenas con afinidad por AAG, lo que aumentaría el nivel plasmático de esas sustancias, que podrían producir un efecto fisiológico anormal. El caso contrario también es posible. Un nivel anormal de sustancias endógenas en determinadas condiciones podría desplazar a los fármacos de los sitios de unión de la proteína lo que podría potenciar los efectos del fármaco en cuestión. Por ejemplo, los niveles de bilirrubina se incrementan en la hiperbilirrubinemia producida por hepatitis o cirrosis, lo que puede tener repercusiones clínicas significativas.

\subsubsection{Uridino difosfoglucuronosiltranferasa (UDPGT)}

La enzima UDPGT tiene como función catalizar el proceso de glucuronización. Para ello, utiliza el ácido uridino difosfoglucuronico (UDPGA) como aceptor de azúcares y transfiere el ácido glucurónico a un sustrato disponible, dando lugar a los correspondientes $\beta$-Dglucurónidos. $^{70}$ Existe una amplia variedad de sustratos que puedan actuar como aceptores del grupo glucuronilo (grupos hidroxilos, carboxilos, sulfurilos, etc.), lo que hace que numerosos de compuestos tanto endógenos como exógenos sean susceptibles de sufrir glucuronización. Como ejemplo de compuestos endógenos se puede citar la bilirrubina, algunas hormonas o ácidos biliares y como ejemplo 
de exógenos están los fármacos, productos químicos cancerígenos o sustancias ingeridas en la dieta. ${ }^{71}$

Se sintetiza principalmente en el hígado, si bien, también se expresa en otros tejidos como intestino, riñón o colon, y se encuentra unida a la membrana interna del retículo endoplasmático. ${ }^{71}$

La UDPGT pertenece a una amplia superfamilia de enzimas de la que existen dos familias, UDPGT1 y UDPGT2, que a su vez se divide en tres subfamilias, UDPGT1A, UDPGT2A y UDPGT2B. Esto da lugar a alrededor de 20 isoenzimas con una similitud estructural de aproximadamente el $60 \% .^{71}$ Cada isoenzima es específica para un grupo de sustratos. Aunque algunos de estos pueden ser metabolizados por varias isoenzimas, suele haber uno predominante. Esto provoca que cuando una de estas isoenzimas no se expresa adecuadamente pueda dar lugar a transtonos metabólicos como algunas hiperbilirrubinemias (enfermedad de Gilbert). ${ }^{72}$

En cuanto a la interacción de ésta enzima con los AINEs, se han identificado a las isoenzimas UDPGT1A3 y UDPGT2B7 como las principales responsables de la glucuronización de la mayoría de los AINEs. ${ }^{73}$

\section{Parte II: Antiinflamatorios no esteroideos}

\subsection{Perspectiva histórica}

Desde la época de la medicina griega hasta la mitad del siglo XIX, el descubrimiento de agentes medicinales fue catalogado como un arte empírico, donde se combinaron folklore y creencias mitológicas para la utilización de productos vegetales y minerales constituyentes de la farmacopea de la época. 
Ya en el siglo $\mathrm{V}$ a.C., Hipócrates usó el extracto de la corteza y las hojas de sauce para el tratamiento del dolor y el control de la fiebre. Celsius (año 30 a.C.) describió los signos de inflamación (enrojecimiento, fiebre, dolor e hinchazón) y utilizó la corteza de sauce para aliviarlos. ${ }^{74}$ En 1763, el reverendo Edmund Stone inició el primer estudio clínico sobre los efectos del extracto de sauce como tratamiento antifebril, presentando los resultados obtenidos ante la Royal Society en Londres. ${ }^{75}$

El ingrediente activo de la corteza de sauce se debe a la salicina (1828, Johan Andreas Buchner), un glucósido que por hidrólisis libera glucosa y alcohol salicílico. Éste puede ser convertido, tanto in vivo como por manipulación química, en ácido salicílico (antecedente de la aspirina), el cual posee propiedades analgésicas y antiinflamatorias. En 1859 Kolbe sintetiza por primera vez el ácido salicílico, y es en 1897 cuando Félix Hoffmann descubrió el ácido acetilsalicílico, principio activo de la aspirina, que posee propiedades analgésicas, antipiréticas y antiinflamatorias.

Tras el descubrimiento de la aspirina se impulsó el desarrollo de nuevos fármacos de la familia de los antiinflamatorios no esteroideos (AINES). A partir de la segunda mitad del siglo XX surgen fármacos como la indometacina (1960), el ibuprofeno, naproxeno, flurbiprofeno, ketoprofeno, carprofeno, benoxaprofeno y otros derivados de los ácidos 2-arilpropiónicos (1970-80), así como meloxicam, rofecoxib, celecoxib, etc (1990).

\subsection{Actividad farmacológica de los AINES}

Los AINES constituyen uno de los grupos de fármacos más prescritos en la actualidad. Aproximadamente, a nivel mundial, unos 30 
millones de personas consumen diariamente AINES. En España se prescribían hace una década más de 27 millones de envases anuales de estos fármacos.

Los AINES son un grupo de fármacos que poseen actividad antipirética y analgésica cuando son consumidos en dosis bajas y durante cortos períodos de tiempo, y suelen prescribirse para el tratamiento del dolor leve-moderado. Utilizados en dosis mayores y de forma continuada poseen actividad antiinflamatoria, siendo utilizados para el tratamiento sintomático del dolor y la inflamación en enfermedades como artritis reumatoide, artrosis y otras dolencias. Sin embargo, aunque los efectos beneficiosos en el consumo de AINES son notables, también generan efectos adversos en el organismo que pueden llegar a ser graves cuando se toman de forma continuada, los cuales; entre ellos cabe destacar fallo renal, anemia, hepatitis, daño gastrointestinal (formación de úlceras), hemorragias digestivas y perforación. ${ }^{76} \mathrm{La}$ aparición de estos efectos secundarios conduce a la hospitalización de un gran número de pacientes. Por ejemplo, en EEUU se producen más de 100 mil hospitalizaciones graves cada año relacionadas con el daño gastrointestinal; alrededor de un $10 \%$ de estos pacientes hospitalizados mueren. ${ }^{77}$

\subsubsection{Prostaglandinas: inflamación y dolor}

La inflamación es una respuesta de carácter protector contra agentes agresores. Las manifestaciones clínicas de la inflamación se producen por los llamados mediadores químicos. Entre éstos destacan la histamina, la bradiquinina, el factor activador de plaquetas y los derivados del ácido araquidónico (AA), conocidos como eicosanoides, a los que pertenecen las familias de prostaglandinas (PGs), prostaciclina, 
tromboxanos (TXs) y leucotrienos (LTs). ${ }^{78}$ Bajo estímulos fisiológicos y en concentraciones normales, las prostaglandinas regulan numerosas funciones como la coagulación, el metabolismo óseo, el desarrollo y crecimiento del sistema nervioso, la citoprotección de la mucosa gástrica, etc. Sin embargo, también juegan un papel importante en procesos patológicos como cáncer, artritis y Alzeimer, entre otros. ${ }^{79,80}$

El ácido araquidónico proviene del ácido linoleico de los alimentos o se ingiere como parte de la dieta, y se encuentra esterificado a los fosfolípidos de membrana. Frente a una agresión externa se activa la fosfolipasa A2, la cual hidroliza el enlace éster de los fosfolípidos, originando la ruptura de la membrana celular con la

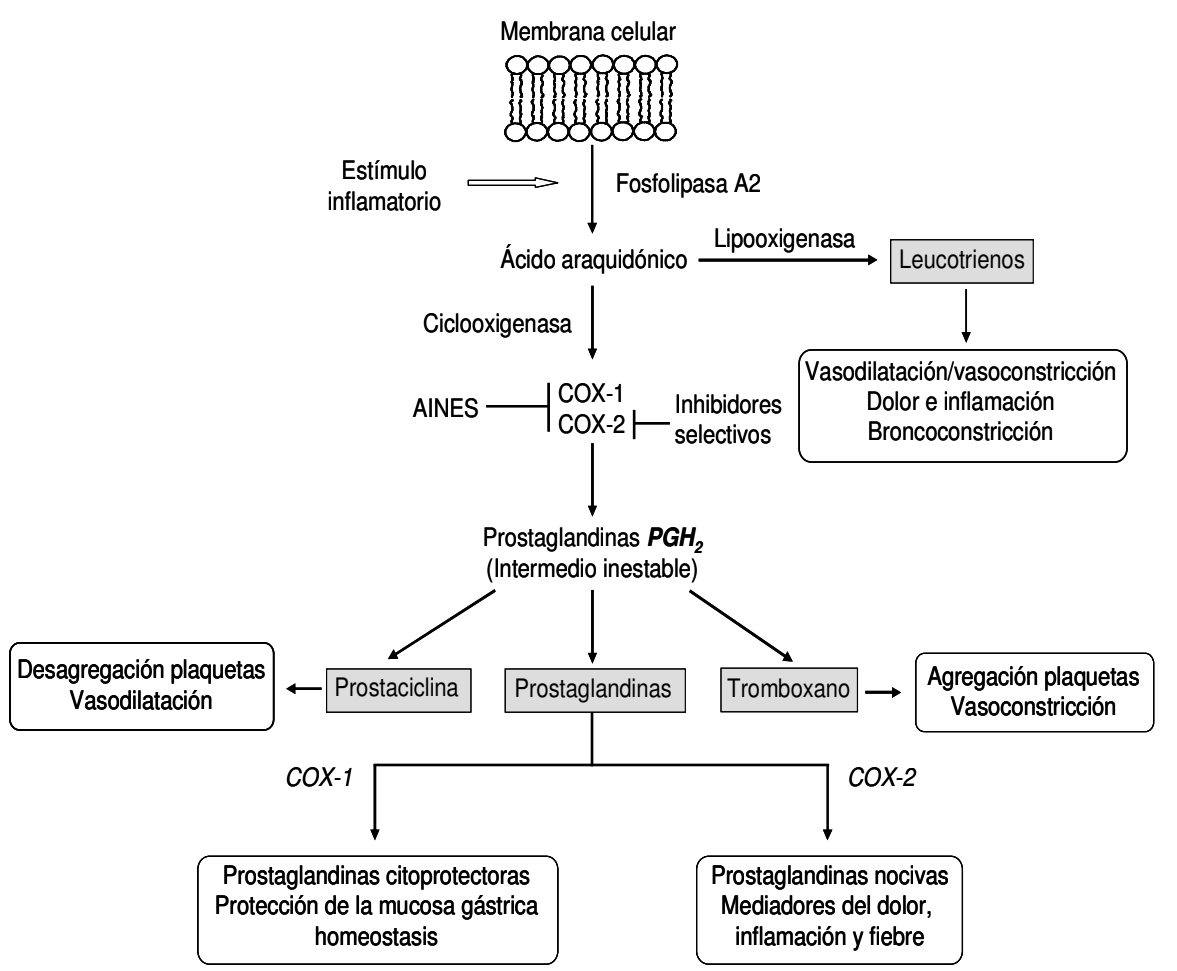

Figura 1.9. Mecanismo de formación de prostaglandinas, prostaciclinas, tromboxanos y leucotrienos a partir de la cascada del ácido araquidónico. 
consiguiente liberación de los mediadores del dolor histamina, bradiquinina y AA. Este último, por acción de la enzima ciclooxigenasa (COX) genera prostaglandinas, prostaciclinas y tromboxanos, y por la vía lipooxigenasa genera leucotrienos, todos ellos mediadores de la inflamación. En la Figura 1.9 se muestra esquemáticamente este proceso.

\subsubsection{Mecanismo de acción de los AINES}

El mecanismo principal de acción de los AINES está relacionado con la inhibición de la enzima COX, responsable de la síntesis de PGs a partir del $A A{ }^{53}$ Esta enzima, tiene como función catalizar la biosíntesis de prostaglandinas a partir del ácido araquidónico; el primer paso consiste en la oxidación de AA para formar $\mathrm{PGG}_{2}$, que tras una posterior reducción forma $\mathrm{PGH}_{2}$, la cual es transformada a través de una cascada de reacciones enzimáticas en los prostanoides primarios $\mathrm{PGE}_{2}, \mathrm{PGF}_{2 \alpha}$, $\mathrm{PGD}_{2}, \mathrm{PGI}_{2}$ y $\mathrm{TXA}_{2}$. Estos juegan un papel importante tanto en mantener las propiedades fisiológicas normales en el organismo como en el proceso inflamatorio.

Existen dos isoformas de COX: COX-1 y COX-2. ${ }^{81,82}$ La primera se expresa de forma constitutiva en casi todas las células del organismo, como en la mucosa gástrica, tejido renal, plaquetas, etc, y es responsable de la síntesis de PGs y $\mathrm{TXA}_{2}$ con propiedades citoprotectoras. Sin embargo, COX-2 se expresa de forma constitutiva en el tejido renal, sinovial y en ciertas células del sistema nervioso central, pero también lo hace en células donde se ha inducido un proceso fisiopatológico nocivo, promoviendo la rápida formación de mediadores de la inflamación. ${ }^{83-85}$ Así pues, COX-2 es la principal responsable de los procesos inflamatorios. Por el contrario, también 
parece ser que está implicada en la producción de prostaciclina $\left(\mathrm{PGI}_{2}\right)$, una prostaglandina vasodilatadora y antitrombótica.

En general, se puede decir que COX-1 es responsable de la síntesis de prostaglandinas citoprotectoras, mientras que COX-2 se relaciona con la síntesis de prostaglandinas nocivas para el organismo. Por esta razón, se cree que los efectos adversos gastrointestinales derivados por el consumo de AINES no selectivos de COX son producidos por la inhibición de COX-1, mientras que sus propiedades como antiinflamatorios se deben a la inhibición de COX-2 (Figura 1.10).

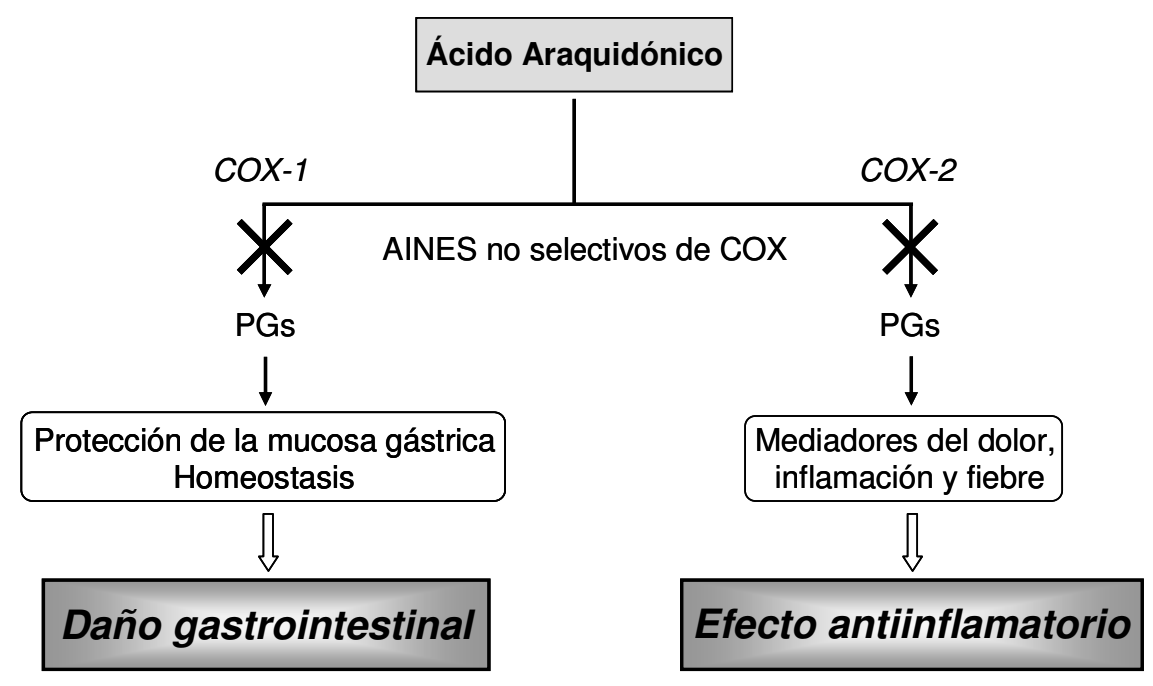

Figura 1.10. Mecanismo general de inhibición de COX-1 y COX-2 por acción de AINES no selectivos de COX.

\subsubsection{Los AINES como inhibidores de COX}

Los inhibidores de las ciclooxigenasas se pueden clasificar en cuatro tipos:

1- Los que inhiben de forma irreversible tanto a COX-1 como a COX-2, como por ejemplo la aspirina, que produce la acetilación 
selectiva del grupo hidroxilo de un residuo de serina en la posición 530 en ambas isoenzimas. ${ }^{86}$

2- Aquellos que producen una inhibición competitiva reversible de ambas isoformas. El ibuprofeno o el mefenamato forman parte de este grupo.

3- Los que llevan a cabo una inhibición lenta y dependiente con el tiempo de COX-1 y COX-2. Ejemplo de éstos son los derivados de los ácidos 2-arilpropiónicos (como el flurbiprofeno) y la indometacina. ${ }^{87}$

4- Finalmente, los que dan lugar a una inhibición selectiva de COX-2 en un proceso lento y dependiente del tiempo. En este grupo se encuentran los coxibs, como celecoxib, rofecoxib, etc. ${ }^{88}$

\section{5. Ácidos 2-arilpropiónicos}

Los ácidos 2-arilpropiónicos son fármacos antiinflamatorios no esteroideos de uso común para el tratamiento de la inflamación, fiebre, dolor asociado a la artritis reumatoide, osteoartritis, daños leves en los tejidos, como tendinitis y bursitis, prevención de migrañas, etc. ${ }^{89-91}$

La estructura general de estos fármacos se muestra en la Figura 1.11. Poseen un grupo Ar que puede ser de distinta naturaleza (naftaleno, bifenilo, benzofenona, benzoiltiofeno, etc) y otra parte propiónica con un centro quiral que puede ser $(S)$ - o $(R)$-.

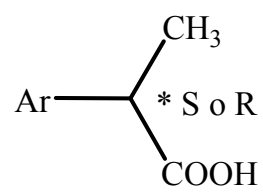

Figura 1.11. Estructura general de los ácidos 2-arilpropiónicos. 
Generalmente, el enantiómero (S)- es el farmacológicamente activo, $^{92}$ si bien, la mayoría de ellos se comercializa en su forma racémica, razón por la cual se suelen llevar a cabo los estudios de interacción con ambos enantiómeros. Algunos de estos fármacos son capaces de absorber la luz solar y de inducir la producción de reacciones fototóxicas y fotoalérgicas, generando daños en la piel. ${ }^{93}$ Los síntomas clínicos de fototoxicidad incluyen quemaduras de la dermis, eritema, edema, hiperpigmentación, descamación, etc. ${ }^{94}$

En la Figura 1.12 se muestran las estructuras químicas de algunos fármacos de la familia de los ácidos 2-arilpropiónicos.<smiles>COc1ccc2cc(C(C)C(=O)O)ccc2c1</smiles>

Naproxeno (NPX)<smiles>CC(C(=O)O)c1cccc(C(=O)c2cccs2)c1</smiles>

Suprofeno (SP)<smiles>CC(C(=O)O)c1cccc(C(=O)c2ccccc2)c1</smiles>

Ketoprofeno (KPF)

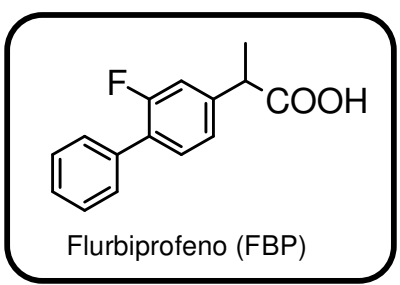<smiles>CC(C(=O)O)c1ccc2c(c1)[nH]c1ccc(Cl)cc12</smiles>

Carprofeno (CPF)<smiles>CC(C(=O)O)c1ccc(C(=O)c2ccccc2)s1</smiles>

Acido Tiaprofenico (ATP)

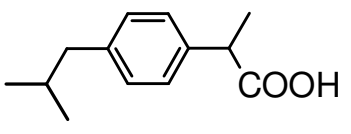

Ibuprofeno (IBP) 
en esta tesis doctoral. Posee actividad analgésica, antiinflamatoria y antipirética, y se utiliza para el tratamiento de varias enfermedades como la artritis reumatoide, osteoartritis, desordenes oftálmicos, etc. ${ }^{95-97}$ Se trata de un compuesto quiral y aunque los ácidos arilpropiónicos se usan comúnmente como racémicos, un comportamiento diferente en su biotransformación enzimática o en la unión a proteínas transportadoras de los enantiómeros puede resultar en una farmacocinética enantioselectiva. ${ }^{97,98}$ Se absorbe bien después de administración oral, se encuentra completamente unido a proteínas plasmáticas a concentraciones terapéuticas y se excreta esencialmente como el correspondiente acil glucurónido (FBPGluc) en la orina. ${ }^{99}$

\section{Parte III: Metabolismo}

\subsection{Aspectos generales}

Las células viven mientras existe la posibilidad de recambio de materia con el medio externo; el conjunto de reacciones que se realiza durante ese tiempo es el metabolismo. Esta palabra viene del término griego "metabolismós" que significa cambio. El metabolismo representa la suma de cambios químicos que convierten a los nutrientes, la materia prima necesaria para alimentar a los organismos vivos, en energía. ${ }^{100}$ Consta de cientos de reacciones enzimáticas organizadas en distintas rutas. Estas rutas ocurren paso a paso, transformando sustratos en productos finales a través de una gran cantidad de intermedios químicos específicos. En el metabolismo la inmensa mayoría de las reacciones están catalizadas por enzimas, y además, ocurren en secuencias en las 
que al menos uno de los pasos está regulado y es irreversible. Estas vías metabólicas, si son cerradas, son denominadas ciclos metabólicos. Las vías metabólicas se regulan al alterarse la actividad o cantidad de alguna enzima, y también al verse controlado el paso a través de una membrana de algún metabolito involucrado en la vía en cuestión. ${ }^{100}$

El metabolismo tiene dos vertientes: el anabolismo y el catabolismo. Las rutas catabólicas son productoras de energía mientras que las rutas anabólicas son consumidoras de energía. Estos 2 procesos son contrarios, pero se complementan y no pueden existir el uno sin el otro. ${ }^{101}$

El catabolismo posibilita la formación de ATP y la oxidación de compuestos de mayor complejidad estructural (carbohidratos, lípidos y proteínas) obtenidas bien del medio ambiente o bien de las reservas celulares, en compuestos más simples (ácido láctico, etanol, dioxido de carbono, urea o amoniaco). Es un proceso normalmente exergónico, y a menudo la energía química liberada es capturada en forma de ATP. ${ }^{100}$

El anabolismo es un proceso sintético en el cual se ensamblan biomoléculas complejas (proteínas, ácidos nucléicos, polisacáridos y lípidos) a partir de precursores más simples. Esta biosíntesis implica la formación de nuevos enlaces covalentes, por lo que es necesario el aporte de energía química para llevar a cabo dichos procesos endergónicos. Esa energía la recoge de las moléculas de ATP generadas durante el catabolismo.

Cabe destacar que catabolismo y anabolismo ocurren simultáneamente en la célula. Las rutas metabólicas competidoras a menudo están localizadas en compartimentos celulares diferentes, de esa forma, aislando procesos opuestos en diferentes compartimentos se evitan interferencias entre ellos. Por ejemplo, las enzimas responsables del catabolismo de ácidos grasos, la ruta de oxidación de ácidos grasos, 
se encuentran en la mitocondria. Por el contrario, la biosíntesis de ácidos grasos tiene lugar en el citosol. ${ }^{101}$

\subsection{Metabolismo de fármacos: Farmacocinética $y$ farmacodinámica}

En el metabolismo de fármacos hay un concepto muy importante que es el de biodisponibilidad. Este hace referencia a la fracción de fármaco administrada que es capaz de alcanzar su diana farmacológica. Debido a la dificultad para calcular esa fracción, en la práctica, la biodisponibilidad es la parte del fármaco que aparece en el plasma. Esto forma parte de dos aspectos más generales como son la farmacocinética y la farmacodinámica. ${ }^{101}$

\section{Farmacocinética}

Es la ciencia que describe los movimientos de un fármaco en el organismo. Este movimiento está influenciado por cuatro procesos diferentes pero interrelacionados entre ellos:

Absorción: Es el proceso mediante el cual una molécula de fármaco pasa del sitio donde se administra hasta el flujo sanguíneo. Cuando el fármaco se administra por via intravenosa es absorbido al 100\% (biodisponibilidad del 100\%), mientras que cuando se administra por otras vias como oral, subcutánea, etc., su grado de absorción se ve afectado por muchos factores incluyendo el grado de disolución, el metabolismo antes de la absorción o la capacidad de atravesar el tracto gastrointestinal.

Distribución: Es el proceso mediante el cual el fármaco se transporta por el torrente sanguíneo hasta su sitio de acción, incluyendo fluidos extracelulares y/o células de tejidos y órganos. Entre los factores 
que afectan a la distribución de un fármaco se encuentran el flujo sanguíneo, la unión a proteínas plasmáticas, uión a tejidos, liposolubilidad, $\mathrm{pH} / \mathrm{pK}_{\mathrm{a}}$ y la permeabilidad de membrana.

Metabolismo: Es el proceso por el cual el organismo transforma un fármaco en una sustancia química activa, inactiva o tóxica. Se pueden dar varios casos: a) fármaco no activo (profármaco) que se activa mediante el metabolismo. Un ejemplo es la aspirina. El ácido acetilsalicílico se desacetila generando el ácido salicílico que es el principio activo; b) fármacos activos cuyos metabolitos también poseen efectos farmacológicos. Es el caso de numerosos psicofármacos como el diazepan (el desmetildiazepan también es activo); c) fármaco activo y de baja toxicidad pero metabolito mucho más tóxico. Esto sucede con el paracetamol que tiene un metabolito acetilado marcadamente hepatotóxico.

Como ya se describió anteriormente los cambios metabólicos se producen mediante dos tipos de reacciones que frecuentemente son secuenciales y que se conocen como las reacciones de fase 1 y de fase 2.

Eliminación: Es la extracción irreversible de un fármaco y/o su metabolito de la circulación sistémica. El proceso de eliminación ocurre normalmente en el riñón y si no es completa, la acumulación del fármaco y/o metabolito puede producir efectos adversos. Otras rutas de eliminación incluyen pulmones (exhalación), piel, saliva y glándulas mamarias.

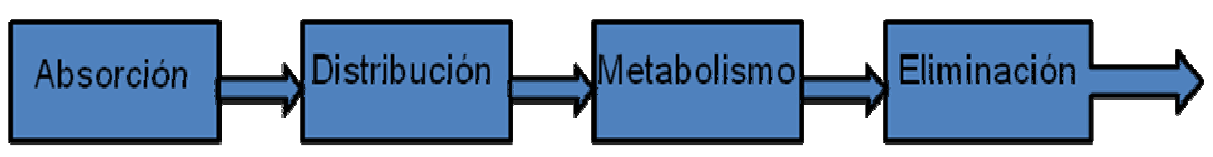

Figura 1.13. Procesos involucrados en la farmacocinética. 


\section{Farmacodinámica}

Es la relación entre la concentración de fármaco en el sitio de acción y la respuesta farmacológica, terapéutica o tóxica en ese sitio de acción. A menudo es dificil medir la concentración de fármaco en el sitio de acción, por lo que se hace esencial la relación farmacocinética/farmacodinámica para entender y relacionar la concentración de fármaco en la sangre u otro fluido biológico con su respuesta farmacológica, terapéutica o tóxica.

\subsubsection{Metabolismo del Flurbiprofeno}

En general los AINES se absorben bien en el tracto gastrointestinal, a excepción de algunos, como la aspirina, que experimenta una hidrólisis presistémica para formar ácido salicílico. ${ }^{99}$ Esta familia de fármacos se unen fuertemente a las proteínas plasmáticas (fundamentalmente a la albumina), lo que limita su distribución en el organismo a los espacios extracelulares. La eliminación de los AINES depende en gran medida de una biotransformación hepática y la excreción renal del fármaco sin cambios normalmente es pequeña (< $5 \%$ de la dosis administrada).

En cuanto al flurbiprofeno, se detalla a continuación su farmacocinética:

\section{* Absorción}

Es rápidamente absorbido tras la administración oral de una o varias dosis, consiguiéndose el máximo de concentración a 1.5-3 h después de la ingestión. ${ }^{102,103}$ La concentración máxima en sangre se reduce cuando FBP se toma con las comidas, pero la cantidad absorbida no se ve afectada. ${ }^{104}$ 
* Distribución

El FBP se distribuye en el fluido sinovial: a las $6 \mathrm{~h}$ de una dosis oral de $100 \mathrm{mg}$, la concentración sinovial es comparable con la concentración plasmática. $^{105}$ A concentraciones terapéuticas, se encuentra unido, al menos, en un $99 \%$ a proteínas plasmáticas ${ }^{106}$ y su volumen de distribución aparente es de alrededor de $0.1 \mathrm{l} / \mathrm{kg}$.

* Eliminación

Una vez en el organismo, es metabolizado por el hígado en dos fases. En la primera se le introducen grupos hidroxilos en varias posiciones del grupo bifenilo dando lugar a los derivados 4'-hidroxi, 3'hidroxi-4'metoxi y 3',4'-dihidroxi. ${ }^{103}$ (Figura 1.14).<smiles>CCOCCOCCOCCOCCCO</smiles>

4'- hidroxi-flurbiprofeno<smiles>C[C@H](C(=O)O)c1ccc(-c2ccc(O)c(O)c2)c(F)c1</smiles>

3',4'-dihidroxi-flurbiprofeno<smiles>COc1ccc(-c2ccc([C@@H](C)C(=O)O)cc2F)cc1O</smiles>

Figura 1.14. Estructuras de los metabolitos de fase I del flurbiprofeno

El principal metabolito del FBP es el $\beta$-1-O-acil glucurónido que es producto de la conjugación con el ácido D-glucurónico durante la fase II de la ruta metabólica principalmente en el hígado (aunque 
también lo hace en otros órganos como el riñón o el intestino) (Figura 1.15). ${ }^{107-110}$ Este importante proceso biológico, que es catalizado por la UDPGT, ${ }^{70,71,111,112}$ opera como una ruta de desintoxicación incrementando la hidrofilicidad del fármaco original, y de esa forma, permitiendo su eliminación final por la orina o la bilis. ${ }^{113,114}$<smiles>C[C@H](C(=O)O[C@@H]1O[C@H](C(=O)O)[C@@H](O)[C@H](O)[C@H]1O)c1ccc(-c2ccccc2)c(F)c1</smiles>

(2S)-FBPGluc

Figura 1.15. Estructura 1-O-acil-D-glucurónido de flurbiprofeno

La cantidad de fármaco excretado por la orina sin transformar, más el metabolizado coincide con la dosis administarda. En todos los casos, del 60 al $70 \%$ de estos compuestos están presentes en la orina en su forma conjugada de glucurónido o sulfato. La vida de media de eliminación del FBP es de 3 o 4 horas y no parece ser muy diferente en tratamientos de larga duración. ${ }^{115,116}$

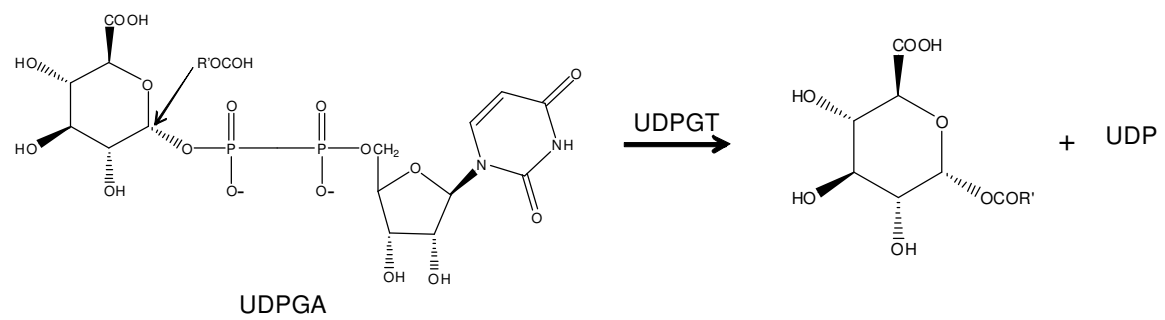

Figura 1.16. Biosíntesis del $\beta$-1-O-acil glucurónido en el organismo

La biosíntesis del $\beta$-glucurónido es una reacción en la que el ácido glucurónico se encuentra en forma de ácido uridino difosfoglucuronico, 
UDPGA. En este proceso, la enzima (UDPGT) cataliza una reacción de sustitución nucleofílica, $\mathrm{SN}_{2}$, que transcurre con inversión de la configuración en $\mathrm{C} 1$ del ácido glucurónico convirtiendo el ácido $\alpha-D$ glucurónico en UDPGA a ácido $\beta$-D-glucurónico en el conjugado. Además, no es posible una interconversión entre los dos anómeros del ácido glucurónico, ni en la UDPGA ni en el conjugado formado (figura 1.16).

Los acil glucurónidos son moléculas muy reactivas que pueden dar lugar a varias reacciones que son altamente dependientes del $\mathrm{pH}$ y de la temperatura. El primer caso del que se tiene constancia es el de la bilirrubina, que tras reagrupamiento por migración del grupo acilo, da lugar a un isómero que es resistente a la $\beta$-glucuronidasa. Además, más adelante se comprobó que este isómero era el responsable de la unión covalente de la bilirrubina a la ASH en enfermedades hepatobiliares. Desde el punto de vista del desarrollo de nuevos fármacos es importante conocer la posible toxicidad asociada a los metabolitos de éstos. En condiciones fisiológicas, la reacción más común es la hidrólisis para dar lugar al fármaco de partida. Este proceso puede ser catalizado por varios agentes ( $\beta$-glucuronidasas, estereasas, etc.) resultando en un ciclo fútil, ya que la eliminación del plasma es el resultado de la competición entre la conjugación del fármaco, la desconjugación del glucurónido (hidrólisis) y la eliminación renal. El proceso de hidrólisis es muy dependiente del $\mathrm{pH}$ y de la temperatura. A $\mathrm{pH}$ fisiológico o superior aumenta la posibilidad de que se produzca la hidrólisis mientras que a pH más ácidos el proceso que predomina es el de reagrupamiento.

Como se mencionó con antelación, este proceso de reagrupamiento puede dar lugar a que el glucurónido se una covalentemente a la $\mathrm{ASH}$, fundamentalmente mediante la reacción de 
Amadori a través de un intermedio tipo imina, formando un aducto que puede provocar reacciones adversas en el organismo como efectos coleostáticos, anafilácticos, etc.

\section{Parte IV: Aspectos generales}

\subsection{Fotólisis de Destello Laser}

A mediados de los años 60 apareció el primer trabajo sobre fotólisis de destello laser (FDL). ${ }^{117}$ En él, Lindqvist aprovechó el pulso de un laser de $\mathrm{N}_{2}$ (337 $\mathrm{nm}$ ) para detectar el estado excitado triplete de la acridina.

Se utiliza un laser pulsado para excitar una muestra y generar los diferentes estados excitados. Inmediatamente después del pulso de laser se registra el espectro de absorción de las especies generadas mediante una lámpara UV-Vis. El sistema de detección consta de un monocromador y un fotomultiplicador que envían la señal a un osciloscopio para registrarla y mandarla a un ordenador para su posterior tratamiento.

Con esta técnica se obtienen datos de absorción frente a tiempo a una longitud de onda determinada. Este tipo de registro nos permite estudiar la cinética de desactivación de los estados excitados generados y obtener información valiosa sobre dichos estados, como su tiempo de vida. Además, monitorizando la señal a muchas longitudes de onda se puede construir el espectro de absorción de las diferentes especies transitorias presentes en el medio.

Para el uso de esta metodología es necesario que se cumplan una serie de requisitos: 
- El compuesto tiene que absorber luz a la longitud de onda de excitación del laser.

- Tras la irradiación, se generen intermedios (tripletes, radicales libres, iones radicales, birradicales, carbocationes, etc.) fácilmente detectables: que absorban en la región UV-Vis y vivan en una escala de tiempos de nano/microsegundos.

- La irradiación de la proteína no produce ninguna señal, al menos en la misma región donde lo hagan los intermedios del compuesto.

- El producto $\phi_{T} \cdot \varepsilon_{T}$ permanece constante.

\subsection{Antecedentes bibliográficos inmediatos}

El conocimiento de las interacciones fármaco/proteína es fundamental para comprender la biodistribución, el metabolismo, la eliminación y el efecto farmacológico de los fármacos en el organismo. El número de técnicas utilizadas para la realización de este tipo de estudios es muy amplio y variado. Entre las más destacadas se encuentran: dicroísmo circular, ultracentrifugación, diálisis de equilibrio, cromatografía líquida, electroforesis capilar, cristalografía de rayos $\mathrm{X}$, fluorescencia por desactivación del Trp, etc. El uso de estas técnicas ofrece ventajas, pero también algunos inconvenientes y limitaciones. ${ }^{118,119}$

Algunos de los métodos más frecuentemente utilizados para estudiar las interacciones fármaco/proteína se describen brevemente: con el método de ultracentrifugación se puede determinar la masa molecular de una proteína, la estequiometría de formación de complejos macromoleculares, la afinidad de un sustrato por la macromolécula, etc. 
El fundamento de esta técnica se basa en la determinación de la velocidad de sedimentación de las macromoléculas, las cuales son sometidas a un campo centrífugo elevado tal que la fuerza de centrifugación es mayor que la de difusión, por lo que existe un transporte neto de materia hacia el fondo de la celda. Permite fraccionar las moléculas en base a las diferencias en coeficiente de sedimentación, que es función de la masa, densidad y la forma macromolecular. También es posible estudiar el equilibrio de sedimentación, donde las muestras se someten a campos centrífugos moderados hasta que se igualan las fuerzas opuestas de centrifugación y difusión. Esta permite realizar un análisis cuantitativo de las asociaciones que dan lugar a la formación de complejos macromoleculares. Sin embargo, en cuanto a las limitaciones que implica el uso de esta técnica, se pueden indicar la del seguimiento de un procedimiento experimental complejo y laborioso, donde se requieren horas (15-24h) para la adquisición de datos de un único experimento. Además, se debe tener en cuenta un gran número de diversos factores a la hora de realizar un ensayo experimental, lo cual dificulta la reproducibilidad de los resultados obtenidos.

La electroforesis capilar se utiliza generalmente para la separación de péptidos y proteínas. El fundamento del mecanismo de separación se basa en la aplicación de un campo eléctrico donde la electroforesis se realiza en un tubo capilar, produciéndose una eficaz separación de los analitos basándose en la relación carga/masa de estos. Es una técnica de uso general, pero ofrece ciertos problemas de reproducibilidad.

En la bibliografía se encuentran muy pocos trabajos relacionados con el uso de la técnica de fotólisis de destello láser para estudiar las interacciones entre fármacos y proteínas. Ejemplo de ello 
son los estudios del fármaco carprofeno en $\mathrm{ASH},{ }^{120}$ nabumetona en ASB,${ }^{121}$ nafazolina en $\mathrm{ASB}^{122}$ o ketoprofeno en ASB. ${ }^{123} \mathrm{La}$ interacción del carprofeno (AINE perteneciente a la familia de los ácidos 2arilpropiónicos) con ASH es uno de los primeros casos donde se observó una interacción estereoselectiva entre el estado excitado triplete del fármaco y la proteína. $^{120}$ Se observó que existe estereodiferenciación en diferentes procesos: 1) en la desactivación del estado excitado triplete del carprofeno, 2) en la formación del fotoproducto mayoritario del fármaco, que corresponde al producto de fotodeshalogenación, 3) en la formación de un enlace covalente fotoinducido con $\mathrm{ASH}$, y 4 ) en la ocupación del sitio de unión de mayor afinidad del fármaco con la proteína (sitio II), donde el enantiómero (S)se une más eficazmente a este sitio que su homólogo $(R)$-.

Recientemente se han caracterizado mediante técnicas de fluorescencia y FDL los estados excitados del FBP y FBPMe ${ }^{124}$ así como su interacción con $\mathrm{ASH}$ y $\mathrm{ASB}^{125}$ obteniéndose los siguientes datos. El espectro UV-vis presenta una banda de absorción con un máximo a $246 \mathrm{~nm}$ y un hombro a $274 \mathrm{~nm}$. Tienen un máximo de emisión de fluorescencia a $310 \mathrm{~nm}$. En lo referente a FDL $\left(\lambda_{\mathrm{exc}}=266 \mathrm{~nm}\right)$, ambos muestran una banda de absorción triplete-triplete centrada a $360 \mathrm{~nm}$ y un $\tau_{\mathrm{T}}$ en atmósfera de aire y PBS como disolvente de $1.5 \mu \mathrm{s}$.

Tabla 1.2. Datos fotofísicos de FBP y FBPMe (entre paréntesis) en disolución de PBS con $\lambda_{\text {exc }}=266 \mathrm{~nm}$.

\begin{tabular}{|c|c|c|c|}
\hline Medio & $\phi_{\mathrm{F}}$ & $\tau_{\mathrm{F}}(\mathbf{n s})$ & $\tau_{\mathrm{T}}(\boldsymbol{\mu s})$ \\
\hline $\mathbf{N}_{2}$ & $0.15(0.20)$ & $0.7(1.2)$ & $106(87.4)$ \\
\hline Aire & $0.12(0.17)$ & $0.6(0.9)$ & $1.5(1.5)$ \\
\hline
\end{tabular}


En cuanto a los trabajos de interacción con la proteína, ${ }^{125}$ se han determinado los tiempos de vida de FBP y FBPMe dentro de ASH y ASB, así como el porcentaje de ocupación de ambos sustratos en los sitios de unión de las proteínas (tabla 1.3 y 1.4).

Tabla 1.3. Tiempos de vida de triplete de FBP y FBPMe en ASH y ASB.

\begin{tabular}{|c|c|c|c|c|c|c|c|c|}
\cline { 2 - 9 } \multicolumn{1}{c|}{} & \multicolumn{4}{c|}{ ASH } & \multicolumn{4}{c|}{ ASB } \\
\cline { 2 - 9 } \multicolumn{1}{c|}{} & \multicolumn{2}{c|}{ FBP } & \multicolumn{2}{c|}{ FBPMe } & \multicolumn{2}{c|}{ FBP } & \multicolumn{2}{c|}{ FBPMe } \\
\cline { 2 - 9 } & $\boldsymbol{S}$ & $\boldsymbol{R}$ & $\boldsymbol{S}$ & $\boldsymbol{R}$ & $\boldsymbol{S}$ & $\boldsymbol{R}$ & $\boldsymbol{S}$ & $\boldsymbol{R}$ \\
\hline Libre & 1.5 & 1.5 & 1.5 & 1.5 & 1.5 & 1.5 & 1.5 & 1.5 \\
\hline $\begin{array}{l}\text { Sitio I } \\
\text { Sitio II }\end{array}$ & 11.2 & 10.2 & 31.4 & 157.6 & 10.8 & 6.6 & 19.3 & 19.7 \\
\cline { 2 - 9 } & 35.9 & 39 & 4.1 & 16.6 & 86.5 & 58.6 & 4.6 & 2.8 \\
\hline
\end{tabular}

Tabla 1.4. Porcentaje de ocupación de FBP y FBPMe en ASH y ASB a relació molar $1: 1$.

\begin{tabular}{|l|c|c|c|c|c|c|c|c|}
\cline { 2 - 9 } \multicolumn{1}{c|}{} & \multicolumn{4}{c|}{ ASH } & \multicolumn{4}{c|}{ ASB } \\
\cline { 2 - 9 } \multicolumn{1}{c|}{} & \multicolumn{2}{c|}{ FBP } & \multicolumn{2}{c|}{ FBPMe } & \multicolumn{2}{c|}{ FBP } & \multicolumn{2}{c|}{ FBPMe } \\
\cline { 2 - 9 } \multicolumn{1}{c|}{} & $\boldsymbol{S}$ & $\boldsymbol{R}$ & $\boldsymbol{S}$ & $\boldsymbol{R}$ & $\boldsymbol{S}$ & $\boldsymbol{R}$ & $\boldsymbol{S}$ & $\boldsymbol{R}$ \\
\hline Libre & 20 & 15 & 0 & 0 & 22 & 8 & 32 & 25 \\
\hline Sitio I & 28 & 32 & 68 & 65 & 33 & 35 & 43 & 48 \\
\hline Sitio II & 52 & 53 & 32 & 35 & 45 & 57 & 25 & 27 \\
\cline { 2 - 9 }
\end{tabular}




\subsection{Referencias bibliográficas}

1. Barrett, G. C.; Davies, J. S. Amino Acids, Peptides and Proteins;

Royal Society of Chemistry: Cambridge, 2004; Vol. 34.

2. Petsko, G., Ringe, D. 2003. Protein Structure and Function. Blackwell Publishing.

3. Branden, C., Tooze, J. 1999. Introduction to Protein Structure. Taylor and Francis eds.

4. Peters, T. Adv. Protein Chem. 1985; 37: 161.

5. Peters, T. All About Albumin; Biochemistry, Genetics and Medical Applications, Academic Press, 1995.

6. Israili, Z. H. Drug Metabolism Review. 2001; 33: 161.

7. Yamada, H., Shimizu, S. Angew. Chem. Int. Ed. Eng. 1988; 27: 622.

8. Wong, C. H. Science. 1989; 244: 1145.

9. Robertson A, Karp WB, Brodersen R. Dev Pharmacol Ther 1990;15:106.

10. Harmatz D, Blauer G. Arch Biochem Biophys 1975;170:375.

11. Stern L, Brodersen R. Pediatrics 1987;79:154.

12. Zucker SD, Goessling W, Gollan JL. J Biol Chem 1995;270:1074.

13. Sugio, S., Kashima, A., Mochizuki, S., Noda, M., Kobayashi, K. Protein Eng. 1999; 12: 439-446.

14. Dockal, M., Carter, D. C., Ruker, F. J. Biol. Chem. 1999; 274: 29303.

15. Kragh-Hansen, U., Chuang, V. T. G., Otagiri, M. Biol. Pharm. Bull. 2002; 25: 695-704.

16. Ewaskievicz, J. I., Devlin, T. M., Ch'ih, J. J. Biochem. Biophys. Res. Commun. 1991; 179: 1095-1100.

17. Drmanovic, Z., Voyatzi, S., Kouretas, D., Sahpazidou, D., Papageorgiou, A., Antonoglou, O. Anticancer Res. 1999; 19: 4113-4124. 
18. Agarwal, R. P., Phillips, M., McPherson, R. A., Hensley, P. Biochem. Pharmacol. 1986; 35: 3341-3347.

19. Georges, S. H., Presle, N., Buronfosse, T., Fournel-Gigleux, S., Magdalou, J., Lapicque, F. Chirality. 2000; 12: 53-62.

20. Dubois-Presle, N., Lapicque, F., Maurice, M. H., Fournel-Gigleux, S., Magdalou, J., Abiteboul, M., Siest, G., Netter, P. Mol. Pharmacol. 1995; 47: 647-653.

21. Ikeda, T., "Proceedings of the International Symposium on Serum Albumin and $\alpha_{1}$-Acid Glycoprotein", ed. by Otagiri, M., Sugiyama, Y., Testa, B., Tillement, J. P., Kumamoto, Japan. 2001, pp. 173-180.

22. He, K. M., Carter, D. C. Nature. 1992; 358: 29.

23. Carter, D. C., Ho, J. X. Adv. Protein Chem. 1994; 45: 153-203.

24. Curry, S. et al, Nat. Struct. Biol. 1998; 5: 827-835.

25. Ferrer, M., Duchowicz, R., Carrasco, B, Garcia de la Torre, J., Acuña, A. U. Biophys. J. 2001; 80: 2422-2430.

26. Keire, D. A., Mariappan, S. V., Peng, J., Rabenstein, D. L. Biochem. Pharmacol. 1993; 46: 1059-1069.

27. Sudlow, G., Birkett, D. J., Wade, D. N. Mol. Pharmacol. 1976; 12: 1052.

28. Lapicque, F., Muller, N., Payan, E., Dubois, N. Clin. Pharmacokinet. 1993; 25: 115.

29. Rahman, M. H., Yamasaki, K., Shin, Y.-H., Lin, C. C., Otagiri, M. Biol. Pharml. Bull. 1993; 16: 1169.

30. Bhattacharya, A. A., Curry, S., Franks, N. P. J. Biol. Chem. 2000; 275: 38731-38738.

31. Bhattacharya, A. A., Grüne, T., Curry, S. J. Mol. Biol. 2000; 303: 721-732.

32. Menke, G., Wörner, W., Kratzer, W., Rietbrock, N. Arch. Pharmacol. 1989; 339: 42. 
33. Kragh-Hansen, U. Dan. Med. Bull. 1990; 37: 57-84.

34. Rahman, M. H., Maruyama, T., Okada, T., Imai, T., Otagiri, M. Biochem. Pharmacol. 1993; 46: 1733-1740.

35. Rahman, M. M., Rahman, M. H., Rahman, N. N. Pakistan J. Pharm. Sci. 2005; 18: 43-47.

36. Lentner, C. Documenta Geigy Scientific Tables. Physical Chemistry. Blood, Somatometric Data, 8 ${ }^{\mathbf{a}}$ Ed.; Ciba Geigy Corporation: West Caldwell, NJ, 1984; 3; 135-137, 140-142.

37. Carpentier, V., Midoux, P., Monsigny, M., Roche, A. C. Biol. Cell. 1993; 77; 187-193.

38. Weissman, S., Godsmith, B., Winzler, R., Lepper, M.H. J. Lab. Clin. Med. 1961; 57; 7-15.

39. Jakab, L., Kalabay, L. Acta Microbiol. Immunol. Hung. 1998; 45; 409418.

40. Rolan, P. E., Muirhead, M., Clarkson, A. R. Nephron. 1986; 42; 345346.

41. Haraldsson, B., Rippe, B. Acta Physiol. Scand. 1987; 129; 127-135.

42. Frantz, M., Jung, M. L., Ribereau-Gayon, G, Anton, R. 2000; 50; 471-478.

43. Moore, D. F., Rosenfeld, M. R., Gribbon, P. M., Winlove, C. P., Tsai, C. M. Inflammation. 1997; 21; 69-82.

44. Athamna, A., Kramer, M. R., Kahane, I. FEMS Inmunol. Med. Microbiol. 1996; 15; 135-141.

45. Superti, F., Marziano, M. L., Tinari, A., Donelli, G. Comp. Immunol. Microbiol. Infect. Dis. 1993; 16; 55-62.

46. Su, S. J., Yang, B. C., Wang, Y. S., Yeh, T. M. Immunopharmacology. 1999; 41; 21-29.

47. Van Molle, W., Libert, C., Fiers, W., Broukaert, P. J. Immunol. 1997; $159 ; 3555-3564$. 
48. Libert, C. Acad. Geneeskd. Belg. 1997; 59; 515-523

49. Cheresh, D. A., Haynes, D. H., Paul, R. D., Lopez, D. M., Silverman, M. A., Distasio, J. A. Proc. Am. Assoc. ancer Res. 1982; 23; 255.

50. Cheresh, D. A., Haynes, D. H., Distasio, J. A. Immunology. 1984; 51; 541-548.

51. Schmid, K. In The Plasma Proteins: Structure, Function and Genetic Control, $2^{\text {nd }}$ Ed.; Putnam, F. W. ed.; Academic Press: New York. 1975; Vol I; 183-228.

52. K. Schmid, R.B. Nimberg, A. Kimura, H. Yamaguchi, Binette, J.P. Biochim. Biophys. Acta. 1977; 492; 291-302.

53. Schmid, K. J. Am. Chem. Soc. 1953; 75; 60-68.

54. Hochepied, T., Berger, F.G., Baumann, H. and Libert, C. Cytokine Growth Factor Rev., 2003; 14; 25-34.

55. Rojo-Dominguez, A. and Hernandez-Arana, A. Protein Seq. Data Anal. 1993; 5; 349-355.

56. Kopecky, V. Jr., Ettrich, R., Hofbauerova, K., Baumruk, V. Biochem. Biophys. Res. Commun. 2003; 300; 41-46.

57. Aubert, J. P., Loucheux-Lefebvre, M. H. Arch. Biochem. Biophys. 1976; 175; 400-409.

58. Friedman, M. L., Wermeling, J. R., Halsall, H. B. Biochem. J. 1986; 236; 149-153.

59. Kopitar, V.Z., Weisenberger, H. Arzneim. Forsch. (Drug Res) 1971; $21 ; 859-862$.

60. Schmid, K., Kaufman, H., Isemura, S., Bauer, F., Emura, J., Motoyama, T., Ishiguro, M. Nanno, Biochemistry 1973; 12; 2711-2724. 61. Albani, F., Riva, R., Contin, M., Baruzzi, A. Br. J. Clin. Pharmacol. $1984 ; 18 ; 244-246$.

62. Schmid, K., Kaufman, H., Isemura, S., Bauer, F., Emura, J., 
Motoyama, T., Ishiguro, M., Nanno, S. Biochemistry. 1973; 12; 27112724.

63. Grimaldi, B., Hamberger, C., Tremblay, D. Prog. Clin. Biol.

Res. 1989; 300; 445-448.

64. Schley, J., Mueller-Oerlinghausen, B. Pharmacopsychiatry 1983; 16; 82-85.

65. Israili, Z.H., El-Attar, H. Clin. Pharmacol. Ther. 1983; 33; 255.

66. Milhaly, G.W., Ching, M.S., Klejn, M.B., Paull, J., Smallwood, R.A. $1987 ; 24 ; 769-774$.

67. Nyberg, G., Martensson, E. 1982; 319; 189-196.

68. Goolkasian, D.L., Slaughter, R.L., Edwards, D.J., Lalka, D. 1983; 25; 413-417.

69. Curtin, N.J., Newell, D.R., Harris, A.L. 1989; 38, 3281-3288.

70. Tukey, R.H., Strassburg, C.P. Annu. Rev. Pharmacol. Toxicol. 2000; 40; 581-616.

71. Kiang, T.K.L., Ensom, M.H.H., Chang, T.K.H. Pharmacol. Ther. 2005; 106; 97-132.

72. Bosma, P.J. J. Hepatol. 2003; 38; 107-117.

73. Kuehl, G.E., Lampe, J.W., Potter, J.D., Bigler, J. Drug Metab. Dis. 2005; 33; 1027-1035.

74. Vane, J. and Botting, R. M. FASEB. J. 1987; 1: 89-96.

75. Stone, E. Philos. Trans. R. Soc. London. 1763; 53: 195-200.

76. Gibson, T. J. Rheumatol. 1990; 27: 87- 90.

77. Silverstein, F. E. Dig. Dis. Sci. 1998; 43: 447-458.

78. Smith, T., McCrackens, J., Shin, Y.-K, DeWitt, D. J. Biol. Chem. 2000; 275: 40407-40415.

79. Vane, J. R., Bakhle, Y. S., Botting, R. M. Ann. Rev. Pharmacol. Toxicol. 1998; 38: 97-120.

80. Bakhle, Y. S., Botting, R. M. Mediators. Inflamm. 1996; 5: 305-323. 
81. Fu, J., Masferrer, J., Seibert, K., Raz, A., Needleman, P. J. Clin. Inves. 1990; 86: 1375-9.

82. Xie, W., Chipman, J. G., Robertson, D.L. et al. Proc. Nat. Acad. Sci. USA. 1991; 88: 2692-6.

83. Crofford, L. J. J. Rheumatol. 1997; 24: 15-19.

84. Hla, T. and Neilson, K. Proc. Nat. Acad. Sci. USA. 1992; 89: 73487388.

85. Crofford, L. J. et al. J. Clin. Invest. 1994; 93: 1095-1101.

86. Roth, G. J., Standford, N. and Majerus, P. W. Proc. Nat. Acad. Sci. USA. 1975; 72: 3073-3076.

87. Kulmacz, R. J. and Lands, W. E. M. J. Biol. Chem. 1985; 260: $12572-12578$.

88. Gierse, J. K. et al. J. Biol. Chem. 1996; 271: 15810-15814.

89. Rovensky, J., Micekova, D. Drug. Exp. Clin. Res. 2000; 26: 19-24.

90. Bellamy, N., Bensen, W. G., Ford, P. M., Huang, S. H., Lang, J. Y. Clin. Invest. Med. 1992; 15: 427-433.

91. Muckle, D. S. Am. J. Med. 1986; 80: 76-80.

92. Greig, M. E., Griffin, R. L. J. Med. Chem. 1975; 18: 112-116.

93. Miranda, M. A. Phototoxicity of drugs. Academic Press, San Diego. 1997. 289-315.

94. Boscá, F. and Miranda, M. A. J. Photochem. Photobiol B: Biol.. 1998; 43: 1-26.

95. Landoni, M. F.; Soraci, A. Curr. Drug. Metab. 2001, 2, 37.

96. Lewis, A. J.; Furst, D. E. Nonsteroidal Anti-Inflammatory Drugs: Mechanism and Clinical Uses, $2^{\text {nd }}$ Edition; Marcel Dekker: New York, 1994.

97. Evans, A. M. J. Clin. Pharmacol. 1996, 36, 7S.

98. Knadler, M. P.; Hall, S. D. Drug Metab. Dispos. 1991, 19, 280. 
99. Verbeeck, R. K.; Blackburn, J. L.; Loewen, G. R. Clin. Pharmacokinet. 1983, 8, 297.

100. Garrett, R.H., Grisham, C.M. Biochemistry, Harcourt College Pub., 1996

101. Cardellá, R. Bioquímica médica, Editorial Ciencias Médicas, 1999.

102. Kaiser, D.G., Shaw, S.R., Vangiessen, G.J. J. Pharm. Sci. 1974; 63; 567-570.

103. Risdall, P.C., Adams, S.S., Crampton, E.L., Marchant, B. Xenobiotica. 1978; 8; 691-704.

104. Kozma, C., Daffner, R. European Congress of Rheumatology, Wiesbaden. 1979.

105. Chalmers, T.M., Glass, R.C., Risdall, P.C. Curr. Med. Res. Op. $1977 ; 5 ; 17-20$.

106. Kaneo, Y., Kai, A., Kiryu, S., Iguchi, S. J. Pharm. Soc. Jap. 1976; $96 ; 1412-1416$.

107. Stachulski, A. V.; Harding, J. R.; Lindon, J. C.; Maggs, J. L.; Park, B. K.; Wilson, I. D. J. Med. Chem. 2006, 49,. 6931.

108. Dickinson R.G. Proc. West. Pharmacol. Soc. 1993, 36, 157.

109. Bedford, C.T. J. Chromatogr. B 1998, 717, 313.

110. G. J. Dutton, Glucuronidation of Drugs and other Compounds, CRC Press, Boca Raton, 1980.

111. Turgeon, D.; Carrier, J.S.; Chouinard, s.; Bélanger, A. Drug Metab. Dispos. 2003, 31, 670.

112. Magdalou, J.; Chajes, V.; Lafaurie, C.; Siest, G. Drug Metab. Dispos. 1990, 18, 692.

113. Spahn-Langguth, H.; Benet, L. Z. Drug. Metab. Rev. 1992, $24,5$.

114. Lucaciu, R.; Ionescu, C. Farmacia 2005, 53, 10.

115. Adams, S.S., Crampton, E.L., Nicholson, J.S., Risdall, P.C. International Congress of Rheumatology, Kyoto, Japan. 1973. 
116. Cardoe, N., de Silva, M., Glass, R.C., Risdall, P.C. Curr. Med. Res. Op. $1977 ; 5 ; 21-25$.

117. Lindqvist, L. Hebd. Seances Acad. Sci., Ser. C. 1966; 263; 852.

118. Jia, Z., Ramstad, T., Zhong, M. J. Pharm. Biomed. Anal. 2002; 405: 413.

119. Lucas, L. H., Price, K. E., Larive, C. K. J. Am. Chem. Soc. 2004; 126: 14258.

120. Lhiaubet-Vallet, V., Sarabia, Z., Boscá, F., Miranda, M. A. J. Am. Chem. Soc. 2004; 126: 9538.

121. Martínez, L. J., Scaiano, J. C. Photochem. Photobiol. 1998; 68: 646.

122. Sortino, S., Scaiano, J. C., Giuffrida, S. New. J. Chem. 1999; 23 : 1159.

123. Monti, S., Manet, I., Manoli, F., Morrone, R., Nicolosi, G., Sortino, S. Photochem. Photobiol. 2006; 82: 13.

124. Jiménez, M.C., Miranda, M. A., Tormos, R., Vayá, I. Photochem. Photobiol. Sci. 2004; 3; 1038-1041.

125. Vayá, I., Bueno, C.J., Jiménez, M.C., Miranda, M.A. ChemMedChem 2006; 1; 1015-1020. 



\subsection{Objetivos}

A la luz de los resultados obtenidos previamente en el grupo estudiando las interacciones entre flurbiprofeno y albúminas séricas humana y bovina, el objetivo del presente trabajo consiste en ampliar los campos de aplicación de la técnica de fotólisis de destello láser.

Para ello se plantean diferentes situaciones en las que la interacción fármaco-proteína resultara clave y analizar el problema mediante espectroscopía de absorción transitoria.

Como sustratos para los diferentes estudios se han seleccionado, además de FBP y FBPMe, el glucurónido del mismo (FBPGluc), sintetizado en varios pasos a partir de FBP.

La técnica de fotólisis de destello láser es muy sensible, capaz de detectar las especies transitorias que genera el sustrato por absorción de luz a concentraciones muy bajas (de hasta $10^{-6} \mathrm{M}$ ). Además es un método sencillo y de rápida ejecución y ofrece resultados altamente reproducibles y de fácil procesado.

Concretamente se han planteado los siguientes objetivos específicos:

- Estudiar la interacción de FBP, FBPMe y FBPGluc con albúminas séricas de distintas especies. Es conocida la similitud estructural entre las AS de distintas especies, pero también que pueden tener diferentes comportamientos en cuanto a su interacción con fármacos. Por ello se aplicará la técnica FDL al estudio de interacción de los tres ligandos con las albúminas séricas de conejo, perro, cerdo, oveja y rata, debido a que estas especies son regularmente utilizadas en estudios de nuevos fármacos. 
- Una vez sintetizado FBPGluc, se utilizará para estudiar la actividad glucuronidasa de las diferentes albúminas. Éste es un proceso que puede tener importantes implicaciones biológicas en cuanto a posibles efectos nocivos relacionados con la eliminación del fármaco del organismo. Se hará uso de los conocimientos previos de la interacción FBP-AS en el estado excitado para cuantificar la cantidad de FBPGluc hidrolizado por cada proteína.

- Otra situación de gran relevancia biológica planteada es el estudio de la interacción de los sustratos con dos proteínas transportadoras diferentes presentes simultaneamente en el medio. La a-glicoproteína ácida humana es una proteína transportadora presente en distintos fluidos y tejidos que en determinadas condiciones (como procesos inflamatorios) es capaz de competir con ASH en su interacción con fármacos. De esta forma, la técnica de FDLserá aplicada al estudio de las interacciones de FBP, FBPMe y FBPGluc en sistemas binarios conteniendo ASH y AAG presentes simultáneamente.

- Por último, se estudiará la viabilidad de esta metodología para la determinación de la composición enantiomérica de mezclas de los enantiómeros de FBP y FBPMe. Se llevará a cabo un análisis de mezclas de composición conocida usando las albúminas séricas como selectores quirales. 


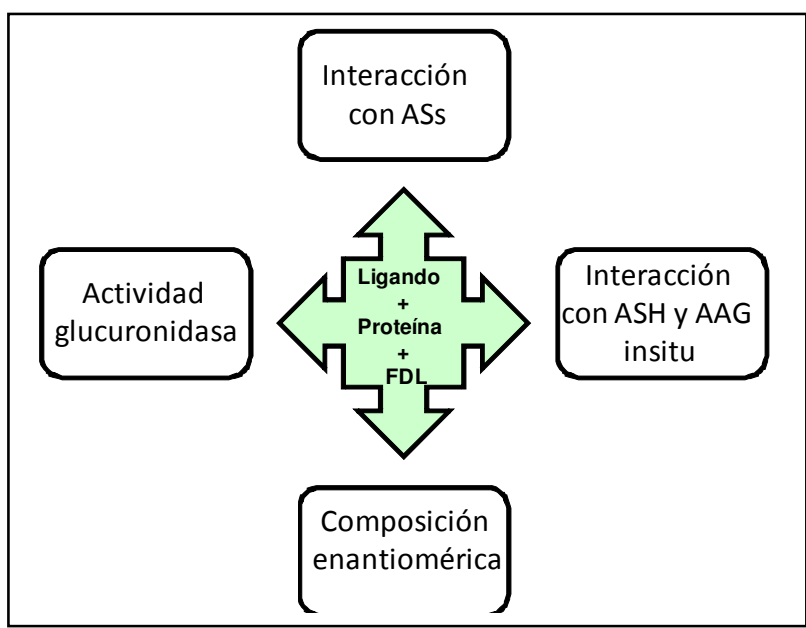

Figura 2.1. Esquema de los objetivos de ésta tesis 

CAPÍTULO 3. Estudio de las interacciones entre FBP, FBPGluc y FBPMe y albúminas séricas de distintas especies 



\subsection{Introducción}

Como se ha expuesto en la introducción, profundizar en el conocimiento sobre cómo se produce la interacción entre xenobióticos y albúmina sérica es de gran importancia desde el punto de vista de la farmacocinética, la farmacodinámica y la toxicidad asociada a cualquier sustancia.

Los antiinflamatorios de la familia de los ácidos 2-arilpropiónicos se unen preferentemente al sitio II de ASH en algunos casos de forma estereoselectiva. Para FBP, también se encuentra descrito que el sitio de mayor afinidad es el sitio II de la proteína; habiéndose encontrado cierto grado de estereoselectividad con la ASB pero no con la $\mathrm{ASH} .{ }^{17}$ En cambio, FBPMe se une principalmente al sitio I y tiene una gran estereoselectividad con ASH pero no con ASB.

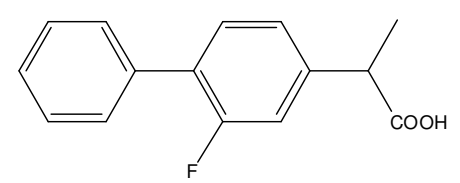

FBP

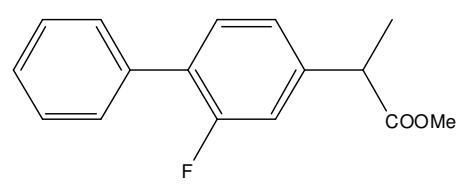

FBPMe<smiles>CC(C(=O)OC1O[C@H](C(=O)O)[C@H](O)[C@H](O)[C@H]1O)c1ccc(-c2ccccc2)c(F)c1</smiles>

FBPGluc

Figura 3.1. Estructuras de los ligandos estudiados 
En cuanto a FBPGluc, su interacción con ASH y ASB se estudiará por primera vez a lo largo de este capítulo.

La diferencia en el comportamiento de estos ligandos en su unión a estas dos proteínas a pesar de su similitud estructural, nos lleva a interesarnos por la interacción de estos compuestos con albúminas de otras especies como el cerdo (ASCe), la oveja (ASO), el conejo (ASC), el perro (ASP), y la rata (ASR), también usadas en ensayos de nuevos fármacos y con una alta similitud estructural entre ellas.

Para estudiar estas interacciones se usó la técnica de fotólisis de destello láser (FDL). Los estados excitados triplete de FBP, FBPGluc y FBPMe son muy sensibles al medio, por lo que pueden ser de gran utilidad para examinar las posibles diferencias en los microentornos que cada AS proporciona al fármaco. ${ }^{19}$ Así, se obtendrán los tiempos de vida de triplete $\left(\tau_{T}\right)$ de FBP, FBPGluc y FBPMe dentro de cada albúmina a partir de las curvas de desactivación; mediante un análisis de regresión de dichas curvas se establecerá la distribución del sustrato en los sitios de unión de las proteínas. 


\subsection{Resultados y discusión}

\subsubsection{Datos fotofisicos de FBPGluc}

Con anterioridad a ésta tesis se caracterizó la fotofísica de FBP y FBPMe cuyos datos se muestran en la introducción (Tabla 1.2). En cuanto a FBPGluc, su fotofísica ha sido estudiada a lo largo de esta tesis. Su espectro UV-Vis fue muy similar al de FBP y FBPMe, ya que el cromóforo dominante continua siendo el bifenilo. El espectro de fluorescencia de FBPGluc, al igual que el de FBP y FBPMe, también resultó tener un máximo a $310 \mathrm{~nm}$ (Figura 3.2).

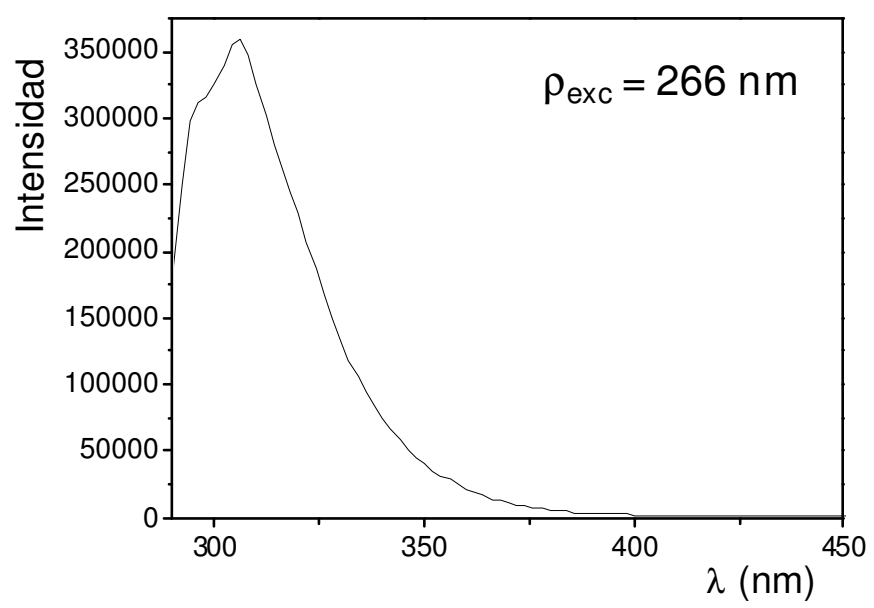

Figura 3.2. Espectro de flurescencia del S-FBPGluc en PBS, aire $\left(\lambda_{\text {exc }}=266\right.$ $\mathrm{nm})$.

En los experimentos de FDL, se encontró una banda de absorción triplete-triplete centrada a $360 \mathrm{~nm}$ con un $\tau_{\mathrm{T}}$ de $1.8 \mu \mathrm{s}\left(\lambda_{\mathrm{exc}}=\right.$ $266 \mathrm{~nm}, \mathrm{PBS}$, aire) (Figura 3.3). 


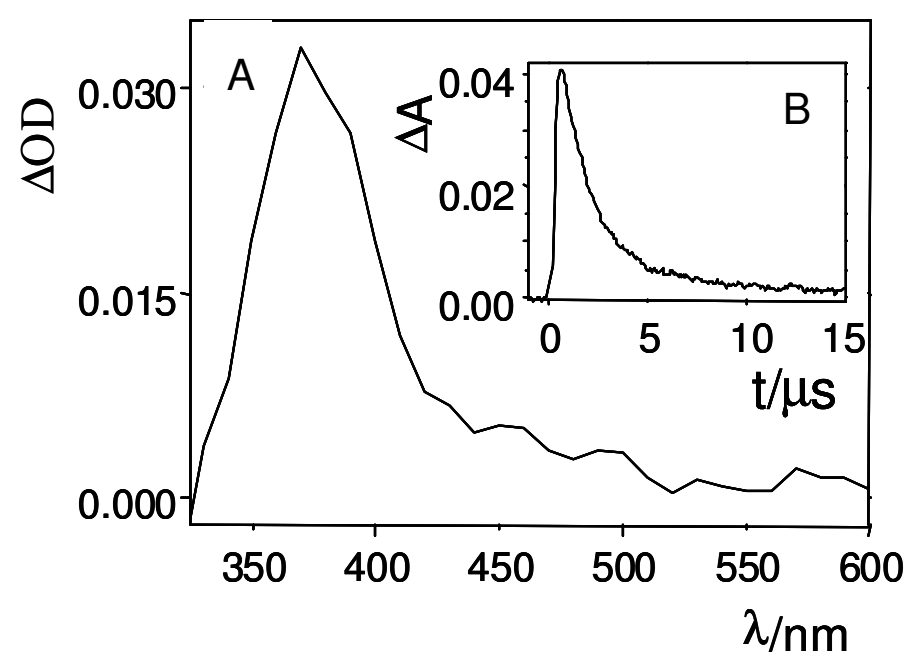

Figura 3.3. Fotólisis de destello laser $\left(\lambda_{\mathrm{exc}}=266 \mathrm{~nm}, \mathrm{PBS}, \mathrm{pH}=7.4\right.$, aire $)$ de (2S)-FBPGluc. A. Espectro de absorción de obtenido $0.5 \mu$ s después del pulso de laser. B. Curva de desaparición monitorizada a $360 \mathrm{~nm}$.

Una vez caracterizados los estados excitados triplete en ausencia de proteína, se procedió al estudio de interacción de éstos con las diferentes SAs. Se utilizaron los dos enantiómeros de cada sustrato por separado, con el fin de determinar una posible estereodiferenciación en la interacción con la proteína.

\subsubsection{Sistemas flurbiprofeno/albúmina sérica}

Se comenzó con el estudio por FDL del $(S)$ y $(R)$-FBP en presencia de las albúminas de las diferentes especies. Para ello se prepararon disoluciones en tampón fosfato (PBS $0.01 \mathrm{M}, \mathrm{pH}=7.4$ ) de (S) y $(R)$-FBP con AS a diferentes relaciones molares comprendidas entre $4: 1$ y $0.8: 1$. En todo este rango, la concentración de FBP se mantuvo constante $\left(2.5 \times 10^{-5} \mathrm{M}\right)$, variando la de AS. Tras excitación a $266 \mathrm{~nm}$ en aire, se obtuvo la banda correspondiente al primer estado 

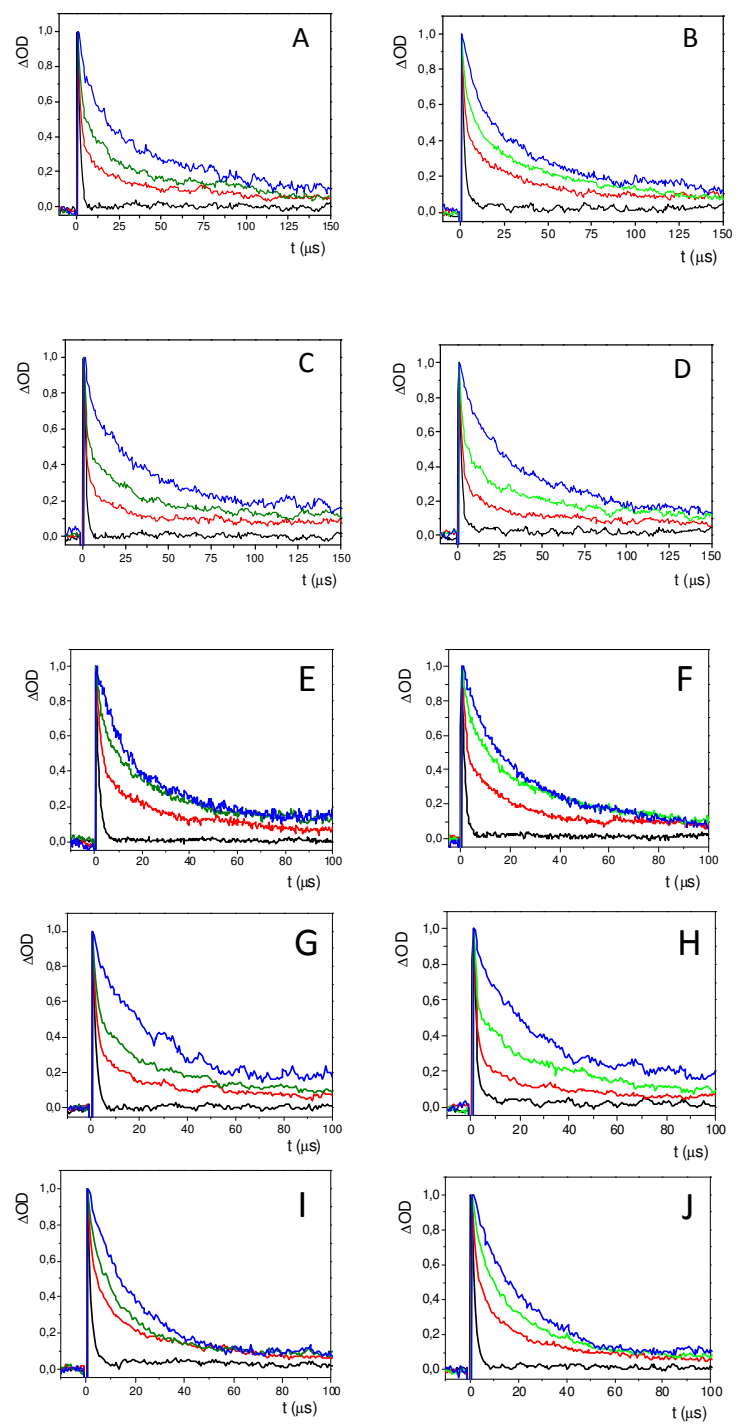

Figura 3.4. Curvas de desaparición normalizadas de $(S)$ y $(R)$-FBP (Negro) y de las mezclas 4:1 (Rojo), 2:1 (Verde) y 0.8:1 (Azul), tras FDL ( $\lambda_{\mathrm{exc}}=266 \mathrm{~nm}, \lambda_{\text {mon }}=360$ $\mathrm{nm}$ ) en presencia de distintas AS: A- S-FBP/ASCe, B- R-FBP/ASCe, C- S-FBP/ASO, D$R$-FBP/ASO, E- $S$-FBP/ASC, F- $R$-FBP/ASC, G- $S$-FBP/ASP, H- $R$-FBP/ASP, I- $S$ FBP/ASR, J- $R$-FBP/ASR 
excitado triplete del FBP centrada a $360 \mathrm{~nm}$. Se realizó un análisis de regresión de la cinética de desactivación de dicho estado triplete para todas las disoluciones.

A diferencia de la situación en la que no hay proteína (ley monoexponencial, $\left.\tau_{\mathrm{T}}=1.5 \mu \mathrm{s}\right)$, en presencia de ASs las curvas de desaparición fueron más largas (figura 3.4) y se ajustaron con la ecuación ec. 1.

$$
\Delta O D=\Delta O D_{0}+A_{L} e^{\left(-t / \tau_{L}\right)}+A_{I} e^{\left(-t / \tau_{I}\right)}+A_{I I} e^{\left(-t / \tau_{I I}\right)} \quad \text { (ec. 1) }
$$

donde $\Delta O D$ es la absorbancia del estado excitado, $\tau_{L}, \tau_{\mid}$y $\tau_{\|}$son los tiempos de vida de triplete libre y unido sitio I y II, y $A_{L}, A_{I}$ y $A_{\|}$los correspondientes fáctores preexsponenciales.

En todos los casos se observa un incremento del tiempo de vida dentro de la proteína, que se puede atribuir a una mayor protección del estado excitado del FBP en ese microentorno frente al ataque de diversos reactivos, como oxígeno u otra molécula de FBP, entre otros.

Tras el ajuste de estas curvas de desaparición, se pueden observar dos comportamientos bien diferenciados atendiendo a la especie de la albúmina sérica usada.

En ASCe y ASO a proporciones molares 1:1 o superiores se necesita un ajuste multiexponencial con tres componentes, siempre con una componente de $1.5 \mu$ s, lo que indica que existe FBP libre en disolución. Por debajo de la relación 1:1, es necesario una función con dos términos monoexponenciales. No se encuentra la componente de $1.5 \mu \mathrm{s}$, lo que indica la ausencia de FBP libre. Las otras dos componentes de los ajustes se asignan a FBP unido a sitio I (componente minoritaria) y sitio II (componente mayoritaria) de la albúmina correspondiente. 
En la tabla 3.1 se muestran los tiempos de vida de triplete encontrados para los sistemas FBP/ASCe y FBP/ASO obtenidos haciendo uso de la ec. 1.

Tabla 3.1. Tiempos de vida de triplete $(\mu \mathrm{s})$ del FBP unido a ASCe y ASO.

\begin{tabular}{|l|c|c|c|c|}
\cline { 2 - 5 } \multicolumn{1}{c|}{} & \multicolumn{2}{c|}{ ASCe } & \multicolumn{2}{c|}{ ASO } \\
\cline { 2 - 5 } \multicolumn{1}{c|}{} & $\boldsymbol{S}$ & $\boldsymbol{R}$ & $\boldsymbol{S}$ & $\boldsymbol{R}$ \\
\hline Libre & 1.5 & 1.5 & 1.5 & 1.5 \\
Sitio I & 6.5 & 6.8 & 6.5 & 8 \\
Sitio II & 44.5 & 45 & 54.5 & 62 \\
\hline
\end{tabular}

Un comportamiento diferente presentan ASC, ASP y ASR; en estos casos es necesario a relaciones molares superiores a 1:1 un ajuste con únicamente dos componentes, por debajo de esa relación una función monoexponencial es suficiente (excepto para ASP que sigue necesitando dos monoexponenciales por debajo de la relación $1: 1)$ pero con un tiempo de vida muy superior a $1.5 \mu \mathrm{s}$.

En este caso, la asignación de los diferentes tiempos de vida con los sitios de unión fue la siguiente: el tiempo de vida de $1.5 \mu \mathrm{s}$ corresponde, evidentemente, a la especie libre, mientras que el tiempo largo corresponde a FBP en un sitio de unión de esas proteínas, lo que indica que FBP sólo se une a un sitio de estas proteínas. Por tanto en este caso el término $A_{I} e^{\left(-t / \tau_{I}\right)}$ sería nulo.

En la tabla 3.2 se muestran los tiempos de vida para ASC, ASP y ASR.

Tabla 3.2. Tiempos de vida de triplete $(\mu \mathrm{s})$ del FBP unido a ASC, ASP y ASR.

\begin{tabular}{|c|c|c|c|c|c|c|}
\cline { 2 - 7 } \multicolumn{1}{c|}{} & \multicolumn{2}{c|}{ ASC } & \multicolumn{2}{c|}{ ASP } & \multicolumn{2}{c|}{ ASR } \\
\cline { 2 - 7 } \multicolumn{1}{c|}{} & $\boldsymbol{S}$ & $\boldsymbol{R}$ & $\boldsymbol{S}$ & $\boldsymbol{R}$ & $\boldsymbol{S}$ & $\boldsymbol{R}$ \\
\hline Libre & 1.5 & 1.5 & 1.5 & 1.5 & 1.5 & 1.5 \\
Unido & 18 & 21 & 27 & 24.5 & 18 & 19.5 \\
\hline
\end{tabular}


Fijando los tiempos de vida en la ec. 1 se pueden obtener los valores de los factores preexponenciales $A_{L}, A_{l}$ y $A_{\| l}$, que están relacionadas con el porcentaje de $(S)$ - o $(R)$-FBP libre en disolución o dentro de los sitios de unión. Así, la cantidad de fármaco libre se determinó según:

$$
\% F B P_{L}=\frac{A_{L}}{A_{I}+A_{I I}+A_{L}} \times 100 \quad \text { (ec. 2) }
$$
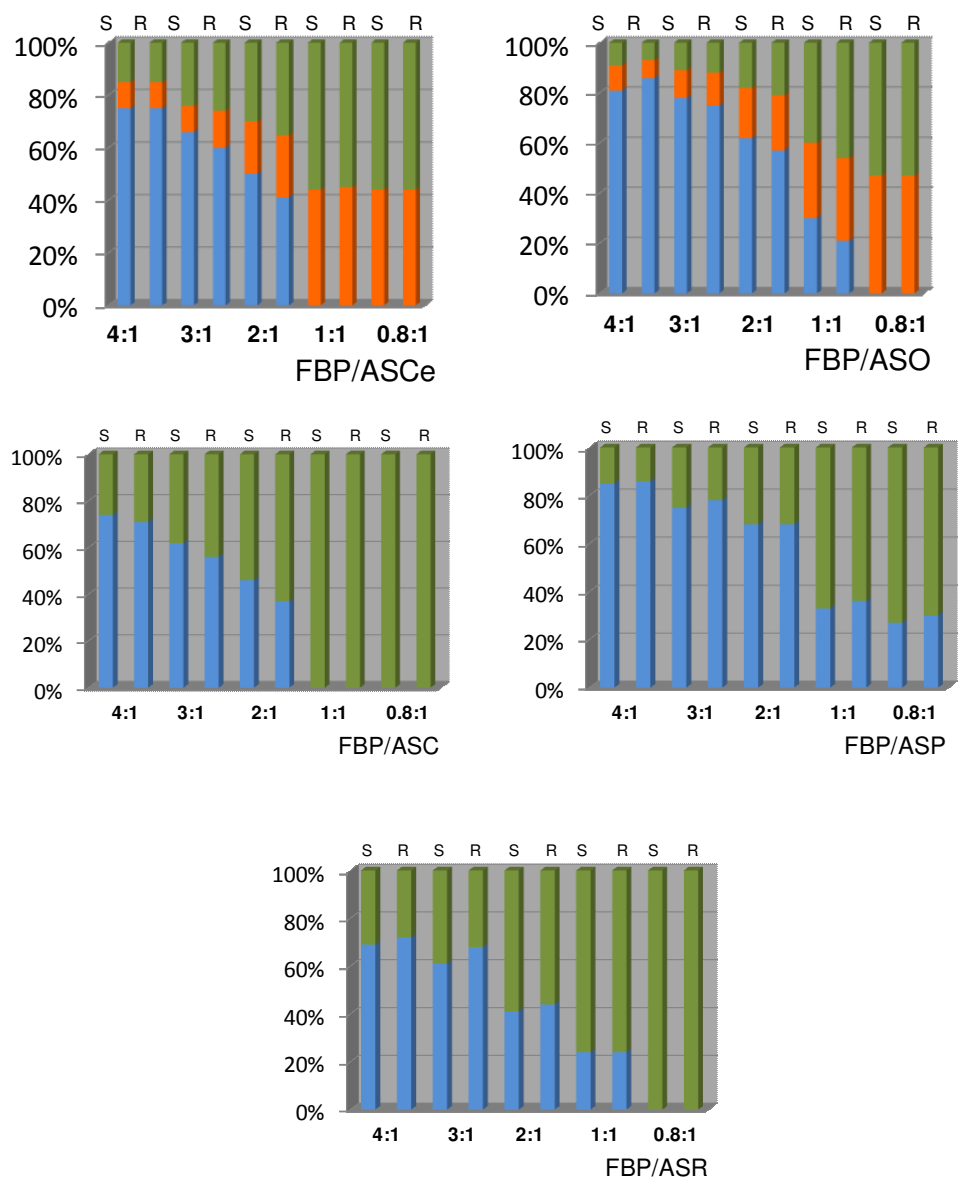

Figura 3.5. Porcentaje de (S)- y (R)-FBP libre (Azul), unido a sitio I (Naranja) y sitio II (Verde) de ASCe, ASO, ASC, ASP y ASR 
Teniendo en cuenta que el sitio de mayor afinidad para el FBP en la albúmina sérica es el sitio II, la componente mayoritaria del ajuste anterior se ha asignado a FBP en sitio II y la minoritaria a FBP en sitio I. La figura 3.5 muestra los valores de ocupación de FBP en las diferentes albúminas séricas.

Para corroborar las asignaciones propuestas de sitio I y sitio II, se realizaron experimentos de FDL pero introduciendo sondas de desplazamiento con una afinidad conocida por cada sitio de unión de la proteína. En concreto se adicionó ibuprofeno (IBP), como ligando específico de sitio II, con relación molar FBP/AS/IBP 0.7:1:1. Tras someter estas mezclas a FDL y obtener las correspondientes curvas de desaparición, se determinaron los valores de ocupación de los diferentes sitios de unión fijando los tiempos previamente calculados. Como se puede observar en la tabla 3.3, la adición de IBP a las mezclas con ASCe y ASO, en las que el FBP se une a dos sitios, provoca la disminución de la componente de mayor tiempo de vida y el aumento de la otra componente. Además, no se observa la componente de $1.5 \mu$ s lo que indica que todo el FBP desplazado del sitio II se une al sitio I.

Tabla 3.3. Porcentaje de $(S)$ - y $(R)$-FBP unido a ASCe y ASO con ausencia y presencia de IBP en proporción 0.7:1:1.

\begin{tabular}{|c|c|c|}
\cline { 2 - 3 } & Sitio I & Sitio II \\
\hline S-FBP/PSA & 49 & 51 \\
\hline $\boldsymbol{R}$-FBP/PSA & 60 & 40 \\
\hline $\boldsymbol{R}$-FBP/PSA/IBP & 60 & 52 \\
\hline S-FBP/SSA & 41 & 40 \\
\hline S-FBP/SSA/IBP & 59 & 59 \\
\hline $\boldsymbol{R}$-FBP/SSA & 35 & 65 \\
\hline $\boldsymbol{R}$-FBP/SSA/IBP & 47 & 53 \\
\hline
\end{tabular}


Con las otras proteínas (tabla 3.4) además de la disminución en la componente mayoritaria de $\tau_{\mathrm{T}}$, se produce un aumento en la componente de $\tau_{\mathrm{T}}=1.5 \mu$ s (FBP libre), lo que confirma la existencia de un solo sitio de unión para el FBP en estas proteínas.

Tabla 3.4. Porcentaje de (S)- y (R)-FBP unido a ASC, ASP y ASR con ausencia y presencia de IBP en proporción 0.7:1:1.

\begin{tabular}{|c|c|c|}
\cline { 2 - 3 } \multicolumn{1}{c|}{} & Libre & Unido \\
\hline S-FBP/ASC & 0 & 100 \\
\hline $\boldsymbol{S}$-FBP/ASC/IBP & 26 & 74 \\
\hline $\boldsymbol{R}$-FBP/ASC & 0 & 100 \\
\hline $\boldsymbol{R}$-FBP/ASC/IBP & 0 & 100 \\
\hline S-FBP/ASP & 34 & 66 \\
\hline S-FBP/ASP/IBP & 45 & 55 \\
\hline $\boldsymbol{R}$-FBP/ASP & 23 & 77 \\
\hline $\boldsymbol{R}$-FBP/ASP/IBP & 48 & 52 \\
\hline S-FBP/ASR & 0 & 100 \\
\hline S-FBP/ASR/IBP & 22 & 78 \\
\hline $\boldsymbol{R}$-FBP/ASR & 0 & 100 \\
\hline $\boldsymbol{R}$-FBP/ASR/IBP & 29 & 71 \\
\hline
\end{tabular}

En cuanto al comportamiento de cada isómero, cabe destacar que nos se aprecia una gran estereodiferenciación en los tiempos de vida de FBP dentro de las diferentes proteínas estudiadas. Solo existe una pequeña estereodiferenciación en el grado de ocupación, encontrándose que el isómero $(R)$ se acomoda más fácilmente dentro del sitio de unión. 


\subsubsection{Sistemas FBPGluc/ASs}

Después de estudiar la interacción de FBP con todas las albúminas, se procedió a realizar el mismo estudio con los dos enantiómeros de su glucurónido.

La síntesis de los glucurónidos se consiguió por el método descrito en la literatura por Baba et al. ${ }^{26,27}$ con algunas modificaciones, y que consiste en una reacción de sustitución entre el 3,4-tri-O-acetil-1bromo-1-deoxi- $\alpha$-D-glucopiranuronato y la sal de cesio de (S)- o (R)FBP. Tras purificar por HPLC, se procede a una doble desprotección enzimática con enzimas específicas. Primero se desprotegen los grupos $\mathrm{OH}$ del anillo de azúcar mediante amano AS lipasa (LAS), una enzima específica de grupos acetato. Posteriormente se desprotege el ácido carboxílico de FBP con esterasa de hígado porcina (PLE) que es específica de ésteres metílicos. El esquema de esta reacción se muestra en la figura 3.7.

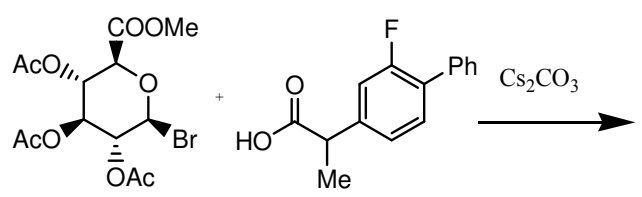

$(S)$ - or $(R)$-FBP

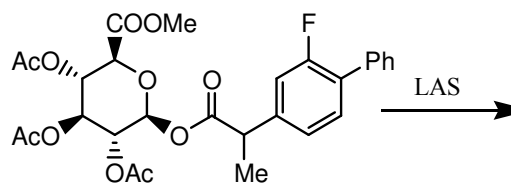

(2S)- or (2R)-1<smiles>COC(=O)[C@H]1O[C@H](OC(=O)C(C(C)C)[N+]([O-])c2ccc(-c3ccccc3)c(F)c2)[C@H](O)[C@H](O)[C@H]1O</smiles>

$(2 S)$ - or $(2 R)-2$<smiles>[N]C(C(=O)O[C@H]1O[C@H](C(=O)O)[C@H](O)[C@@H](O)[C@H]1O)c1ccc(-c2ccccc2)c(F)c1</smiles>

(2S)- or (2R)-FBPGluc

Figura 3.7. Síntesis de (2S)-y (2R)-FBPGluc. Abreviaturas: LAS, Amano AS Lipasa;PLE, Estereasa de Hígado Porcina 
Tras FDL de (2S)- o (2R)-FBPGluc $\left(1.5 \times 10^{-5} \mathrm{M}\right.$, PBS $0.01 \mathrm{M}$, $\mathrm{pH}=7.4, \lambda_{\mathrm{exc}}=266 \mathrm{~nm}$, aire) se observó un espectro de absorción transitoria con máximo a $360 \mathrm{~nm}$, correspondiente a la absorción T-T de FBPGluc (figura 3.3).

Posteriormente se realizaron los experimentos en presencia de las albúminas séricas, comenzando con ASH para luego aplicar la misma metodología al resto de proteínas. En presencia de diferentes cantidades de ASH, los experimentos de FDL de (2R)-FBPGluc también dieron lugar a la banda característica de ${ }^{3} \mathrm{FBP}^{*}$. Contrariamente al comportamiento en ausencia de proteína, las curvas de desactivación a $360 \mathrm{~nm}$ (Figura 3A) no siguieron una simple ley monoexponencial sino que necesitaron de un ajuste multiexponencial y tuvieron lugar a escalas de tiempo mayores.

Para analizar las curvas de desaparición a $\lambda_{\max }=360 \mathrm{~nm}$, se procedió de la siguiente forma: para el caso de $(2 \boldsymbol{R})$-FBPGluc en ASH (relación molar 1:3.33) a tiempo cero, solo se encuentran dos tiempos de vida, por lo que la ley de ajuste contiene dos términos monoexponenciales

$$
\Delta O D=\Delta O D_{0}+A_{L}^{F B P G l u c} e^{\left(-t / \tau_{L}^{F B P G h c}\right)}+A_{U}^{F B P G l u c} e^{\left(-t / \tau_{U}^{\text {FBPChuc }}\right)}
$$

donde $\tau_{\mathrm{L}}^{\text {FBPGluc }}(1.8 \mu \mathrm{s})$ y $\tau_{\cup}^{\text {FBPGluc }}(25.0 \mu \mathrm{s})$ corresponden a $(2 \boldsymbol{R})$ FBPGluc libre en disolución y unido a proteína, respectivamente. 

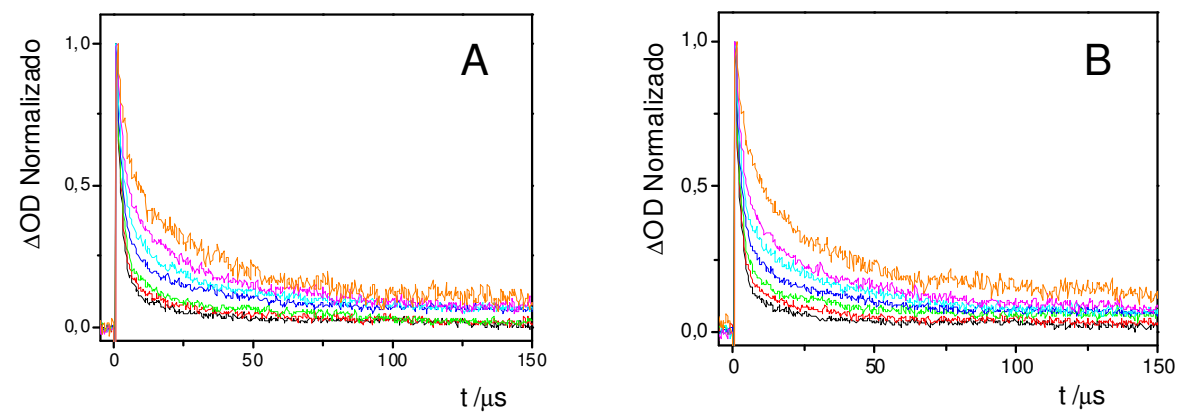

Figura 3.8. Fotólisis de destello laser $\left(\lambda_{\mathrm{exc}}=266 \mathrm{~nm}\right)$ de FBPGluc/ASH a diferentes relaciones molares. Curvas de desactivación normalizadas monitorizadas a $360 \mathrm{~nm}$. A: (2R)-FBPGluc. B: (2S)-FBPGluc. Relaciones molares: 1:0.25 (negro), 1:0.33 (rojo), 1:0.50 (verde), 1:1.00 (azul oscuro), 1:1.43 (celeste), 1:2.00 (rosa), 1:3.33 (naranja).

El porcentaje de (2R)-FBPGluc en cada entorno se obtuvo de los correspondientes factores pre-exponenciales $A_{L}{ }^{\text {FBPGluc }}$ y $A_{U}{ }^{\text {FBPGluc }}$ de la siguiente forma:

$$
\% \text { FBPGluc }_{L}=\frac{A_{L}}{A_{L}+A_{U}} \times 100 \quad \text { (ec. 4) }
$$

En paralelo, se realizaron experimentos con (2S)-FBPGluc y se observó una tendencia similar (Figura 3.8 B). Los dos tiempos de vida de triplete encontrados en presencia de albúmina sérica humana fueron idénticos a aquellos encontrados para (2R)-FBPGluc, dentro de los margenes de error. La distribución entre glucurónido libre y unido, obtenida de nuevo a partir de los factores pre-exponenciales $A_{L}{ }^{\text {FBPGluc }} y$ $A_{U}{ }^{\text {FBPGluc }}$, dio valores muy parecidos a los determinados para el isómero (2R)- (Tabla 3.5, entrada 1). 
Tabla 3.5. Porcentajes iniciales de (2S)- y (2R)-FBPGluc libre y unido a ASH a diferentes relaciones molares ${ }^{\mathrm{a}}$.

\begin{tabular}{cccccc}
\hline & & \multicolumn{2}{c}{ Libre } & \multicolumn{2}{c}{$\begin{array}{c}\text { Unido a } \\
\text { Proteína }\end{array}$} \\
Entrada & {$\left[_{\text {FBPGluc }] /[\mathrm{HSA}]^{\mathrm{b}}}\right.$} & $(2 R)-$ & $(2 S)-$ & $(2 R)-$ & $(2 S)-$ \\
\hline 1 & $1: 3.33$ & 66 & 63 & 34 & 37 \\
2 & $1: 2.00$ & 73 & 73 & 27 & 27 \\
3 & $1: 1.43$ & 76 & 78 & 24 & 22 \\
4 & $1: 1.00$ & 81 & 82 & 19 & 18 \\
5 & $1: 0.50$ & 89 & 88 & 11 & 12 \\
6 & $1: 0.33$ & 91 & 91 & 9 & 9 \\
7 & $1: 0.25$ & 93 & 93 & 7 & 7 \\
\hline
\end{tabular}

a Los errores relativos estuvieron por debajo del $5 \%$ de los valores determinados. ${ }^{\mathrm{b}}$ Condiciones: $\left[\right.$ FBPGluc] $=1.5 \times 10^{-5} \mathrm{M}, \mathrm{PBS} 0.01 \mathrm{M}, \mathrm{T}=22^{\circ} \mathrm{C}$.

Posteriormente, los tiempos de vida de triplete fueron fijados a $1.8 \mu \mathrm{s}$ y $25.0 \mu \mathrm{s}$ en todo el rango de concentraciones para aplicar la ec. 3; es destacable que se obtuvieron valores muy similares $\left(\tau_{T}, A\right)$ sin fijar los valores de $\tau_{\mathrm{T}}$. En todos los casos (entrada 1-7, tabla 3.5) se encontró una importante contribución de la componente de menor tiempo de vida, indicando que siempre había glucurónido libre en la disolución. El análisis de regresión de las curvas de desaparición (Figura 3.9 A, B) permitió obtener los valores de los coeficientes $A_{L}{ }^{\text {FBPGluc }}$ y $A_{U}{ }^{\text {FBPGluc }}$ y a partir de ellos los porcentajes de las dos especies (libre y unida) con tiempos de vida diferentes (Tabla 3.5). Las curvas del ajuste y los 
parámetros derivados de él se muestran para dos casos representativos en la Figura 3.9.
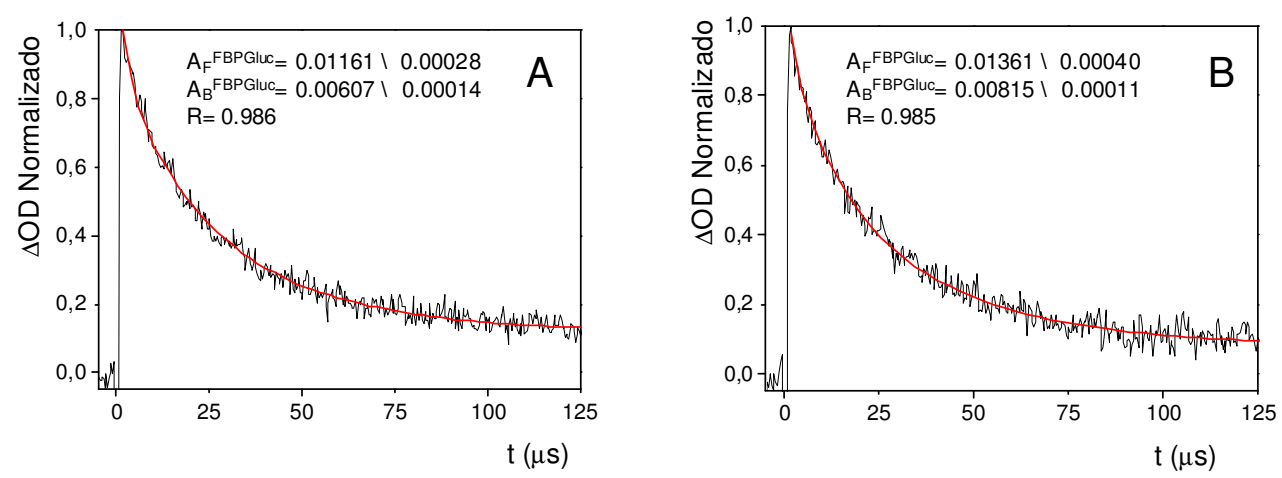

Figura 3.9. Fotólisis de destello laser $\left(\lambda_{\mathrm{exc}}=266 \mathrm{~nm}\right)$ de FBPGluc/ASH a relación molar 1:3.33 (linea negra) junto con el correspondiente ajuste (línea roja). A: (2R)-FBPGluc. B: (2S)-FBPGluc. Los parámetros indicados corresponden con el ajuste de la línea roja y la ec. 3 .

De entre los resultados anteriores, algunas observaciones merecen un comentario especial por sus relevantes implicaciones biológicas. Primero, incluso a bajas relaciones molares FBPGluc/ASH, una gran cantidad de glucurónido permanece sin unir a la proteína. Esto está de acuerdo con el aumento de hidrosolubilidad del glucurónido respecto al fármaco de partida, lo que facilita su eliminación; además, no hay estereodiferenciación en el proceso de unión a la proteína, ya que no se observaron diferencias significativas entre el grado de unión de (2S)- y (2R)-FBPGluc. Asimismo, solo se proporciona un tipo de microentorno por parte de la proteína para (2S)- y (2R)-FBPGluc, a diferencia del fármaco de partida FBP, que se une a dos sitios en $\mathrm{ASH}^{23}$ Se llevaron a cabo experimentos de desplazamiento con una sonda específica de sitio II (ibuprofeno). ${ }^{29}$ En presencia de esta sonda, 
a una relación molar 1:3:1 [FBPGluc]/[ASH]/[IBP], la contribución de la componente de $\tau_{\top}=25 \mu$ s disminuyó hasta un $20 \%$.

A continuación se estudió la interacción de FBPGluc con el resto de albúminas mediante FDL. Para ello se prepararon disoluciones en tampón fosfato (PBS $0.01 \mathrm{M}, \mathrm{pH}=7.4)$ de $(S)$ y $(R)$-FBPGluc con AS a diferentes relaciones molares FBPGluc/AS comprendidas entre $4: 1 \mathrm{y}$ 0.3:1. La concentración de FBPGluc se mantuvo constante $\left(1.5 \times 10^{-5}\right.$ M), variando la de AS. Tras someter estas disoluciones a FDL $\left(\lambda_{\mathrm{exc}}=\right.$ $266 \mathrm{~nm}$, aire) se obtuvo la banda característica al primer estado excitado triplete del FBP a $360 \mathrm{~nm}$. Se realizó un análisis de regresión de la cinética de desactivación de dicho estado triplete para todas las disoluciones con AS en ausencia de proteínas. Las diferentes curvas de desaparición para las mezclas de $(S)$ y $(R)$-FBPGluc con las distintas proteínas se muestran en la figura 3.10.

De nuevo se observó que el $\tau_{\top}$ es mucho mayor en presencia de proteína. También quedó de manifiesto que, a diferencia del caso de FBP, cuando se ajustan las curvas de desaparición solo se necesitan dos términos monoexponenciales para todas las albúminas, siendo uno de ellos la componente con $\tau_{T}=1.8 \mu$ s. 

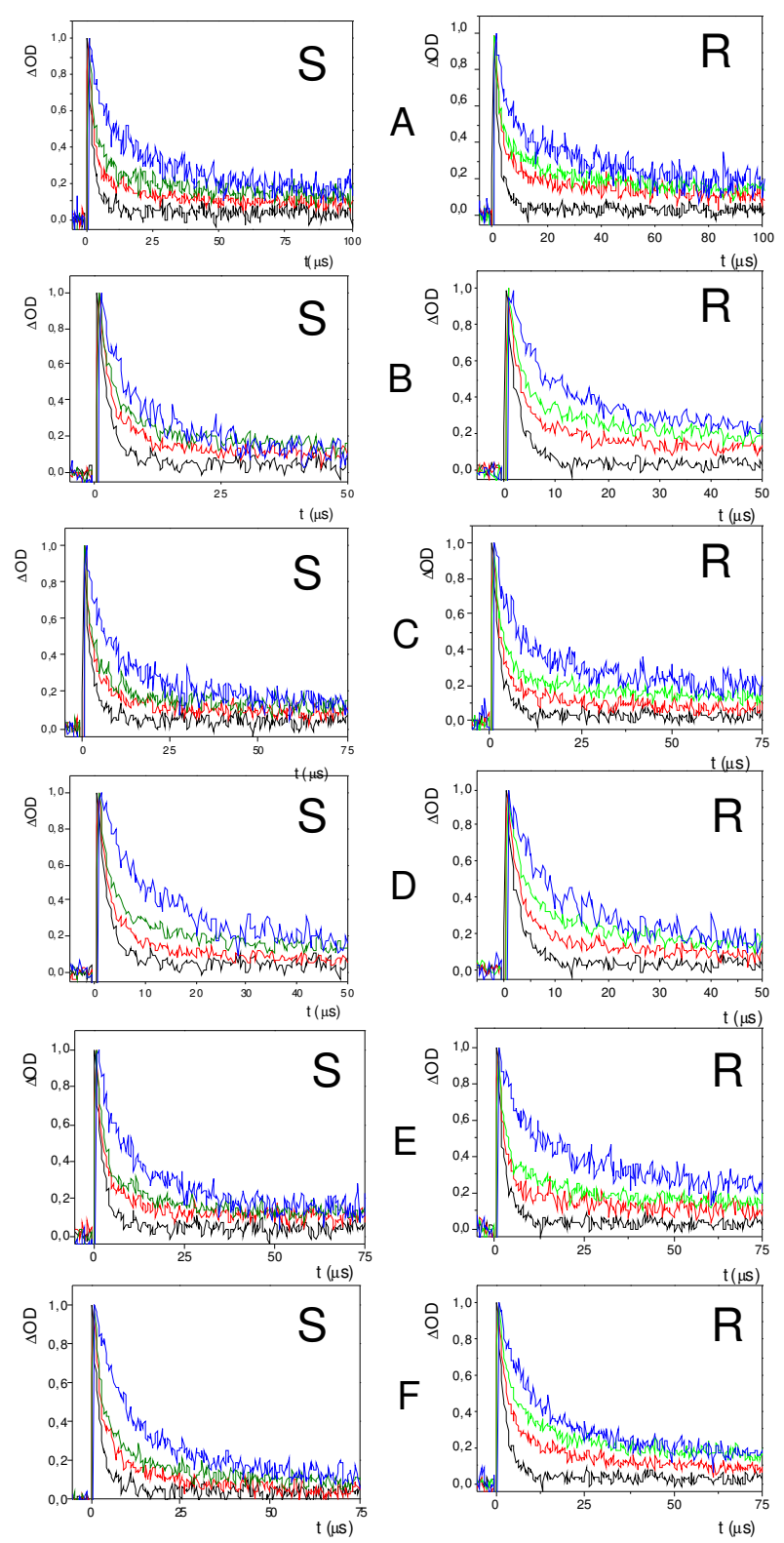

Figura 3.10. Curvas de desaparición normalizadas de $(S)$ y $(R)$-FBPGluc (Negro) y de las mezclas 4:1 (Rojo), 2:1 (Verde) y 0.3:1 (Azul), tras FDL ( $\lambda_{\text {exc }}=266 \mathrm{~nm}, \lambda_{\text {mon }}=360$ nm) en distintas albúminas séricas: A- ASB, B- ASCe, C- ASO, D- ASC, E- ASP, FASR. 
Ello indicaría la presencia de un único microentorno dentro de la proteína para FBPGluc. En la tabla 3.6 se muestran los tiempos de vida de (2S)- $y(2 R)-F B P G l u c$ en todas las albúminas.

Tabla 3.6. Tiempos de vida de triplete $(\mu \mathrm{s})$ del FBPGluc unido a ASB, ASCe, ASO, ASC, ASP y ASR.

\begin{tabular}{|c|c|c|c|}
\cline { 3 - 4 } \multicolumn{1}{c|}{} & \multirow{2}{*}{ Libre } & \multicolumn{2}{c|}{ Unido } \\
\cline { 3 - 4 } \multicolumn{1}{c|}{} & $\tau_{\mathrm{T}}(\mathbf{S})$ & $\tau_{\mathbf{T}}(\mathbf{R})$ \\
\hline ASB & 1.8 & 23.0 & 31.0 \\
\hline ASCe & 1.8 & 14.0 & 25.0 \\
\hline ASO & 1.8 & 10.0 & 20.0 \\
\hline ASC & 1.8 & 12.5 & 13.0 \\
\hline ASP & 1.8 & 14.0 & 17.0 \\
\hline ASR & 1.8 & 14.2 & 20.0 \\
\hline
\end{tabular}

Cabe destacar que en algunas ASs se apreció cierta estereodiferenciación en su interacción con la proteína atendiendo a los tiempos de vida de triplete. En el caso de ASO el tiempo de vida del enantiómero $(R)$ - es el doble que el del $(S)$-. También es destacable el hecho de que en todas las proteínas estudiadas el isómero $(R)$ - es el que tiene el tiempo de vida mayor dentro de la proteína.

En la figura 3.11 podemos ver los datos de ocupación de (2S)- y (2R)-FBPGluc en cada una de las albúminas séricas. 

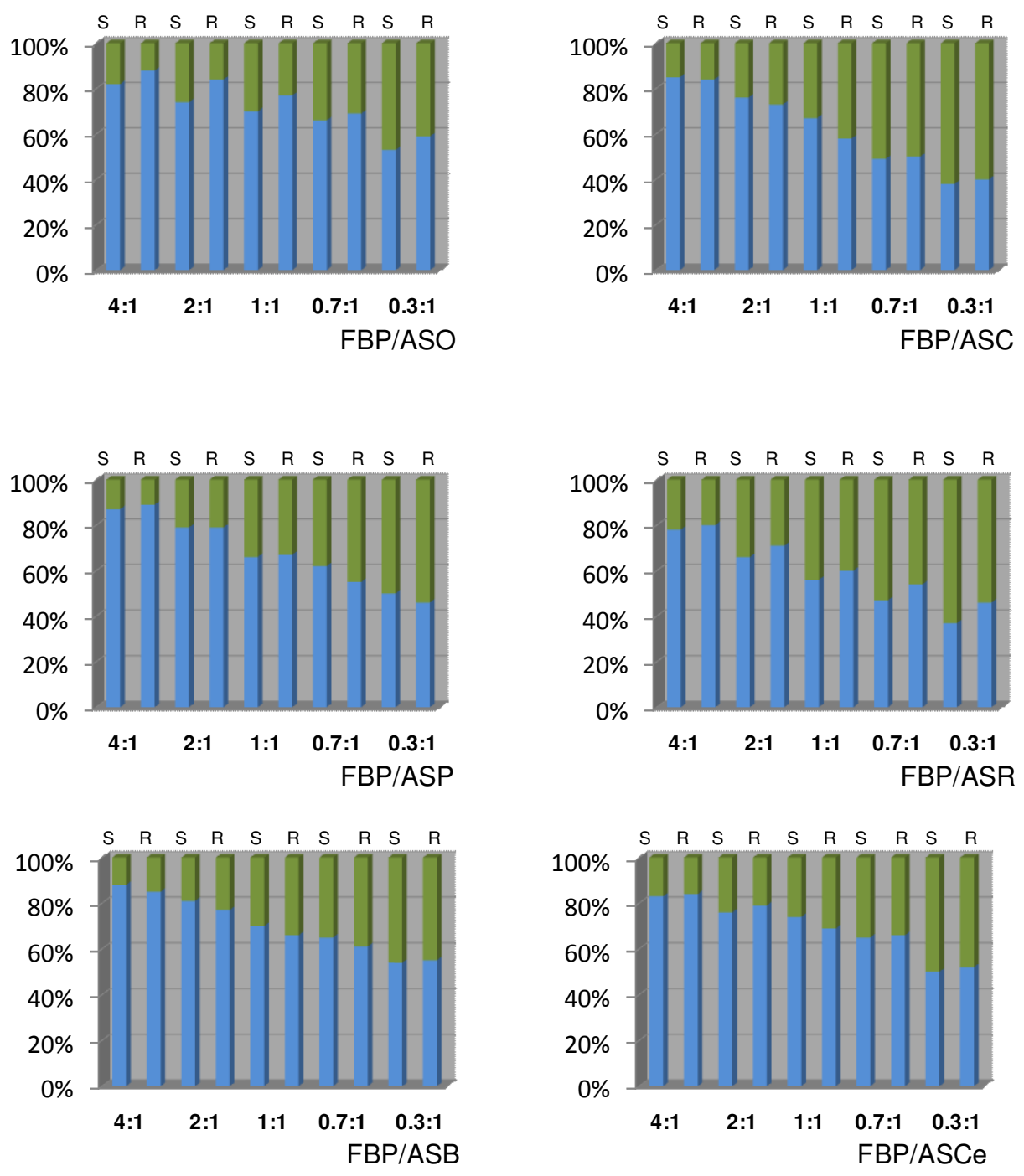

Figura 3.11. Porcentaje de (S)- y (R)-FBPGluc libre (Azul) y unido (Verde) a ASB, ASCe, ASO, ASC, ASP y ASR.

Se puede apreciar que, como en el caso de $\mathrm{ASH}$, incluso a proporciones bajas FBPGluc/SA, aún permanece gran cantidad de FBPGluc libre en disolución. Los casos donde hay más FBPGluc 
incluido en la proteína son los de ASC y ASR, con alrededor de un $40 \%$ de unión a relaciones molares 0.3:1.

\subsubsection{Sistemas FBPMe/AS}

Un estudio similar se realizó para el profármaco FBPMe. Para ello se prepararon disoluciones en tampón fosfato (PBS $0.01 \mathrm{M}, \mathrm{pH}=$ 7.4) de (S)- y (R)-FBPMe con AS a diferentes relaciones molares FBPMe/AS comprendidas entre 4:1 y 0.7:1. La concentración de FBPMe se mantuvo constante $\left(2.5 \times 10^{-5} \mathrm{M}\right)$, variando la de AS.
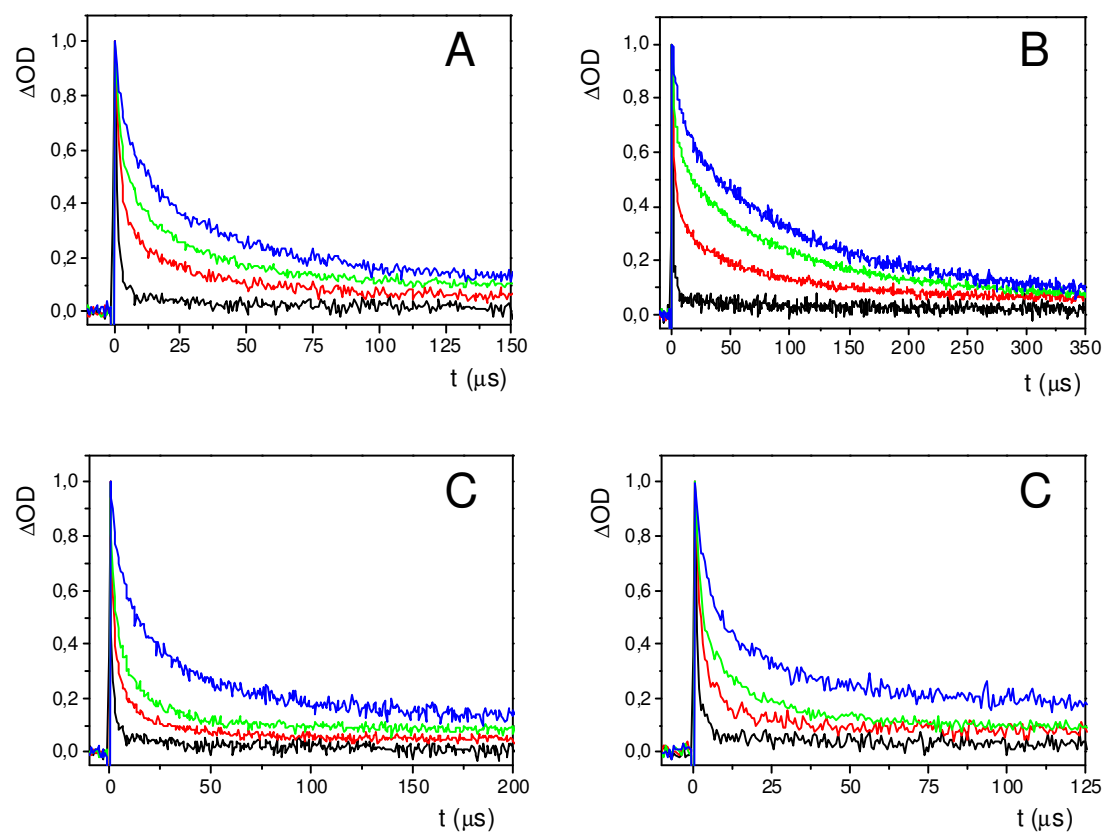

Figura 3.12. Curvas de desaparición normalizadas del $(S)$ y $(R)$-FBPMe (Negro) y de las mezclas 4:1 (Rojo), 2:1 (Verde) y 0.7:1 (Azul), tras FDL ( $\lambda_{\text {exc }}=266 \mathrm{~nm}$, $\lambda_{\text {mon }}=360 \mathrm{~nm}$ ) en ASCe y ASO: A- S-FBPMe/ASCe, B- R-FBPMe/ASCe, C- $S$ FBPMe/ASO, D- $R$-FBPMe/ASO 
Tras someter estas disoluciones a FDL $\left(\lambda_{\mathrm{exc}}=266 \mathrm{~nm}\right.$, aire) se obtuvo de nuevo la banda correspondiente al primer estado excitado triplete del FBPMe a $360 \mathrm{~nm}$.

Posteriormente se realizó un análisis de regresión de las curvas de desaparición de dicho estado triplete para todas las disoluciones en ausencia y presencia de AS. En el caso de ASCe y ASO se encontró que el FBPMe interacciona con los dos sitios de unión de la proteína mientras que para ASC, ASP y ASR solo se produce interacción con un solo sitio. En la figura 3.12 se muestran las curvas de desactivación de ASCe y ASO a diferentes proporciones FBPMe/AS.

En este caso, para ajustar las curvas de desactivación, necesitamos usar una ecuación con tres términos monoexponenciales para relaciones molares por encima de 1:1 para ASCe y 0.7:1 para ASO, con una componente de $1.5 \mu$ siempre presente indicando la existencia de FBPMe libre en disolución, mientras que para esas relaciones e inferiores necesitamos dos términos y ya no se observa FBPMe libre.

Por otro lado estarían ASC, ASP y ASR que necesitan un ajuste de segundo orden en todas las relaciones molares con una componente de $1.5 \mu$ s siempre presente, lo que indica que incluso por debajo de la proporción 0.7:1 queda FBPMe libre en disolución. En la figura 3.13 se muestran las curvas de desactivación para las mezclas de FBPMe con ASC, ASP y ASR. 

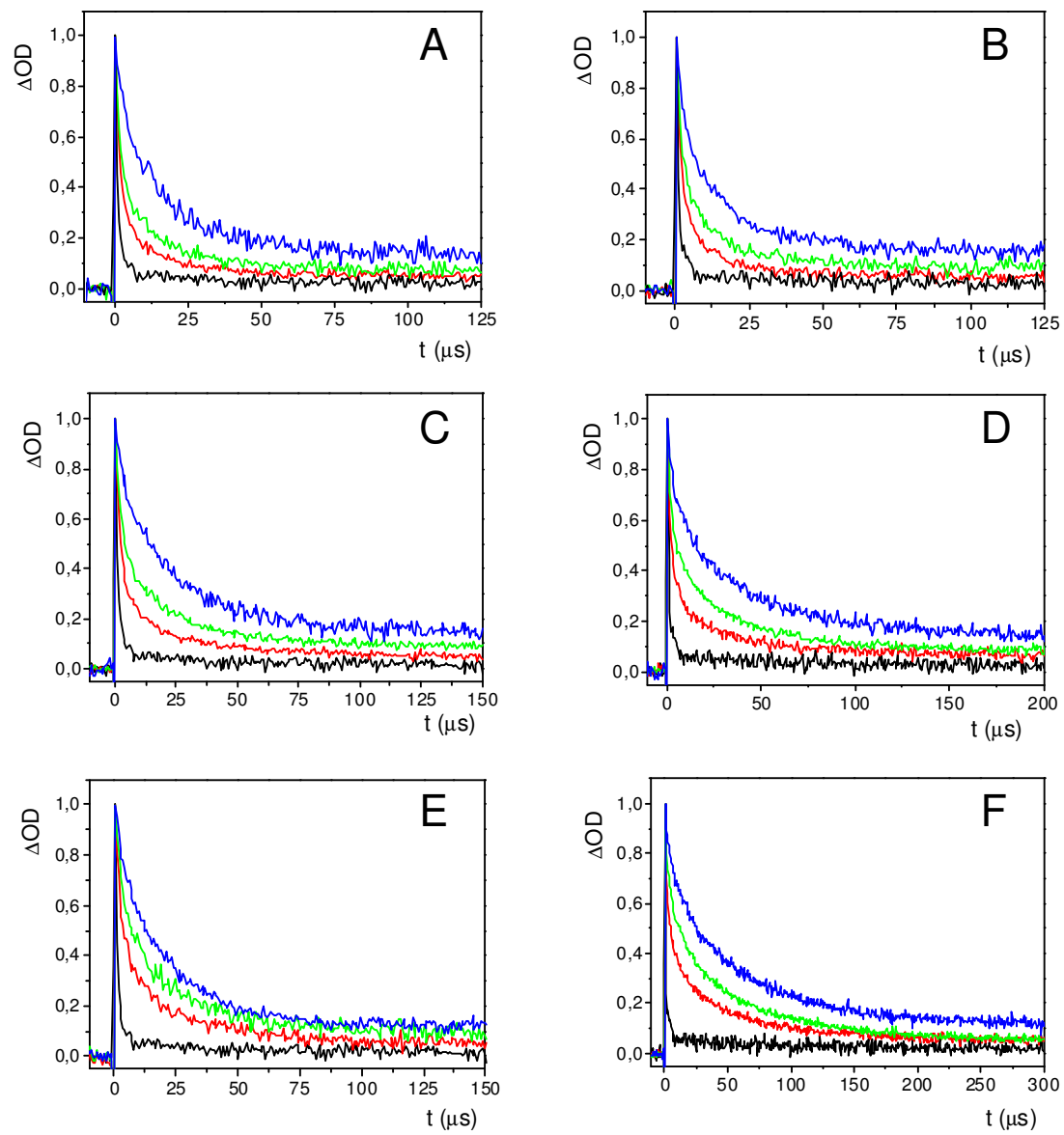

Figura 3.13. Curvas de desaparición normalizadas del $(S)$ y $(R)$-FBPMe (Negro) y de las mezclas 4:1 (Rojo), 2:1 (Verde) y 0.8:1 (Azul), tras FDL ( $\lambda_{\text {exc }}=266 \mathrm{~nm}$, $\lambda_{\text {mon }}=360 \mathrm{~nm}$ ) en ASC, ASP y ASR: A- S-FBPMe/ASC, B- R-FBPMe/ASC, C- $S$ FBPMe/ASP, D- $R$-FBPMe/ASP, E- $S$-FBPMe/ASR, F- $R$-FBPMe/ASR

Tras el análisis de regresión con las ecuaciones correspondientes obtenemos los tiempos de vida de triplete de cada enantiómero dentro de cada albúmina. En la tabla 3.7 se exponen los tiempos de vida encontrados para la interacción de FBPMe con ASCe y ASO. 
Tabla 3.7. Tiempos de vida de triplete $(\mu \mathrm{s})$ del FBPMe unido a ASCe y ASO.

\begin{tabular}{|c|c|c|c|c|}
\cline { 2 - 5 } \multicolumn{1}{c|}{} & \multicolumn{2}{c|}{ ASCe } & \multicolumn{2}{c|}{ ASO } \\
\cline { 2 - 5 } \multicolumn{1}{c|}{} & S & $\boldsymbol{R}$ & $\boldsymbol{S}$ & $\boldsymbol{R}$ \\
\hline Libre & 1.5 & 1.5 & 1.5 & 1.5 \\
Sitio II & 6.0 & 9.5 & 7 & 7 \\
Sitio I & 41.2 & 95.3 & 34 & 40 \\
\hline
\end{tabular}

De nuevo se observa que en ambas proteínas el tiempo de vida es mucho mayor que para el FBPMe solo. Además, sobretodo en el caso de ASCe, se encuentra una gran estereodiferenciación en el sitio II de la proteína. Esto hace que la ASCe sea una buena candidata como selector quiral.

Procedemos de la misma manera con las otras tres ASs y obtenemos los tiempos de vida que se muestran en la tabla y. 8 .

Tabla 3.8. Tiempos de vida de triplete $(\mu \mathrm{s})$ del FBPMe unido a ASC, ASP y ASR.

\begin{tabular}{|c|c|c|c|c|c|c|}
\cline { 2 - 7 } \multicolumn{1}{c|}{} & \multicolumn{2}{c|}{ ASC } & \multicolumn{2}{c|}{ ASP } & \multicolumn{2}{c|}{ ASR } \\
\cline { 2 - 7 } \multicolumn{1}{c|}{} & $\boldsymbol{S}$ & $\boldsymbol{R}$ & $\boldsymbol{S}$ & $\boldsymbol{R}$ & $\boldsymbol{S}$ & $\boldsymbol{R}$ \\
\hline Libre & 1.5 & 1.5 & 1.5 & 1.5 & 1.5 & 1.5 \\
Unido & 13 & 14 & 21 & 38 & 23 & 52 \\
\hline
\end{tabular}

Cabe destacar que en el caso de ASP y ASR también existe una gran estereodiferenciación en el proceso de unión con FBPMe y que de nuevo es el enantiómero R- el que tiene el tiempo de vida mayor dentro de la proteína.

A continuación se fijan los tiempos obtenidos anteriormente en las ecuaciones de ajuste para obtener así los porcentajes de ocupación dentro de cada albúmna sérica. 
En las figuras 3.14 y 3.15 podemos ver la ocupación de FBPMe en cada una de las albúminas séricas.
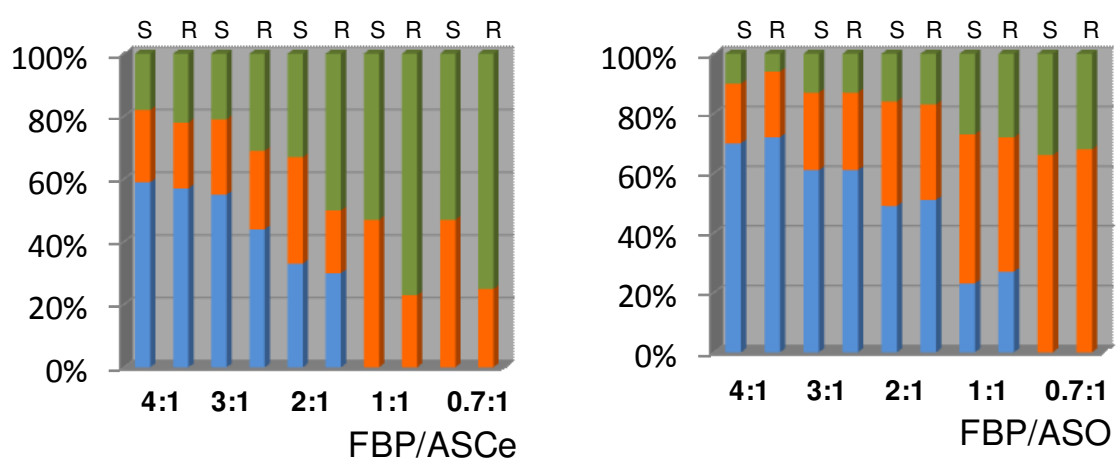

Figura 3.14. Porcentaje de (S)- y (R)-FBPMe libre (Azul), unido a sitio I (Naranja) y sitio II (Verde) de ASCe $(\mathbf{A})$ y ASO (B)
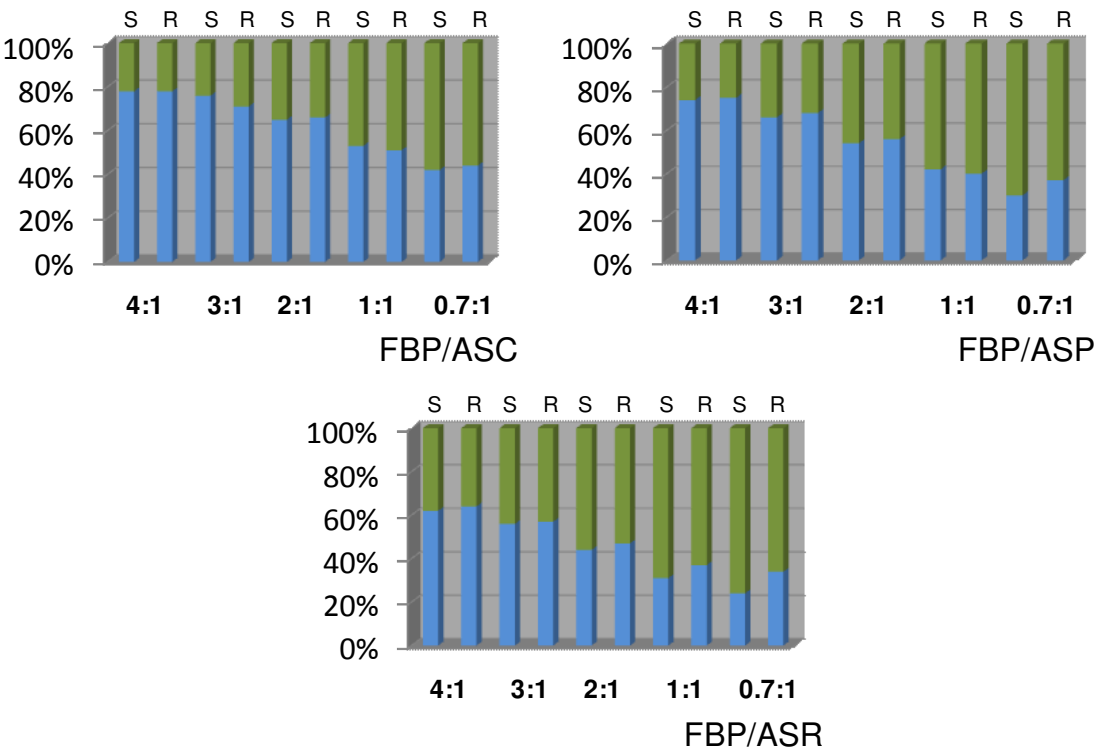

Figura 3.15. Porcentaje de $(S)$ - y $(R)$-FBP libre (Azul) y unido a sitio II (Verde) de ASC, ASP y ASR. 


\subsection{Conclusiones}

Se ha realizado un estudio de la interacción de FBP, su principal metabolito, FBPGluc, y FBPMe con albúminas séricas de distintas especies. Para ello se ha hecho uso del estado excitado triplete de estos sustratos como sonda debido a su gran sensibilidad de estos al medio. De este estudio se desprenden las siguientes conclusiones:

- Es posible calcular la distribución de cada sustrato dentro de los sitios de unión de las proteínas a partir de los factores preexponenciales.

- En el caso de FBP no se encontró una gran estereodiferenciación en su interacción con las diferentes albúminas séricas.

- En las albúminas ASCe y ASO, FBP se une a dos sitios de (sitio I y sitio II).

- En el caso de ASC, ASP y ASR el fármaco sólo se une a un sitio de la proteína.

- Se llevó a cabo la síntesis del 1- $\beta$-O-acil-glucurónido del FBP.

- Se aprecia como el glucurónido se une menos a las albúminas séricas que el fármaco de partida.

- Sólo existe un microentorno dentro de la proteína para el FBPGluc en todas las albúminas séricas estudiadas.

- Para casi todas las albúminas existe un cierto grado de estereodiferenciación en su interación con FBPGluc.

- En el FBPMe existe una notable estereodiferenciación en su interacción con ASCe, ASP y ASR.

- Dentro de las proteínas los tiempos de vida de triplete del isómero $(R)$ - son siempre mayores que los del isómero $(S)$-. 


\subsection{Parte experimental}

\subsubsection{Materiales y disolventes}

Las albúminas séricas, amano AS lipasa (LAS), esterasa de hígado porcina (PLE) se compraron en Sigma; (S)-FBP, $(R)$-FBP y 3,4tri-O-acetil-1-bromo-1-deoxi-a-D-glucopiranuronato fueron obtenidos de Aldrich. La solución de tampón fosfato (PBS, pH = 7.4, 0.01M) fue preparada disolviendo tabletas de Sigma en la cantidad apropiada de agua desionizada. Todos los disolventes fueron de calidad HPLC.

\subsubsection{Procedimiento experimental para la síntesis de (2S)- y} (2R)-FBPGluc

La síntesis de (2S)- y (2R)-FBPGluc se llevó a cabo en tres pasos usando un método conocido previamente para otros derivados de ácidos arilpropiónicos ${ }^{26,27}$ con algunas modificaciones (ver Figura 3.7). Brevemente, una solución de 3,4-tri-O-acetil-1-bromo-1-deoxi-a-Dglucopiranuronato (397 mg, $1 \mathrm{mmol}$ ) y la sal de cesio de (S)- o (R)-FBP (244 mg, $1 \mathrm{mmol}$ ) en DMSO (8 ml) fue agitado a $30 \stackrel{\circ}{\circ} \mathrm{C}$ durante $3 \mathrm{~h}$. La mezcla de reacción fue diluida con AcOEt $(100 \mathrm{ml})$ y luego lavada con agua $(3 \times 50 \mathrm{ml}), \mathrm{NaHCO}_{3}$ saturado $(3 \times 50 \mathrm{ml})$ y NaCl saturado $(3 \times 50$ $\mathrm{ml}$ ). La fase orgánica se secó sobre $\mathrm{Na}_{2} \mathrm{SO}_{4}$ y el disolvente evaporado a vacío para conseguir un aceite viscoso. Los productos $(2 R)-1$ y $(2 S)-1$ fueron purificados por HPLC, usando $\mathrm{CH}_{3} \mathrm{CN} / \mathrm{H}_{2} \mathrm{O} / \mathrm{CH}_{3} \mathrm{COOH}(\mathrm{v} / \mathrm{v} / \mathrm{v}$ 70:30:1) como eluyente. Los rendimientos fueron del $40 \%$ y $41 \%$ respectivamente. Una solución de (2R)-1 o (2S)-1 (155 mg, $0.28 \mathrm{mmol}$ ) en 2-metoxietanol (126 ml) se adicionó a una disolución de LAS (15 
$\mathrm{mg} / \mathrm{ml}$ de mezcla de incubación) en tampón fosfato $30 \mathrm{mM}(\mathrm{pH}=5.2)$ y se dejó incubar a $40 \stackrel{\circ}{ } \mathrm{C}$ por $2 \mathrm{~h}$. La mezcla de reacción se extrajo con AcOEt $(3 \times 50 \mathrm{ml})$ y se secó sobre $\mathrm{Na}_{2} \mathrm{SO}_{4}$. El disolvente orgánico se rotavaporó y el producto crudo se purificó por HPLC, usando $\mathrm{CH}_{3} \mathrm{CN} / \mathrm{H}_{2} \mathrm{O} / \mathrm{CH}_{3} \mathrm{COOH}(\mathrm{v} / \mathrm{v} / \mathrm{v}$ 70:30:1) como eluyente, para conseguir (2R)-2 y (2S)-2 (rendimientos del $20 \%$ y $16 \%$ respectivamente). Los ésteres metílicos (2R)-2 y (2S)-2 (50 mg) se disolvieron en DMSO (18 $\mathrm{ml}$ ), y esta disolución se vertió sobre una solución de PLE en disolución tampón fosfato $30 \mathrm{mM}(\mathrm{pH}=5.2)$ a $0.4 \mathrm{mg} / \mathrm{ml}$ y se incubó a $40 \stackrel{\circ}{ } \mathrm{C}$ por 3h. El crudo se extrajo con AcOEt ( 3 x $50 \mathrm{ml}$ ), se secó sobre $\mathrm{Na}_{2} \mathrm{SO}_{4}, \mathrm{y}$ el disolvente fue evaporado a vacío para conseguir, tras purificación por HPLC (eluyente: $\mathrm{CH}_{3} \mathrm{CN} / \mathrm{H}_{2} \mathrm{O} / \mathrm{CH}_{3} \mathrm{COOH}$ (v/v/v 95:5:0.1), los productos finales, (2R)-FBPGluc (16\%) y (2S)-FBPGluc (30\%).

\subsubsection{Datos espectroscópicos de los intermedios sintéticos}

Los espectros de ${ }^{1} \mathrm{H}$ RMN (300 MHz) y ${ }^{13} \mathrm{C}$ RMN (75 MHz) de (R)-1 y (S)-1 se realizaron en $\mathrm{CDCl}_{3}$ mientras que los de $(\boldsymbol{R})-\mathbf{2}$ y $(\boldsymbol{S})-\mathbf{2}$ en $\mathrm{CD}_{3} \mathrm{OD}$; los desplazamientos químicos se registraron en ppm.

(2S)-1: ${ }^{1} \mathrm{H}$ NMR: 1.56 (d, J=7.3 Hz, 3H), 1.93 (s, 3H), 2.01 (s, $3 \mathrm{H}), 2.02$ (s, 3H), 3.71 (s, 3H), 3.82 (q, J= $7.3 \mathrm{~Hz}, 1 \mathrm{H}), 4.17$ (d, J= 9.4 $\mathrm{Hz}, 1 \mathrm{H}), 5.24(\mathrm{~m}, 3 \mathrm{H}), 5.77(\mathrm{~d}, J=7.8 \mathrm{~Hz}, 1 \mathrm{H}), 7.02-7.15(\mathrm{~m}, 2 \mathrm{H}), 7.35-$ $7.46(\mathrm{~m}, 4 \mathrm{H}), 7.48-7.54(\mathrm{~m}, 2 \mathrm{H}) ;{ }^{13} \mathrm{C}$ NMR: $18.0\left(\mathrm{CH}_{3}\right), 20.3\left(\mathrm{CH}_{3}\right), 20.4$ $\left(\mathrm{CH}_{3}\right), 20.5\left(\mathrm{CH}_{3}\right), 44.8(\mathrm{CH}), 52.9\left(\mathrm{CH}_{3}\right), 68.9(\mathrm{CH}), 69.9(\mathrm{CH}), 71.8$ $(\mathrm{CH}), 72.9(\mathrm{CH}), 91.7(\mathrm{CH}), 115.1-140.1$ (C aromáticos ), $166.6(\mathrm{C})$, $168.9(\mathrm{C}), 169.3(\mathrm{C}), 169.8(\mathrm{C}), 171.8(\mathrm{C})$.

(2R)-1: ${ }^{1} \mathrm{H}$ NMR: 1.53 (d, $\left.J=7.1 \mathrm{~Hz}, 3 \mathrm{H}\right), 1.61$ (s, 3H), 1.98 (s, $3 \mathrm{H}), 2.03$ (s, 3H), 3.76 (s, 3H), 3.80 (q, J= $7.1 \mathrm{~Hz}, 1 \mathrm{H}), 4.17$ (d, J= 9.4 $\mathrm{Hz}, 1 \mathrm{H}), 5.08$ (t, J= $8.5 \mathrm{~Hz}, 1 \mathrm{H}), 5.16-5.30(\mathrm{~m}, 2 \mathrm{H}), 5.71(\mathrm{~d}, J=8.1 \mathrm{~Hz}$, 
1H), 7.02-7.15 (m, 2H), 7.35-7.54 (m, 6H). ${ }^{13} \mathrm{C}$ NMR: $17.3\left(\mathrm{CH}_{3}\right), 19.8$ $\left(\mathrm{CH}_{3}\right), 20.3\left(\mathrm{CH}_{3}\right), 20.4\left(\mathrm{CH}_{3}\right), 44.4(\mathrm{CH}), 52.9\left(\mathrm{CH}_{3}\right), 68.9(\mathrm{CH}), 69.5$ $(\mathrm{CH}), 71.6(\mathrm{CH}), 72.9(\mathrm{CH}), 91.4(\mathrm{CH}), 114.8$ - 135.1 (C aromáticos), $166.6(\mathrm{C}), 168.5(\mathrm{C}), 169.3(\mathrm{C}), 169.7(\mathrm{C}), 171.8(\mathrm{C})$.

(2S)-2: ${ }^{1} \mathrm{H}$ NMR: $1.53(\mathrm{~d}, J=7.1 \mathrm{~Hz}, 3 \mathrm{H}), 3.37-3.58(\mathrm{~m}, 3 H), 3.74$ (s, 3H), 3.87-3.99 (m, 2H), $5.53(\mathrm{~d}, J=7.8 \mathrm{~Hz}, 1 \mathrm{H}), 7.12-7.22(\mathrm{~m}, 2 \mathrm{H})$, 7.32-7.46 (m, 4H), 7.50-7.55 (m, 2H); ${ }^{13} \mathrm{C}$ NMR: $19.0\left(\mathrm{CH}_{3}\right), 46.0(\mathrm{CH})$, $53.0\left(\mathrm{CH}_{3}\right), 72.9(\mathrm{CH}), 73.6(\mathrm{CH}), 77.3(\mathrm{CH}), 77.4(\mathrm{CH}), 96.0(\mathrm{CH}), 115.0$ - 136.9 (C aromáticos), $170.8(\mathrm{C}), 174.2(\mathrm{C})$.

(2R)-2: ${ }^{1} \mathrm{H}$ NMR: $1.54(\mathrm{~d}, J=7.2 \mathrm{~Hz}, 3 \mathrm{H}), 3.35-3.50(\mathrm{~m}, 3 \mathrm{H}), 3.77$ (s, 3H), 3.89-3.99 (m, 2H), $5.52(\mathrm{~d}, J=7.8 \mathrm{~Hz}, 1 \mathrm{H}), 7.12-7.24(\mathrm{~m}, 2 \mathrm{H})$, 7.31-7.46 (m, 4H), 7.49-7.54 (m, 2H); ${ }^{13} \mathrm{C}$ NMR: $19.0\left(\mathrm{CH}_{3}\right), 46.0(\mathrm{CH})$, $53.0\left(\mathrm{CH}_{3}\right), 72.9(\mathrm{CH}), 73.6(\mathrm{CH}), 77.3(\mathrm{CH}), 77.4(\mathrm{CH}), 96.0(\mathrm{CH}), 115.0$ - 136.9 (C aromáticos), 170.8 (C), 174.3 (C).

\subsubsection{Fotólisis de destello laser}

Los experimentos de fotólisis de destello laser (FDL) se llevaron a cabo usando un laser pulsado de Nd-YAG (Quantel Brilliant, de 266 $\mathrm{nm}, 5 \mathrm{~ns}$ fwhm, $10 \mathrm{~mJ}$ por pulso) acoplado a un equipo miniaturizado mLFP-111 Luzchem. Este espectrómetro de absorción transitoria incluye una lámpara de xenon, un monocromador de $125 \mathrm{~mm}$, un osciloscopio Tektronix 9-bit de la serie TDS-3000 con ancho de banda de $300 \mathrm{MHz}$, un fotomultiplicador compacto y fuente de alimentación, un portacubetas, conectores de fibra óptica y programa desarrollado en el entorno LabVIEW de National Instruments. El equipo de FDL proporciona un voltaje de pulsos de corte de 5 volt con frecuencia y retardo de la señal programables. 
Todos los espectros transitorios se registraron empleando cubetas de cuarzo de $10 \times 10 \mathrm{~mm}^{2}$ con $4 \mathrm{ml}$ de capacidad; el diámetro del punto de disparo en la cubeta es aproximadamente $4 \mathrm{~mm}$. La absorbancia de FBP y de FBPGluc fue de ca. 0.2 a la longitud de onda del laser, correspondiendo con una concentración de $2.5 \times 10^{-5} \mathrm{M}$ para el FBP y $\quad 1.5 \times 10^{-5} \mathrm{M}$ para el FBPGluc. Todos los experimentos se llevaron a cabo en PBS $(\mathrm{pH}=7.4,0.01 \mathrm{M})$ a $22{ }^{\circ} \mathrm{C}$ y bajo atmósfera de aire.

Para los estudios realizados en presencia de albúmina sérica, se prepararon una serie de disoluciones conteniendo $(S)$ y $(R)$-FBP y $(S)$ - y $(R)$-FBPGluc en presencia de las ASs de todas las especies en un intervalo de concentraciones comprendido entre $4: 1$ y 0.3:1 (disoluciones preparadas en PBS). Las disoluciones fueron preparadas como se detalla a continuación: sobre una disolución $2.5 \times 10^{-5} \mathrm{M}$ de FBP o FBPGluc se añadió una alícuota de una disolución $1 \times 10^{-3} \mathrm{M}$ de AS; la mezcla resultante se guardó durante 15 horas a $4 \stackrel{\circ}{ } \mathrm{C}$ para asegurar un completo equilibrio en la formación del complejo fármaco (o metabolito)/proteína. Pasado este tiempo, se tomaron $4 \mathrm{ml}$ de esta disolución y se introdujeron en la cubeta de cuarzo. La muestra se sometió a FDL, monitorizando la señal a $360 \mathrm{~nm}$ por acumulación de las cinéticas obtenidas tras 10 pulsos de láser. El experimento se realizó por triplicado con muestra fresca. Para la obtención del espectro de la especie transitoria desde 700 a 290 nm, la muestra se sometió a FDL en un intervalo de $10 \mathrm{~nm}$ ( 2 pulsos de láser por cada longitud de onda). El procedimiento experimental seguido para el resto de mezclas $\operatorname{FBP}(0$ FBPGluc)/AS fue el mismo que el explicado anteriormente. 


\subsection{Referencias bibliográficas}

1. Landoni, M. F.; Soraci, A. Curr. Drug. Metab. 2001, 2, 37.

2. Lewis, A. J.; Furst, D. E. Nonsteroidal Anti-Inflammatory Drugs: Mechanism and Clinical Uses, $2^{\text {nd }}$ Edition; Marcel Dekker: New York, 1994.

3. Evans, A. M. J. Clin. Pharmacol. 1996, 36, 7S.

4. Stachulski, A. V.; Harding, J. R.; Lindon, J. C.; Maggs, J. L.; Park, B.

K.; Wilson, I. D. J. Med. Chem. 2006, 49,. 6931.

5. Dickinson R.G. Proc. West. Pharmacol. Soc. 1993, 36, 157.

6. Bedford, C.T. J. Chromatogr. B 1998, 717, 313.

7. G. J. Dutton, Glucuronidation of Drugs and other Compounds, CRC Press, Boca Raton, 1980.

8. Tukey, R. H., Strassburg, C. P. Annu. Rev. Pharmacol. Toxicol. 2000, 40,581

9. Turgeon, D.; Carrier, J.S.; Chouinard, s.; Bélanger, A. Drug Metab. Dispos. 2003, 31, 670.

10. Kiang, T. K. L.; Ensom, M. H. H.; Chang, T. K. H. Pharmacol. Therap. 2005, 106, 97.

11. Magdalou, J.; Chajes, V.; Lafaurie, C.; Siest, G. Drug Metab. Dispos. 1990, 18, 692.

12. Spahn-Langguth, H.; Benet, L. Z. Drug. Metab. Rev. 1992, 24, 5.

13. Lucaciu, R.; Ionescu, C. Farmacia 2005, 53, 10.

14. Knadler, M. P.; Hall, S. D. Drug Metab. Dispos. 1991, 19, 280.

15. Verbeeck, R. K.; Blackburn, J. L.; Loewen, G. R. Clin. Pharmacokinet. 1983, 8, 297.

16. Sudlow, G., Birkett, D. J., Wade, D. N. Mol. Pharmacol. 1976; 12: 1052. 
17. Vayá, I., Bueno, Carlos J., Jiménez, M. Consuelo, Miranda, Miguel A. ChemMedChem. 2006; 1, 1015.

18. Vayá, I., Jimenez, M. Consuelo, Miranda, Miguel A. Journal of Physical Chemistry B, 2008, 112, 2694.

19. Bohne, C., Barra, M., Boch, R., Abuin, E. B., Scaiano, J. C. J. Photochem. Photobiol. A: Chem. 1992; 65: 249. 

CAPÍTULO 4. Estudio de la actividad glucuronidasa de albúminas séricas 



\subsection{Introducción}

Como se ha mencionado anteriormente los fármacos de la familia de los AINEs suelen conjugarse con el ácido glucurónico para dar el correspondiente acil-glucurónido y de esa forma ser eliminados por la orina o la bilis. Los metabolitos 1- $\beta$-O-acil-glucurónidos son moléculas intrínsecamente reactivas (tanto in vivo como in vitro) que pueden dar lugar a multitud de reacciones; con diferencia, la hidrólisis para dar el aglicón de partida es el proceso predominante. ${ }^{15-17}$ Esta reacción puede ser catalizada por distintos agentes ( $\beta$-glucuronidasas, esterasas, etc.) resultando en un ciclo fútil, ya que la eliminación del plasma es un proceso competitivo entre la conjugación del fármaco de partida, la deconjugación del glucurónido, y la eliminación renal. ${ }^{13,14}$

La capacidad de las albúminas séricas de actuar como catalizadores en la hidrólisis de glucurónidos ha sido investigada por diversos métodos, principalmente usando cromatografía líquida normalmente acoplada a RMN o EM.,18-21 Sin embargo, la separación cromatográfica consume tiempo y puede dar lugar a artefactos.

En el presente capítulo se ha estudiado la actividad glucuronidasa de las diferentes albúminas séricas frente a (2R)- y (2S)FBPGluc haciendo uso de la espectroscopía de absorción transitoria. Se basa en la FDL de ambos glucurónidos en presencia de AS, con el triplete del FBP como sonda.

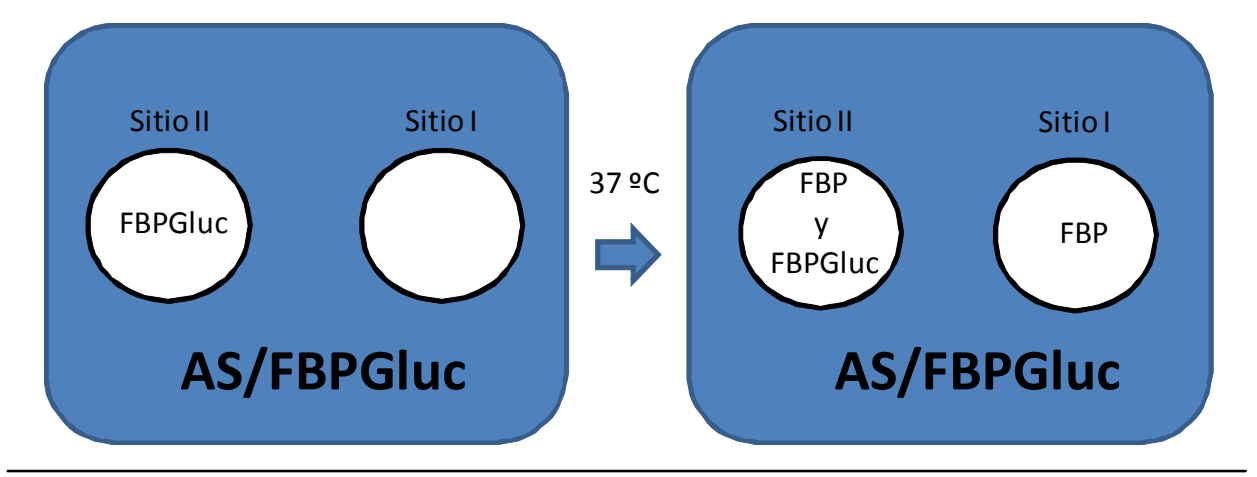




\subsection{Resultados y discusión}

\subsubsection{Hidrólisis de FBPGluc en albúmina sérica humana}

En el capítulo anterior se llevo a cabo el estudio de interacción entre el FBPGluc y la albúmina sérica mediante FDL. Tras ajustar la curva de desaparición obtenida se obtuvieron dos tiempos de vida diferentes; uno de $1.8 \mu$ s correspondiente a FBPGluc libre en disolución, y otro de $25 \mu$ s debido al FBPGluc dentro del sitio II de la proteína.

Después de establecer que la metodología es apropiada para discriminar entre el fármaco y su metabolito, se aplicó la técnica de FDL para investigar in situ la actividad glucuronidasa de la albúmina a temperatura fisiológica $\left(37^{\circ} \mathrm{C}\right)$. Para ello se procedió a preparar disoluciones conteniendo (2R)-FBPGluc y ASH a relación molar 1:3.33. Las disoluciones se colocaron en un baño termostatado a $37^{\circ} \mathrm{C}$, se tomaron alícuotas a diferentes tiempos (de 0 a $21 \mathrm{~h}$ ) y se sometieron a FDL. En todos los casos, se observó una señal centrada a $360 \mathrm{~nm}$; sin embargo, cada una de las trazas necesitó cuatro componentes monoexponenciales en la función matemática para obtener un ajuste preciso de la curva de desactivación, tomando la función la forma

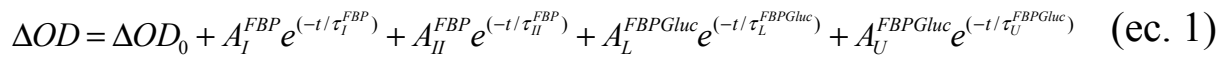

donde $\tau_{1}^{\text {FBP }}$ y $\tau_{\|}{ }^{\text {FBP }}$ son los tiempos de vida de triplete de FBP (formado por la hidrólisis de FBPGluc dentro de la proteína), mientras que $\tau_{\mathrm{L}}^{\text {FBPGluc }}$ y $\tau_{\cup}{ }^{\text {FBPGluc }}$ corresponden a FBPGluc libre en disolución y unido a la proteína.

Esta observación indicó claramente que el proceso de hidrólisis estaba teniendo lugar. 
De la misma forma, los factores preexponenciales $A_{l}^{F B P}$ y $A_{\|}{ }^{F B P}$ se deben a FBP unido a sitio I y sitio II de $A S H$, mientras que $A_{L}{ }^{\text {FBPGluc }}$ y $A_{\cup}{ }^{\text {FBPGluc }}$ corresponden a glucurónido libre y unido. Para obtener el valor de estos coeficientes se fijaron los tiempos de vida en la ec. 1 usando los valores previamente obtenidos de 1.8 y $25 \mu$ s para el caso de (2R)FBPGluc libre en disolución y unido a ASH, y 10.2 y $39.0 \mu$ s para (R)FBP dentro de los sitios de unión de la proteína. ${ }^{23}$ Bajo estas condiciones no se esperaba encontrar (R)-FBP libre en disolución, ya que es conocido que su inclusión dentro de la proteína es total incluso a relaciones molares mayores que la utilizada en este experimento. Asumiendo que $A_{l}{ }^{F B P} / A_{\|}{ }^{F B P}$ permanece constante (e igual a 30/70), se pueden obtener los factores preexponenciales, y a partir de ellos, los porcentajes de FBP y FBPGluc mediante la ec. 2.

$$
\% \text { FBPGluc }_{L}=\frac{A_{L}^{F B P}}{A_{I}^{F B P}+A_{I I}^{F B P}+A_{L}^{F B P G l u c}+A_{U}^{F B P G l u c}} \times 100 \quad \text { ec. } 2
$$

El mismo procedimiento se llevó a cabo con el isómero (2S)FBPGluc.

Como ejemplo, en la figura 4.1 se muestra la curva de desaparición y los factores preexponenciales para mezclas FBPGluc/ASH incubadas $6.5 \mathrm{~h}$. 

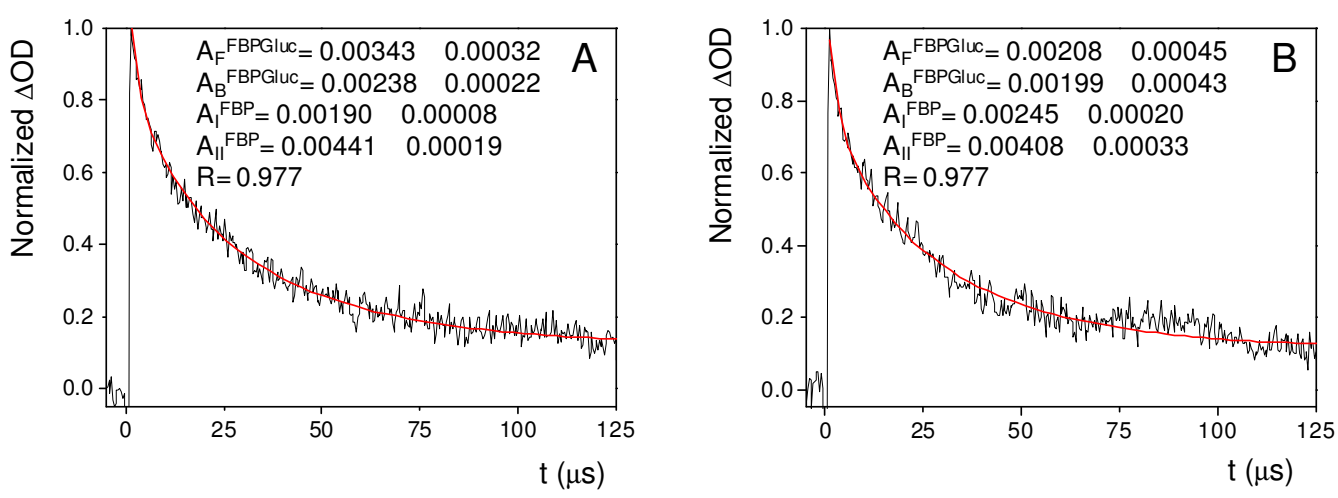

Figura 4.1. Fotólisis de destello laser $\left(\lambda_{\mathrm{exc}}=266 \mathrm{~nm}\right)$ de FBPGluc/HSA de relación molar $1: 3.33$ (linea negra) tras $6.5 \mathrm{~h}$ a $37^{\circ} \mathrm{C}$, junto con el correspondiente ajuste (linea roja). A: (2R)-FBPGluc. B. (2S)-FBPGluc. Los parámetros indicados corresponden al ajuste en rojo y la ec. 1.

El proceso se repitió para alícuotas tomadas a diferentes tiempos tiempos. El curso de la reacción, expresado como los porcentajes de las especies presentes en cada momento, se representa en la figura 6.
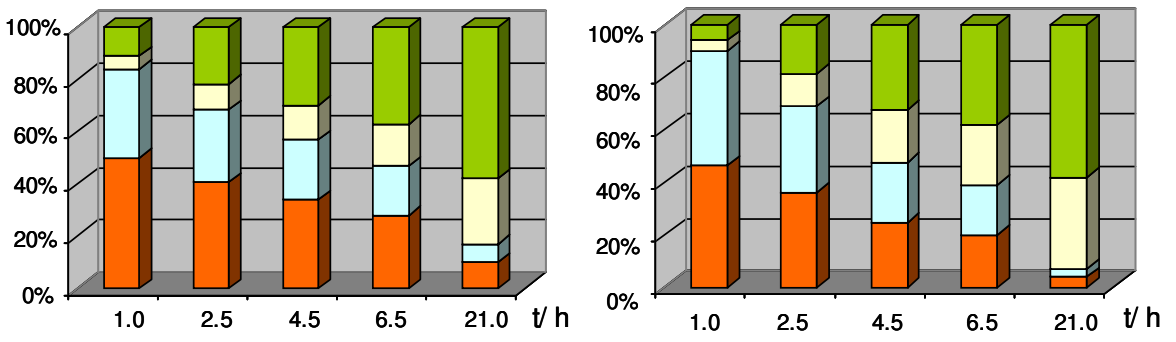

Figura 4.2. Porcentajes de FBPGluc libre (naranja), FBPGluc unido a ASH (azul), FBP en sitio I (amarillo) and FPB en sitio II (verde) para una mezcla inicial FBPGluc/ASH 1:3.33 a diferentes tiempos a $37 \stackrel{\circ}{\circ}$. Izquierda: (2R)-FBPGluc, derecha: (2S)-FBPGluc.

Se realizaron estudios similares a $22 \stackrel{\circ}{ } \mathrm{C}$, y se observó que a esta temperatura el proceso fue mucho más lento (figura 4.3). Como experimento control, se intentó la hidrólisis de los glucurónidos en 
ausencia de $\mathrm{ASH}$ a $37^{\circ} \mathrm{C}$. Para ello, se tomaron alícuotas a diferentes tiempos, se añadió $\mathrm{ASH}$, y la mezcla se dejó equilibrar a $4 \stackrel{\circ}{\circ} \mathrm{C}$. Ahora el rol de la proteína fue actuar como selector, discriminando entre los tiempos de vida de triplete de FBP y FBPGluc, para de esa forma seguir el progreso de la reacción. Los resultados muestran claramente que, en ausencia de ASH, la hidrólisis ocurrió en mucha menor medida (Figura 7). Los datos experimentales anteriores también se trataron con una ecuación de ajuste con solo dos términos monoexponenciales. En este caso, los dos valores de tiempos de vida se fijaron a $1.8 \mu$ s (para el FBPGluc libre) y $25 \mu \mathrm{s}$ (como un valor medio para todas las especies unidas, que son FBPGluc y FBP en sitios I y II). Los resultados fueron similares a aquellos obtenidos con el ajuste de cuatro monoexponenciales, aunque los errores asociados con los factores preexponenciales y la vida media de la cinética de la reacción fueron mayores.

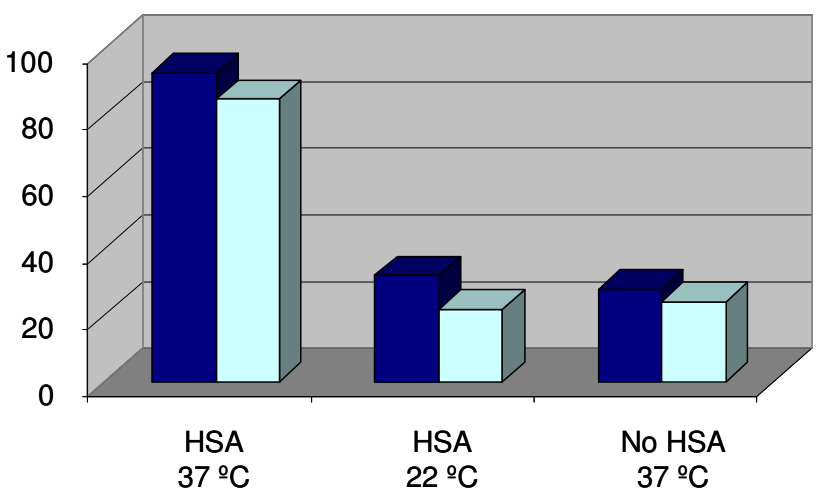

Figura 4.3. Porcentajes de FBP formados por hidrólisis de una mezcla FBPGluc/HSA 1:3.33 tras reaccionar durante $21 \mathrm{~h}$ a $37{ }^{\circ} \mathrm{C}$ y a $22{ }^{\circ} \mathrm{C}$, así como para FBPGluc solo tras $21 \mathrm{~h}$ a $37^{\circ} \mathrm{C}$. (2S)-FBPGluc (Azul oscuro) y (2R)-FBPGluc (Azul claro).

Para comprobar la fiabilidad de los porcentajes obtenidos de los ajustes de la curva de desactivación, se prepararon disoluciones 
conteniendo ( $\boldsymbol{R})$-FBP y (2R)-FBPGluc (a relaciones molares conocidas) en presencia de $\mathrm{ASH}$ y se sometieron a FDL. Definitivamente, se encontró una correlación satisfactoria entre los valores determinados por FDL y los valores reales (Figura 4.4).

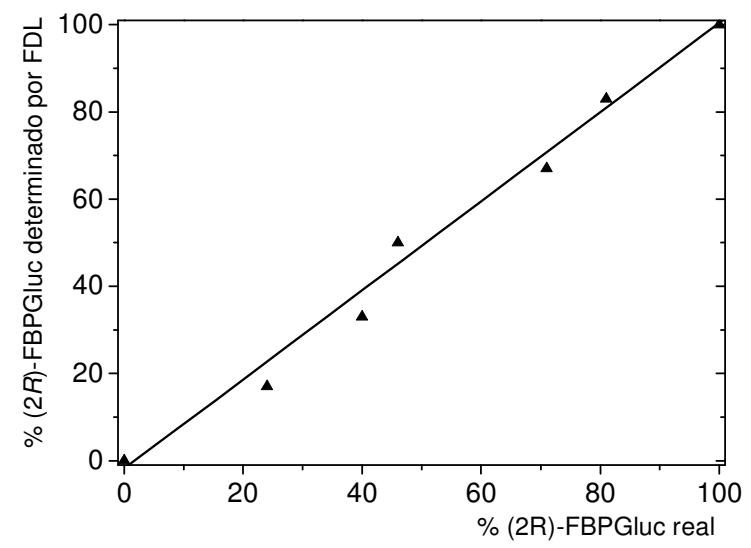

Figura 4.4. Valores determinados por FDL frente a valores reales de los porcentajes de (2R)-FBPGluc para varias mezclas en presencia de $\mathrm{ASH}$, junto con el ajuste lineal para los puntos experimentales.

\subsubsection{Hidrólisis de FBPGluc en otras albúminas séricas}

Con el fin de determinar si las albúminas séricas de otras especies también tienen actividad glucuronidasa comparable a la producida en ASH, se realizaron experimentos similares con ASC, ASP, ASCe, ASO, ASR y ASB. En el capítulo anterior se describió la interacción de FBP y FBPGluc con dichas albúminas, hallándose los tiempos de vida de triplete y el porcentaje de ocupación de los enantiómeros de ambos sustratos en todas las ASs. Utilizando esta información, se procedió del mismo modo que con ASH. 
Así, se prepararon disoluciones en PBS de mezclas FBPGluc/AS a relación molar 1:3.33 y se colocaron en un baño termostatado a $37^{\circ} \mathrm{C}$, simulando condiciones fisiológicas. Se recogieron alícuotas a diferentes tiempos y se sometieron a FDL. En la figura 4.5 se muestran las curvas de desaparición obtenidas tras $21 \mathrm{~h}$ de incubación.
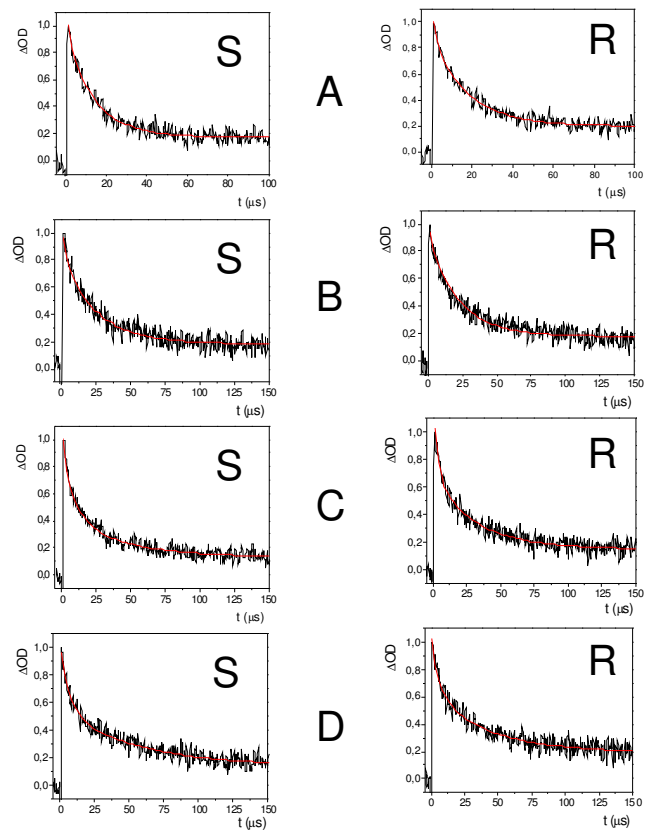

D
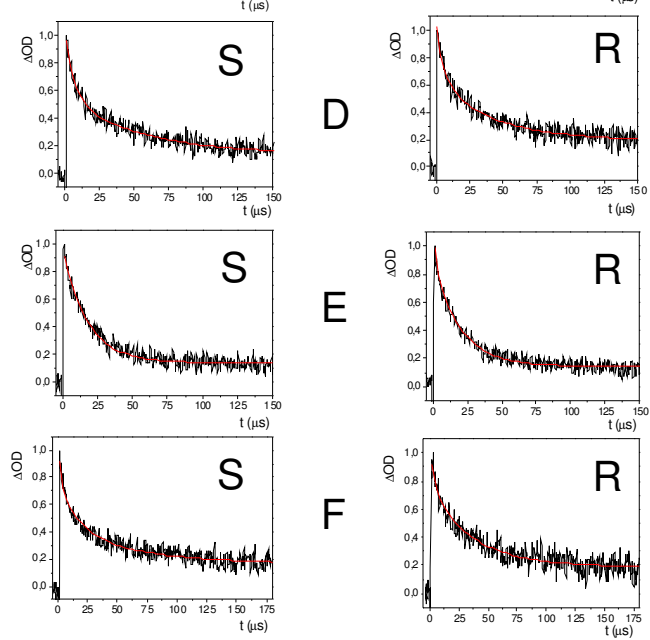

F

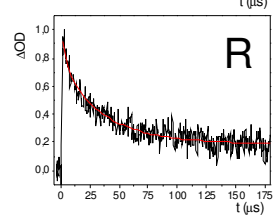

Figura 4.5. Curvas de desaparición normalizadas tras FDL $\left(\lambda_{\mathrm{exc}}=266 \mathrm{~nm}, \lambda_{\mathrm{mon}}\right.$ $=360 \mathrm{~nm})$ de mezclas de $(S)$ y $(R)$-FBPGluc con distintas albúminas séricas a relación molar 1:3.33: A- ASC, B- ASP, C- ASCe, D- ASO, E- ASR, F- ASB. La linea roja es el ajuste correspondiente. 
En este caso, la ecuación utilizada para el ajuste dependerá del número de sitios de unión de FBP y FBPGluc en cada AS. Como se indicó en el capítulo anterior, FBPGluc se une a todas las albúminas en un solo sitio; sin embargo, FBP en algunas AS se une a un solo sitio, mientras que en otras se une en dos.

Por esta razón, para las albúminas con dos sitios de unión se usará la ec 1 , mientras que para las que tengan un solo sitio se aplicará la ec 3.

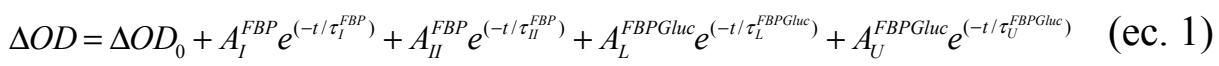

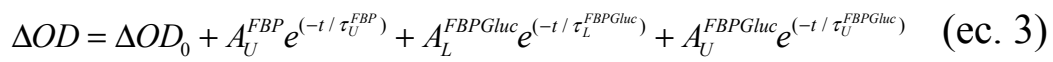

Por medio de estas ecuaciones e introduciendo los tiempos de vida determinados en el capítulo anterior para cada enantiómero de FBP y FBPGluc en las diferentes albúminas, se obtuvieron los factores preexponenciales, y a partir de estos los porcentajes de FBP y FBPGluc libre y unido a la proteína mediante la ec. 2. En la figura 4.6 se muestran los porcentajes de sustrato unido a proteína a tiempo cero y tras $21 \mathrm{~h}$ de incubación a $37^{\circ} \mathrm{C}$. 

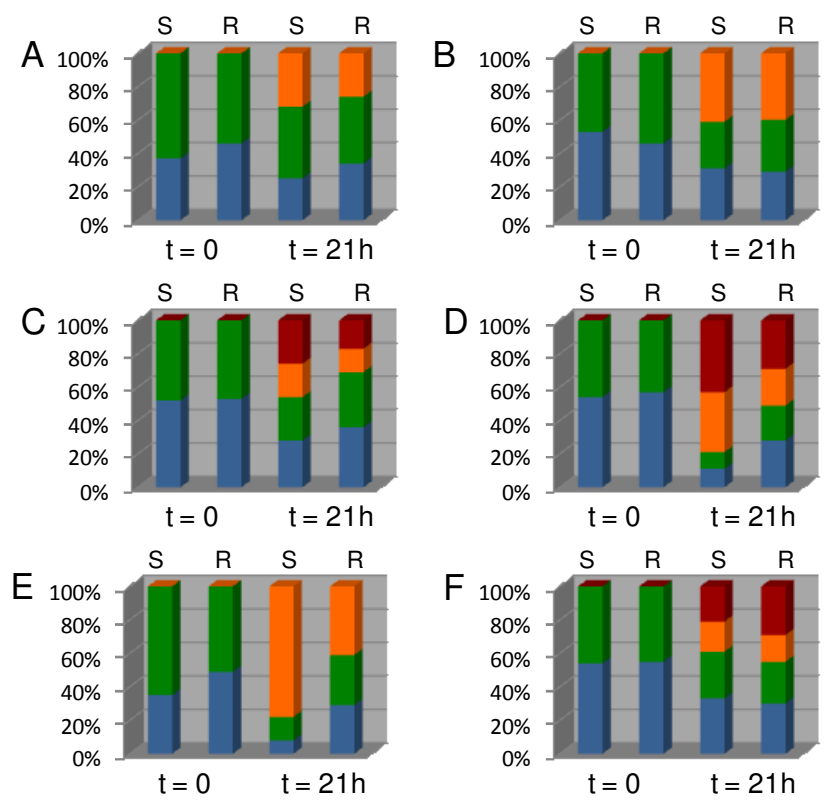

Figura 4.6. Porcentajes de FBPGluc libre (azul), FBPGluc unido a AS (verde), FBP en sitio I (naranja) y FPB en sitio II (rojo) para una mezcla inicial FBPGluc/ASH 1:3.33 a tiempo cero y tras 21 h de incubación a $37^{\circ}$ C. A- ASC, B- ASP, C- ASCe, DASO, E- ASR, F- ASB.

De los resultados obtenidos se desprende que la actividad glucuronidasa depende mucho de la albúmina utilizada. Para obtener datos más precisos y poder compararlos con los de $\mathrm{ASH}$ se realizaron los mismos experimentos control a temperatura ambiente $\left(22^{\circ} \mathrm{C}\right)$ y en ausencia de proteína. En este último caso, se usó la ASH como selector y obtener la cantidad de FBP producido por la hidrólisis. En la figura 4.7 se muestran los datos de estos experimentos. 

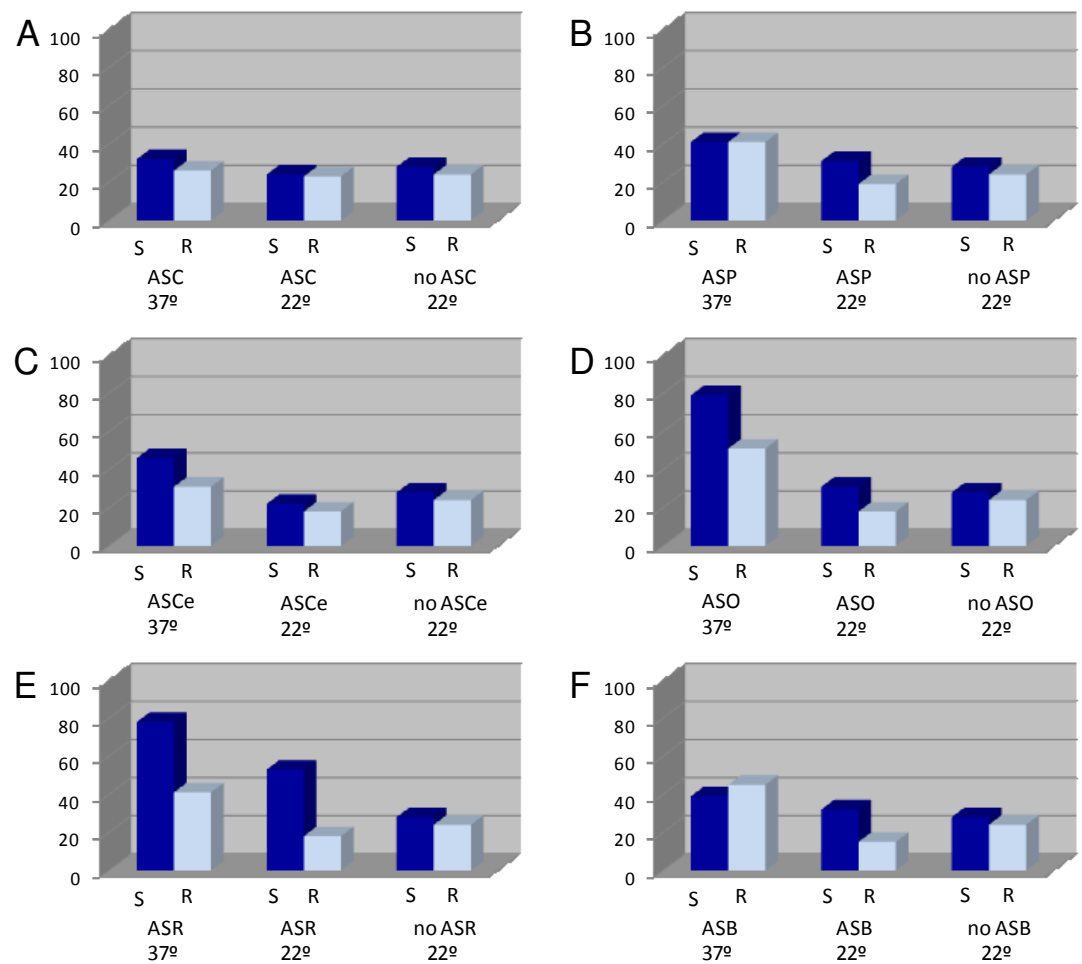

Figura 4.7. Porcentajes de FBP formados por hidrólisis de mezclas FBPGluc/SA 1:3.33 tras reaccionar durante $21 \mathrm{~h}$ a $37{ }^{\circ} \mathrm{C}$ y a $22{ }^{\circ} \mathrm{C}$, así como para FBPGluc solo tras $21 \mathrm{~h}$ a $37^{\circ} \mathrm{C}$. (2S)-FBPGluc (Azul oscuro) y (2R)-FBPGluc (Azul claro). A- ASC, B- ASP, CASCe, D- ASO, E- ASR, F- ASB.

El comportamiento de las ASs se puede clasificar en tres grupos diferentes:

a) ASC, donde no se observa hidrólisis, ya que la cantidad de FBP formado es similar a la formada en ausencia de proteína. Esto podría indicar que, a pesar de la similitud estructural con $\mathrm{ASH}$ (alrededor del 75\%), la configuración de la cavidad del sitio de unión de ASC, o bien las propiedades electrostáticas en dicha cavidad son muy diferentes a las encontradas en la ASH. 
b) En ASP, ASCe y ASB se aprecia un pequeño incremento en la cantidad de FBP respecto a la ausencia de AS, lo que puede indicar que existe actividad glucuronidasa pero en menor grado. Además, el hecho de que a menor temperatura el proceso sea más lento, indica que la reacción enzimática está teniendo lugar.

c) Por último, en ASO y ASR se puede ver un incremento considerable de FBP, por lo que se puede afirmar que la actividad glucuronidasa en estas albúminas es similar a la de ASH. Además, se observa una gran estereoselectividad en el proceso ya que el isómero (S)- se degrada considerablemente más rápido que el (R)- (como también ocurría en ASH). 


\subsection{Conclusiones}

- Se ha desarrollado un nuevo método para determinar la actividad glucuronidasa de albúminas de diferentes especies basado en la espectroscopía de especies transitorias,

- El método se basa en el uso de las diferencias en los tiempos de vida de triplete de FBPGluc y FBP dentro de las albúminas séricas estudiadas.

- El método es rápido y simple, ya que sólo necesita una medida por muestra para proporcionar resultados precisos.

- Como ventajas adicionales, las medidas se llevan a cabo sin necesidad de tratamiento previo de la muestra, evitando una posible alteración de la conformación de la proteína que afectaría al proceso de unión de sustratos. 


\subsection{Parte experimental}

\subsubsection{Materiales y disolventes}

Las albúminas séricas se compraron en Sigma; (S)-FBP, (R)FBP y 3,4-tri-O-acetil-1-bromo-1-deoxi-a-D-glucopiranuronato fueron obtenidos de Aldrich; (S)- y (R)-FBPGluc fueron sintetizados según el método descrito en el capítulo anterior. La solución de tampón fosfato (PBS, pH = 7.4, 0.01M) fue preparada disolviendo tabletas de Sigma en la cantidad apropiada de agua desionizada. Todos los disolventes fueron de calidad HPLC.

\subsubsection{Fotólisis de destello laser}

Los experimentos de fotólisis de destello laser (FDL) se llevaron a cabo usando un laser pulsado de Nd-YAG (Quantel Brilliant, de 266 $\mathrm{nm}, 5 \mathrm{~ns}$ fwhm, $10 \mathrm{~mJ}$ por pulso) acoplado a un equipo miniaturizado mLFP-111 Luzchem.

Todos los espectros transitorios se registraron empleando cubetas de cuarzo de $10 \times 10 \mathrm{~mm}^{2}$ con $4 \mathrm{ml}$ de capacidad; el diámetro del punto de disparo en la cubeta es aproximadamente $4 \mathrm{~mm}$. La absorbancia del FBPGluc fue de ca. 0.2 a la longitud de onda del laser, correspondiendo con una concentración de $1.5 \times 10^{-5} \mathrm{M}$ para el FBPGluc; Todos los experimentos se llevaron a cabo en PBS $(\mathrm{pH}=7.4$, $0.01 \mathrm{M})$ a 22 y $37 \stackrel{\circ}{\circ} \mathrm{C}$ y bajo atmósfera de aire.

Para los estudios realizados se prepararon una serie de disoluciones conteniendo (S)- y (R)-FBPGluc en presencia de las albúminas séricas de todas las especies con relación de 
concentraciones 1:3.33 (preparadas en PBS). Estas disoluciones fueron preparadas como se detalla a continuación: sobre FBPGluc, 1.5 x $10^{-5} \mathrm{M}$, se añadió una alícuota de una disolución $1 \times 10^{-3} \mathrm{M}$ de AS; la mezcla resultante se mantuvo a $37^{\circ} \mathrm{C}$ y a temperatura ambiente (22 $\left.{ }^{\circ} \mathrm{C}\right)$. A diferentes tiempos, se tomaron $4 \mathrm{ml}$ de esta disolución, se introdujeron en la cubeta de cuarzo y se sometieron a FDL, monitorizando la señal a $360 \mathrm{~nm}$ por acumulación de las cinéticas obtenidas tras 10 pulsos de láser. El experimento se realizó por triplicado con muestra fresca. Para la obtención del espectro de la especie transitoria desde 700 a $290 \mathrm{~nm}$, se realizó repetidamente a FDL a intervalos de $10 \mathrm{~nm}$ (2 pulsos de láser por cada longitud de onda). 


\subsubsection{Procedimiento para el ajuste de la desaparición}

Tabla 1. Factores preexponenciales $\left(A_{i}\right)$, con sus correspondientes errores, y el valor de $\mathrm{R}^{2}$ para los ajustes de las curvas de desaparición (FDL a $\lambda_{\mathrm{exc}}=266 \mathrm{~nm}$ ) monitorizado a $360 \mathrm{~nm}$ a $0 \mathrm{~h}$ y $6.5 \mathrm{~h}$ para una mezcla de $(2 \boldsymbol{R})$-FBPGluc/ASH a relación molar 1:3.33. Los ajustes se han hecho usando una función con dos monoexponenciales (ec. 1) o una función con cuatro monoexponenciales (ec. 2).

\begin{tabular}{|c|c|c|c|c|}
\hline$t(h)$ & $\begin{array}{c}\text { Ecuación } \\
\text { usada }^{\text {a }}\end{array}$ & Tipo de especie & Valores de $A_{i}$ & $\mathbf{R}^{2}$ \\
\hline \multirow[b]{2}{*}{0} & \multirow[b]{2}{*}{ ec. 1} & FBPGluc libre & $0.01161 \pm 0.00028$ & \multirow[b]{2}{*}{0.986} \\
\hline & & FBPGluc unido & $0.00607 \pm 0.00014$ & \\
\hline \multirow{4}{*}{0} & \multirow{4}{*}{ ec. 2} & FBPGluc libre & $0.00793 \pm 0.00028$ & \multirow{4}{*}{0.979} \\
\hline & & FBPGluc unido & $0.00549 \pm 0.00019$ & \\
\hline & & FBP en sitio I & $0.00002 \pm 0.00002$ & \\
\hline & & FBP en sitio II & $0.00006 \pm 0.00005$ & \\
\hline \multirow[b]{2}{*}{6.5} & \multirow[b]{2}{*}{ ec. 1} & FBPGluc libre & $0.00348 \pm 0.00040$ & \multirow[b]{2}{*}{0.971} \\
\hline & & FBPGluc unido + FBP libre & $0.00840 \pm 0.00008$ & \\
\hline \multirow{4}{*}{6.5} & \multirow{4}{*}{ ec. 2} & FBPGluc libre & $0.00343 \pm 0.00032$ & \multirow{4}{*}{0.977} \\
\hline & & FBPGluc unido & $0.00238 \pm 0.00022$ & \\
\hline & & FBP en sitio I & $0.00190 \pm 0.00008$ & \\
\hline & & FBP en sitio II & $0.00441 \pm 0.00019$ & \\
\hline
\end{tabular}

${ }^{a}$ Las ecuaciones empleadas para el ajuste son:

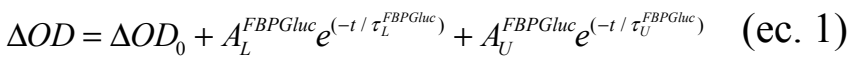

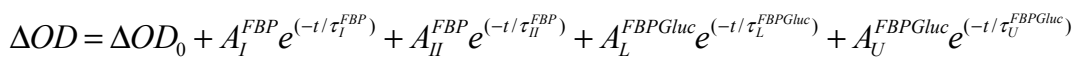

En estas ecuaciones:

$A_{L}{ }^{\text {FBPGluc }}$ corresponde a glucurónido libre $A_{\cup}{ }^{F B P G l u c}$ corresponde a glucurónido unido

$A_{\cup}{ }^{\text {FBP(Gluc) }}$ corresponde a glucurónido unido más FBP unido

$\mathrm{A}_{1}^{\mathrm{FBP}}$ corresponde a $(\boldsymbol{R})$-FBP unido sitio I

$\mathrm{A}_{\|}{ }^{\mathrm{FBP}}$ corresponde a $(\boldsymbol{R})$-FBP unido a sitio II 
$\tau_{\mathrm{L}}{ }^{\text {FBPGluc }}$ es el tiempo de vida de triplete de FBPGluc libre $=1.8 \mu \mathrm{s}$

$\tau_{\cup}{ }^{\text {FBPGluc }}$ es el tiempo de vida de triplete de FBPGluc unido $=25.0 \mu \mathrm{s}$

$\tau_{\cup}{ }^{\mathrm{FBP}(\mathrm{Gluc})}$ es el tiempo de vida de triplete FBPGluc unido más $(\boldsymbol{R})$-FBP, promediado a $25.0 \mu \mathrm{s}$

$\tau_{1}^{\mathrm{FBP}}$ es el tiempo de vida de triplete de $(\boldsymbol{R})$-FBP en el sitio $\mathrm{I}=10.2 \mu \mathrm{s}$

$\tau_{\|}{ }^{\mathrm{FBP}}$ es el tiempo de vida de triplete de $(\boldsymbol{R})$-FBP en el sitio $\|=39.0 \mu \mathrm{s}$

Tabla 2. Factores preexponenciales $\left(A_{i}\right)$, con sus correspondientes errores, y el valor de $R^{2}$ para los ajustes de las curvas de desaparición (FDL a $\lambda_{\text {exc }}=266 \mathrm{~nm}$ ) monitorizado a $360 \mathrm{~nm}$ a $0 \mathrm{~h}$ y $6.5 \mathrm{~h}$ para una mezcla de (2S)-FBPGluc/ASH a relación molar 1:3.33. Los ajustes se han hecho usando una función con dos monoexponenciales (ec. 1) o una función con cuatro monoexponenciales (ec. 2).

\begin{tabular}{|c|c|c|c|c|}
\hline$t(h)$ & $\begin{array}{c}\begin{array}{c}\text { Ecuación } \\
\text { usada }^{\mathrm{a}}\end{array} \\
\end{array}$ & Tipo de especie & Valores de $A_{i}$ & $\mathbf{R}^{2}$ \\
\hline \multirow[b]{2}{*}{0} & \multirow[b]{2}{*}{ ec. 1} & FBPGluc libre & $0.01361 \pm 0.00040$ & \multirow[b]{2}{*}{0.985} \\
\hline & & FBPGluc unido & $0.00815 \pm 0.00011$ & \\
\hline \multirow{4}{*}{0} & \multirow{4}{*}{ ec. 2} & FBPGluc libre & $0.00797 \pm 0.00031$ & \multirow{4}{*}{0.979} \\
\hline & & FBPGluc unido & $0.00469 \pm 0.00030$ & \\
\hline & & FBP en sitio I & $0.00004 \pm 0.00014$ & \\
\hline & & FBP en sitio II & $0.00006 \pm 0.00023$ & \\
\hline \multirow[b]{2}{*}{6.5} & \multirow[b]{2}{*}{ ec. 1} & FBPGluc libre & $0.00263 \pm 0.00034$ & \multirow[b]{2}{*}{0.971} \\
\hline & & FBPGluc unido + FBP libre & $0.00802 \pm 0.00009$ & \\
\hline \multirow{4}{*}{6.5} & \multirow{4}{*}{ ec. 2} & FBPGluc libre & $0.00208 \pm 0.00045$ & \multirow{4}{*}{0.977} \\
\hline & & FBPGluc unido & $0.00199 \pm 0.00043$ & \\
\hline & & FBP en sitio I & $0.00245 \pm 0.00020$ & \\
\hline & & FBP en sitio II & $0.00408 \pm 0.00033$ & \\
\hline
\end{tabular}

${ }^{a}$ Las ecuaciones empleadas para el ajuste son ec. 1 y ec. 2 donde ahora:

$\tau_{1}^{\mathrm{FBP}}$ es el tiempo de vida de triplete de (S)-FBP en el sitio I $=11.2 \mu \mathrm{s}$

$\tau_{\|}{ }^{\mathrm{FBP}}$ es el tiempo de vida de triplete de (S)-FBP en el sitio II $=35.9 \mu \mathrm{s}$ 


\subsection{Referencias bibliográficas}

1. Landoni, M. F.; Soraci, A. Curr. Drug. Metab. 2001, 2, 37.

2. Lewis, A. J.; Furst, D. E. Nonsteroidal Anti-Inflammatory Drugs: Mechanism and Clinical Uses, $2^{\text {nd }}$ Edition; Marcel Dekker: New York, 1994.

3. Evans, A. M. J. Clin. Pharmacol. 1996, 36, 7S.

4. Stachulski, A. V.; Harding, J. R.; Lindon, J. C.; Maggs, J. L.; Park, B.

K.; Wilson, I. D. J. Med. Chem. 2006, 49,. 6931.

5. Dickinson R.G. Proc. West. Pharmacol. Soc. 1993, 36, 157.

6. Bedford, C.T. J. Chromatogr. B 1998, 717, 313.

7. G. J. Dutton, Glucuronidation of Drugs and other Compounds, CRC Press, Boca Raton, 1980.

8. Tukey, R. H., Strassburg, C. P. Annu. Rev. Pharmacol. Toxicol. 2000, 40,581

9. Turgeon, D.; Carrier, J.S.; Chouinard, s.; Bélanger, A. Drug Metab. Dispos. 2003, 31, 670.

10. Kiang, T. K. L.; Ensom, M. H. H.; Chang, T. K. H. Pharmacol. Therap. 2005, 106, 97.

11. Magdalou, J.; Chajes, V.; Lafaurie, C.; Siest, G. Drug Metab. Dispos. 1990, 18, 692.

12. Spahn-Langguth, H.; Benet, L. Z. Drug. Metab. Rev. 1992, 24, 5.

13. Lucaciu, R.; lonescu, C. Farmacia 2005, 53, 10.

14. Knadler, M. P.; Hall, S. D. Drug Metab. Dispos. 1991, 19, 280.

15. Verbeeck, R. K.; Blackburn, J. L.; Loewen, G. R. Clin. Pharmacokinet. 1983, 8, 297.

16. Sudlow, G., Birkett, D. J., Wade, D. N. Mol. Pharmacol. 1976; 12: 1052. 
17. Vayá, I., Bueno, Carlos J., Jiménez, M. Consuelo, Miranda, Miguel A. ChemMedChem. 2006; 1, 1015.

18. Vayá, I., Jimenez, M. Consuelo, Miranda, Miguel A. Journal of Physical Chemistry B, 2008, 112, 2694. 
CAPÍTULO 5. Determinación de la distribución de ligandos en sistemas binarios $A S H / A A G$ 



\subsection{Introducción}

La albúmina sérica humana (ASH) y a-glicoproteína ácida humana (AAG) son proteínas transportadoras plasmáticas. Estas biomoléculas son vehículos para agentes endógenos y exógenos en el torrente sanguíneo; hasta hacerlos llegar a objetivos específicos. De ahí que su interacción con fármacos desempeñe un papel crucial en la farmacocinética y farmacodinámica de los mismos.

Como ya se mencionó en la introducción, ASH es la proteína más abundante en el torrente sanguíneo con una concentración en plasma de $3.5-4 \mathrm{gr} / 100 \mathrm{ml}$ que disminuye a 2-2.5 gr/100 ml en muchas enfermedades, tales como procesos inflamatorios, cirrosis, infarto de miocardio o enfermedades renales. ${ }^{1}$

AAG está formada por 183 aminoácidos y tiene un peso molecular de $44 \mathrm{KDa}$, con hasta un $45 \%$ en masa de hidratos de carbono. ${ }^{4,5,9}$ Principalmente se une a fármacos básicos y neutros, pero es capaz de unirse también a ácidos. ${ }^{4,15}$ Durante algunas enfermedades, como los procesos inflamatorios, la concentración de AAG aumenta desde $50-140 \mathrm{mg} / 100 \mathrm{ml}$ en personas sanas, hasta 300 $\mathrm{mg} / 100 \mathrm{ml.}{ }^{1,5}$ Así, el estudio de la interacción de los fármacos antiinflamatorios 2-arilpropiónicos con estas dos proteínas transportadoras presentes simultáneamente en el medio se convierte en una cuestión importante. El tratamiento de este problema, que es difícil de abordar por las metodologías existentes, permitirá obtener información fiable sobre los niveles de fármaco libre en plasma.

El estudio se plantea con tres sondas: FBP, que se une principalmente a HSA y en menor medida a AAG, FBPMe, que muestra una mayor afinidad por AAG y por último, FBPGluc, el acil glucurónido 
que, como vimos anteriormente, se une en menor grado a $\mathrm{ASH}$ que el FBP.

En el presente trabajo se plantea un estudio sistemático por FDL de sistemas FBP/ASH/AAG, FBPMe/ASH/AAG y FBPGluc/ASH/AAG.

En principio, la diferencia en los $\tau_{\mathrm{T}}$ de las distintas especies en su forma libre y unida a las proteínas transportadoras permitirá determinar la distribución de las especies en uno $u$ otro microambiente. Esta idea se refleja en la Figura 5.1.

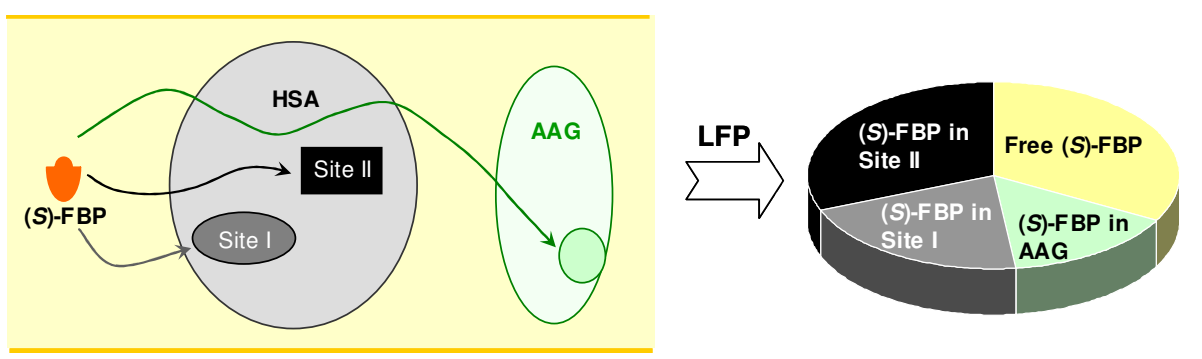

Figura 5.1. Esquema del procedimiento empleado en el presente capítulo 


\subsection{Resultados y discusión}

Como se indica en la introducción, los $\tau_{T}$ de (S)-FBP, (R)-FBP, (S)-FBPMe y (R)-FBPMe en presencia de ASH y ASB se han determinado previamente en nuestro grupo. ${ }^{16}$ Con un procedimiento similar, en el capítulo 3 se describen los $\tau_{T}$ de FBPGluc en ASH. Todos estos valores se resumen en la tabla 5.1.

Tabla 5.1. Tiempos de vida de triplete $(\mu \mathrm{s})$ de ligando en presencia de ASH.

\begin{tabular}{|c|c|c|c|}
\hline & $\tau_{\mathrm{L}}$ & $\tau_{\mathrm{I}}$ & $\tau_{\|}$ \\
\hline (S)-FBP & 1.5 & 11.2 & 35.9 \\
\hline (R)-FBP & 1.5 & 10.2 & 39.0 \\
\hline (S)-FBPMe & 1.5 & 31.5 & 4.1 \\
\hline (R)-FBPMe & 1.5 & 157.6 & 16.6 \\
\hline (S)-FBPGluc & 1.8 & - & 25.0 \\
\hline (R)-FBPGluc & 1.8 & - & 25.0 \\
\hline
\end{tabular}

A continuación se procedió a estudiar del mismo modo la interacción de esos sustratos con AAG. Para ello se prepararon disoluciones de FBP y FBPMe $\left(2.5 \times 10^{-5}\right)$ así como FBPGluc $(1.5 \times 10$ $\left.{ }^{5}\right)$ en presencia de $A A G$ a diferentes relaciones molares y se sometireron a FDL ( $\lambda_{\mathrm{exc}}=266 \mathrm{~nm}$, PBS, aire). En la figura $5.1 \mathrm{se}$ muestran algunas de las curvas de desaparición obtenidas a $\lambda=360$ nm. 

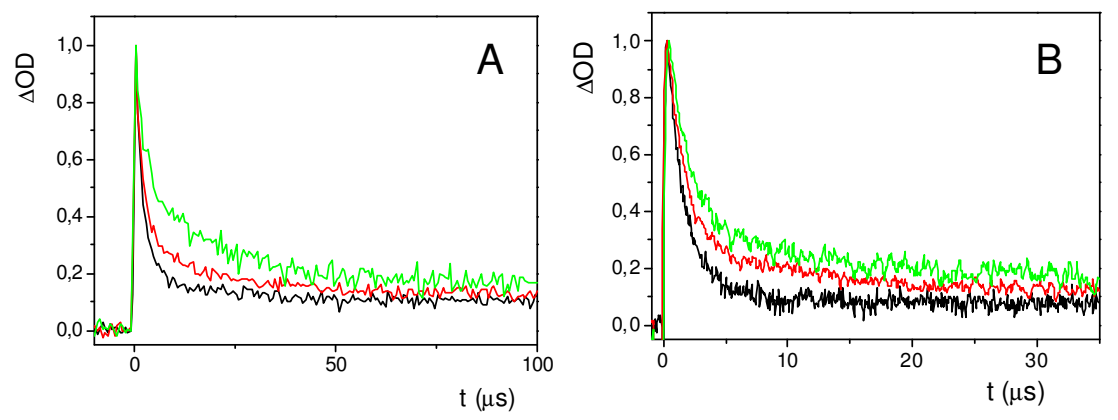

Figura 5.1. Curvas de desaparición $\left(\lambda_{\mathrm{exc}}=266 \mathrm{~nm}\right.$, PBS, aire) monitorizada a $\lambda=360 \mathrm{~nm}$ de mezclas (R)-FBP/AAG y (R)-FBPMe/AAG a distintas relaciones molares: 1:0.5 (negro), 1:1 (rojo) y 1:2 (verde). A: R-FBPMe B: R-FBP

Se puede observar que, tanto las cinéticas de FBP como las de FBPMe se alargan al añadir cantidades crecientes de $A A G$, lo que significa que estos sustratos se unen progresivamente a la proteína. No ocurre lo mismo con FBPGluc; la cinética de desaparición observada fue la misma en presencia y ausencia de $A A G$, indicando que no se produce su inclusión en la proteína. Esto se puede ver en la figura 5.2 donde se representan las cinéticas de todas las mezclas ligando/AAG a relación molar 1:1.

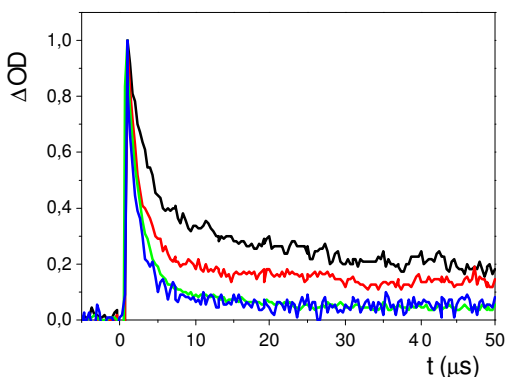

Figura 5.1. Curvas de desaparición ( $\lambda_{\mathrm{exc}}=266 \mathrm{~nm}$, PBS, aire) monitorizada a $\lambda=360 \mathrm{~nm}$ de mezclas (R)-FBP/AAG (rojo), (R)-FBPMe/AAG (negro) y (R)-FBPGluc/AAG (verde) a relación molar 1:1, junto con (R)-FBPGluc en ausencia de $A A G$ (azul). 
Mediante un análisis de regresión de las curvas con la ec. 1, se obtuvieron los tiempos de vida dentro de la proteína.

$$
\Delta O D=\Delta O D_{0}+A_{L} e^{\left(-t / \tau_{L}\right)}+A_{U} e^{\left(-t / \tau_{U}\right)} \quad \text { (ec. 1) }
$$

donde $\tau_{L}$ y $\tau_{U}$ son los tiempos de vida de triplete de la especie libre en disolución y unido a la proteína, y $A_{L}$ y $A_{U}$ son los correspondientes coeficientes preexponenciales.

En ambos casos (FBPMe y FBP) se necesitaron dos términos monoexponenciales para obtener un buen ajuste, conteniendo uno de ellos el tiempo de $1.5 \mu \mathrm{s}$. Los valores de los factores preexponenciales permitieron obtener la distribución del ligando libre y en AAG mediante las ecuaciones siguientes:

$$
\begin{aligned}
& \% F B P_{L}=\frac{A_{L}}{A_{L}+A_{U}} \times 100 \quad(\text { ec. } 2) \\
& \% F B P_{U}=\frac{A_{U}}{A_{L}+A_{U}} \times 100 \quad \text { (ec. 3) }
\end{aligned}
$$

Esto indica que solo existe un sitio de unión en AAG para estos sustratos y que incluso a relaciones molares en las que hay presente poca AAG (se llegó hasta 1:3) queda FBP o FBPMe libre en disolución. Este estudio se llevo a cabo con los dos isómeros por separado. En la tabla 5.2 se muestran los tiempos de vida y los porcentajes de ocupación para todas las especies dentro de AAG. 
Tabla 5.2. Tiempos de vida y porcentajes de ocupación de FBP y FBPMe en $A A G$ a relación molar 1:2.

\begin{tabular}{|c|c|c|}
\hline & $\tau$ & A (\%) \\
\hline \multirow{2}{*}{$(S)-F B P^{a}$} & 1.5 & 85 \\
\hline & 23 & 15 \\
\hline \multirow{2}{*}{$(R)-F B P^{a}$} & 1.5 & 81 \\
\hline & 14 & 19 \\
\hline \multirow{2}{*}{ (S)-FBPMe $e^{a}$} & 1.5 & 45 \\
\hline & 20.0 & 55 \\
\hline \multirow{2}{*}{$(R)-F B P M e^{a}$} & 1.5 & 52 \\
\hline & 19.0 & 48 \\
\hline (S)-FBPGluc ${ }^{b}$ & 1.8 & 100 \\
\hline (R)-FBPGluc ${ }^{b}$ & 1.8 & 100 \\
\hline
\end{tabular}

Una vez analizadas las interacciones de los diferentes sustratos con las dos biomoléculas por separado, se pasó al estudio de la situación en las que las dos proteínas están presentes simultáneamente. Para ello se prepararon disoluciones de (S)-FBP, (S)-FBPMe y (S)-FBPGluc en presencia de ASH y AAG a relaciones molares 1:0.5:0.5 y 1:1:1 y se sometieron a FDL. Algunas de las curvas de desaparición $\left(\lambda_{\text {mon }}=360\right.$ $\mathrm{nm}$ ) se muestran en la figura 5.2. 

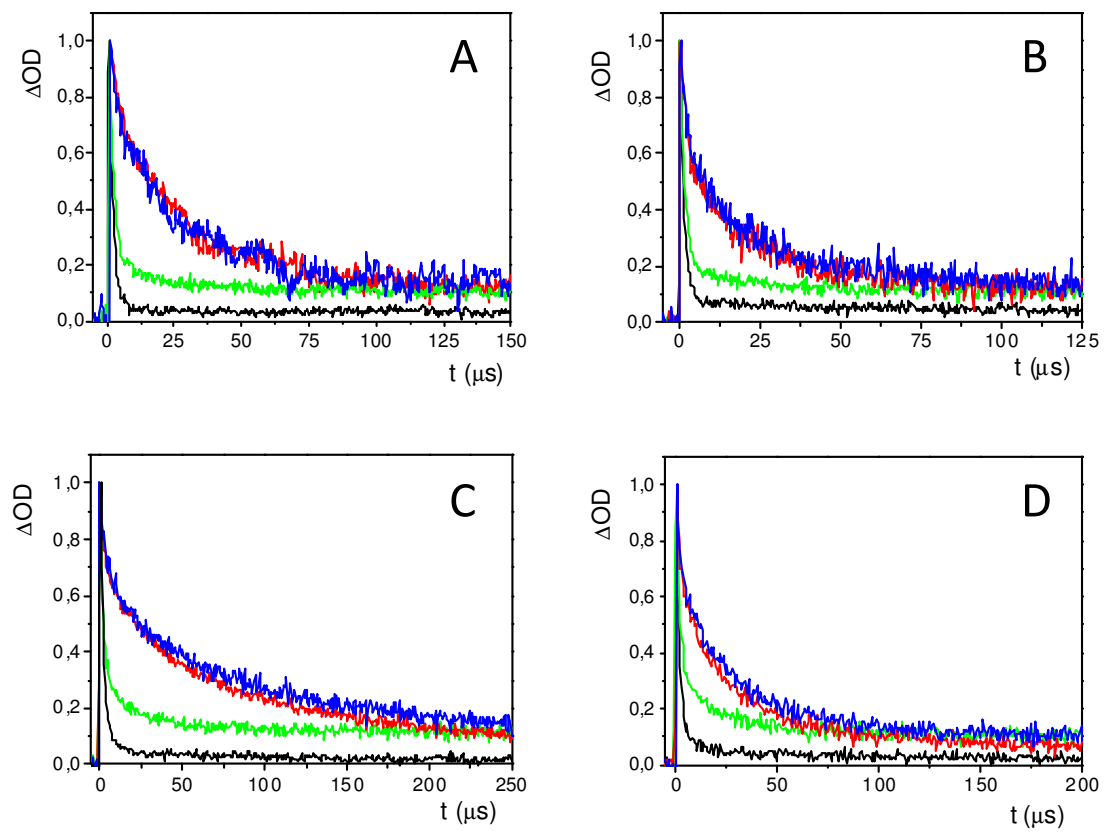

Figura 5.2. Curvas de desaparición $\left(\lambda_{\mathrm{exc}}=260 \mathrm{~nm}, \lambda_{\text {mon }}=360 \mathrm{~nm}\right)$ de $(\mathrm{R})$-FBP (A), (S)-FBP (B), (R)-FBPMe (C) y (S)-FBPMe (D), en presencia de ASH y AAG a diferentes relaciones molares: FBP/AAG y FBPMe/AAG 1:1 (verde), FBP/ASH y FBPMe/ASH 1:1 (rojo) y FBP/ASH/AAG y FBPMe/ASH/AAG 1:1:1 (azul). En negro se representa el correspondiente ligando en ausencia de proteína.

Con los datos de tiempos de vida y relaciónes de los factores preexponenciales obtenidos previamente en los estudios en presencia de $A S H$ y $A A G$ por separado y la ecuación 2, se obtuvieron $A_{A A G}, A_{l}$ y $A_{\| l}$ y a partir de ellos la ocupación de los sitios.

$$
\Delta O D=\Delta O D_{0}+A_{A A G} e^{\left(-t / \tau_{A A G}\right)}+A_{I} e^{\left(-t / \tau_{I}\right)}+A_{I I} e^{\left(-t / \tau_{I I}\right)} \text { ec. } 2
$$


donde $\tau_{\mathrm{AAG}}, \tau_{\mid}$y $\tau_{\|}$son los tiempos de vida correspondiente a cada especie dentro de cada proteína y $A_{A A G}, A_{l}$ y $A_{\|}$son los factores preexponenciales correspondientes.

En la figura 5.3 se muestra la distribución obtenida para cada especie en presencia de las dos proteínas.
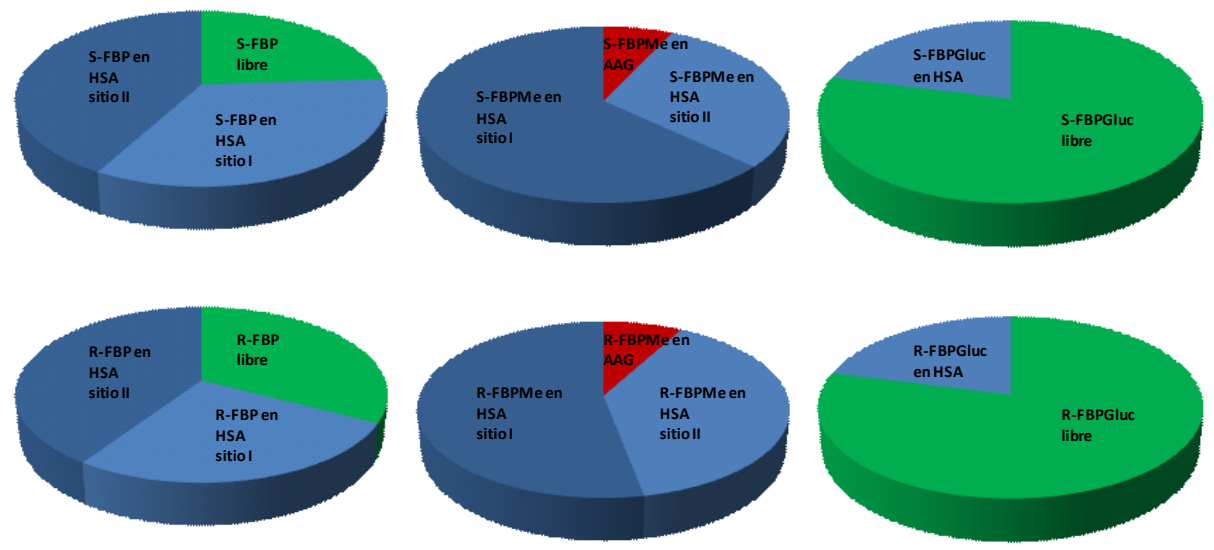

Figura 5.3. Distribución de FBP, FBPMe y FBPGluc con las dos proteínas presentes simultaneamente con relación molar 1:1:1.

Se observan dos comportamientos diferentes: en el caso de FBPMe se aprecia como el ligando se une a las dos proteínas aunque lo hace en mucha mayor medida a ASH. Esto indicaría que a pesar de tener una alta afinidad por las dos proteínas por separado, cuando se mezclan existe mayor tendencia a unirse a la albúmina; el otro comportamiento es el que se observa para FBP y FBPGluc que solo se unen a $\mathrm{ASH}$. En el caso de FBPGluc era previsible ya que, como se mencionó anteriormente, éste no se une a la AAG. Sin embargo, el FBP sí que era capaz de introducirse en la glicoproteína, por lo que en este 
caso, podemos deducir que hay mucha mayor afinidad de FBP hacía ASH que hacía AAG. 


\subsection{Conclusiones}

Mediante la técnica de fotólisis de destello láser y usando la absorción triplete-triplete del flurbiprofeno como sonda, se ha logrado determinar in situ el grado de unión del profármaco, del fármaco o de su principal metabolito a las dos proteínas responsables de su distribución en el organismo presentes simuláneamente. El método es simple, rápido, evita contaminaciones o posibles artefactos resultado de la manipulación de la muestra, ya que es una medida directa sin necesidad de llevar a cabo "work up".

\subsection{Parte experimental}

\subsubsection{Materiales y disolventes}

La albúmina sérica humana y la a-glicoproteína ácida humana se compraron en Sigma; $(S)$-FBP y $(R)$-FBP fueron obtenidos de Aldrich; el FBPGluc se sintetizó mediante método basado en literatura con algunas modificaciones. La solución de tampón fosfato (PBS, $\mathrm{pH}=7.4,0.01 \mathrm{M}$ ) fue preparada disolviendo tabletas de Sigma en la cantidad apropiada de agua desionizada. Todos los disolventes fueron de calidad HPLC.

\subsubsection{Fotólisis de destello laser}

Los experimentos de fotólisis de destello laser (FDL) se llevaron a cabo usando un laser pulsado de Nd-YAG (Quantel Brilliant, de 266 
$\mathrm{nm}, 5 \mathrm{~ns}$ fwhm, $10 \mathrm{~mJ}$ por pulso) acoplado a un equipo miniaturizado mLFP-111 Luzchem.

Para los estudios realizados en presencia de proteínas, se prepararon una serie de disoluciones conteniendo $(S)$ o $(R)$-FBP, (S) o $(\mathrm{R})$-FBPMe y $(S)$ - o $(R)$-FBPGluc en presencia de ASH y AAG. A continuación se describe el procedimiento para una mezcla de relación molar 1:1:1.

A $10 \mathrm{~mL}$ de una disolución $2.5 \cdot 10^{-5} \mathrm{M}$ de (S)-FBPMe en PBS, se adicionaron $2.48 \mu \mathrm{L}$ de ASH $2 \cdot 10^{-3} \mathrm{M}$ en PBS y $2.48 \mu \mathrm{L}$ de AAG $2 \cdot 10^{-3}$ $M$ en PBS. Una alicuota de la disolución resultante $(4 \mathrm{~mL})$ se depositó en una cubeta de cuarzo y se sometió a FDL (10 disparos para monitorizar a $360 \mathrm{~nm}$ ). 


\subsection{Referencias bibliográficas}

1. Kremer J.M.H., Wilting, J., Janssen, L.H.M. Pharmacol. Rev. 1988; 40, 1.

2. Peters, T. All About Albumin; Biochemistry, Genetics and Medical Applications, Academic Press, 1995.

3. Kragh-Hansen, U., Chuang, V. T. G., Otagiri, M. Biol. Pharm. Bull. 2002; 25: 695-704.

4. Otagiri, M. Drug Metab. Pharmacokinet. 2005; 20, 309.

5. Israili, Z. H. Drug Metabolism Review. 2001; 33: 161.

6. He, K. M., Carter, D. C. Nature. 1992; 358: 29.

7. Menke, G., Wörner, W., Kratzer, W., Rietbrock, N. Arch. Pharmacol. 1989; 339: 42.

8. Kragh-Hansen, U. Dan. Med. Bull. 1990; 37: 57-84.

9. K. Schmid, R.B. Nimberg, A. Kimura, H. Yamaguchi, Binette, J.P. Biochim. Biophys. Acta. 1977; 492; 291-302.

10. Kopitar, V.Z., Weisenberger, H. Arzneim. Forsch. (Drug Res) 1971; $21 ; 859-862$.

11. Schmid, K., Kaufman, H., Isemura, S., Bauer, F., Emura, J., Motoyama, T., Ishiguro, M. Nanno, Biochemistry 1973; 12; 2711-2724.

12. Nyberg, G., Martensson, E. 1982; 319; 189-196.

13. Schmid, K. In The Plasma Proteins: Structure, Function and Genetic Control, $2^{\text {nd }}$ Ed.; Putnam, F. W. ed.; Academic Press: New York. 1975; Vol I; 183-228.

15. Albani, F., Riva, R., Contin, M., Baruzzi, A. Br. J. Clin. Pharmacol. 1984; 18; 244-246.

16. Vayá, I., Bueno, Carlos J., Jiménez, M. Consuelo, Miranda, Miguel A. ChemMedChem. 2006; 1, 1015. 
CAPÍTULO 6. Determinación de la composición enantiomérica en mezclas de enantiómeros 



\subsection{Introducción}

La determinación de la composición enantiomérica resulta crucial en diferentes áreas, como por ejemplo en la síntesis de compuestos químicos enantioméricamente puros y sustancias con actividad biológica; ${ }^{1}$ en farmacología, los enantiómeros muestran un comportamiento diferente en términos de actividad, efectos secundarios, toxicidad, metabolismo o mecanismo de transporte. Lo que hace que sea de gran interés el desarrollo de métodos analíticos para determinar la composición enantiomérica de fármacos quirales. ${ }^{2}$

La determinación directa del exceso enantiomérico (ee) puede conseguirse mediante polarimetría; ${ }^{1}$ sin embargo, esta técnica presenta algunas limitaciones prácticas, principalmente relacionadas con la sensibilidad y la baja tolerancia a impurezas. Otros métodos analíticos usados comúnmente están basados en cromatografía de gases y HPLC con fases estacionarias quirales; sus principales desventajas son que consumen tiempo y requieren análisis en serie, lo que limita el número de muestras que pueden ser estudiadas. ${ }^{3}$ En las últimas décadas se han desarrollado otros métodos, ${ }^{4}$ basados en la determinación de diferentes propiedades, que incluyen espectrometría de masas (EM) ${ }^{5}$ espectroscopia de absorción UV/Vis, ${ }^{6}$ termografía $I R,{ }^{7}$ dicroísmo circular, ${ }^{8} \quad$ electroforesis capilar $^{9}{ }^{9} \quad \mathrm{RMN}^{10}{ }^{10}$ espectroscopia de fluorescencia, ${ }^{11}$ ensayos bioquímicos, ${ }^{12}$ etc. Sin embargo, la cuantificación de los niveles de estereoisómeros continúa siendo un problema importante actualmente y, por lo tanto, se requiere aún más investigación para desarrollar nuevas metodologías analíticas.

En principio, la discriminación entre enantiómeros es posible haciendo uso de interacciones supramoleculares tipo huesped-anfitrión. En este contexto, se ha obtenido información útil a partir de análisis 
quimiométricos de espectros de absorción UV/Vis o de fluorescencia en presencia de ciclodextrinas. ${ }^{13}$ Las proteínas son otro importante grupo de selectores quirales. Particularmente, las albúminas séricas (AS) han sido ampliamente utilizadas como fases estacionarias para la resolución cromatográfica de mezclas enantioméricas, ${ }^{14}$ un concepto basado en la posible estereoselectividad en el proceso de unión.

Los valores de $\tau_{\mathrm{T}}$ obtenidos para $(R)$ - y $(S)$-FBPMe en algunas albúminas séricas, revela una importante estereodiferenciación en el estado excitado. Un comportamiento similar con (R)- y (S)-FBP. Por ello se decidió hacer uso de la discriminación quiral entre los tiempos de vida de triplete de los enantiómeros $\mathrm{S}$ y $\mathrm{R}$ en la unión supramolecular con AS para el desarrollo de una nueva metodología dirigida a una valoración rápida y fiable de la composición enantiomérica. La estrategia se basa en la determinación del porcentaje de ambos enantiómeros partiendo de la contribución relativa de los tiempos de vida de triplete obtenidos de la curva de desaparición en presencia de AS como selector quiral. El principio se ilustra en el esquema (esquema 1).

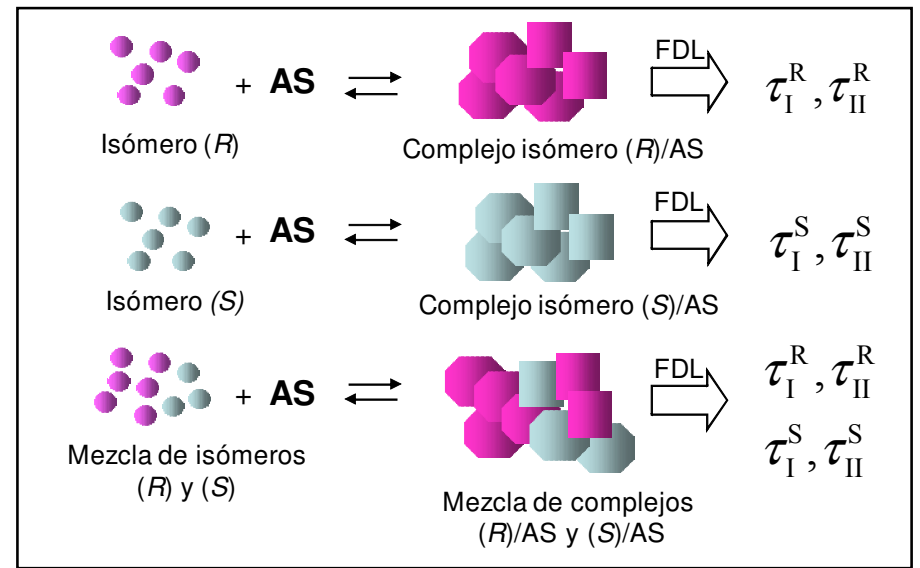

Esquema 1 


\subsection{Resultados y discusión}

Se prepararon una serie de disoluciones conteniendo (S)- y (R)FBPMe (porcentajes de 0:100 a 100:0) en presencia de cantidades equimolares de ASH y se sometieron a FDL. Algunas curvas de desaparición obtenidas se muestran en la Figura 6.1A.
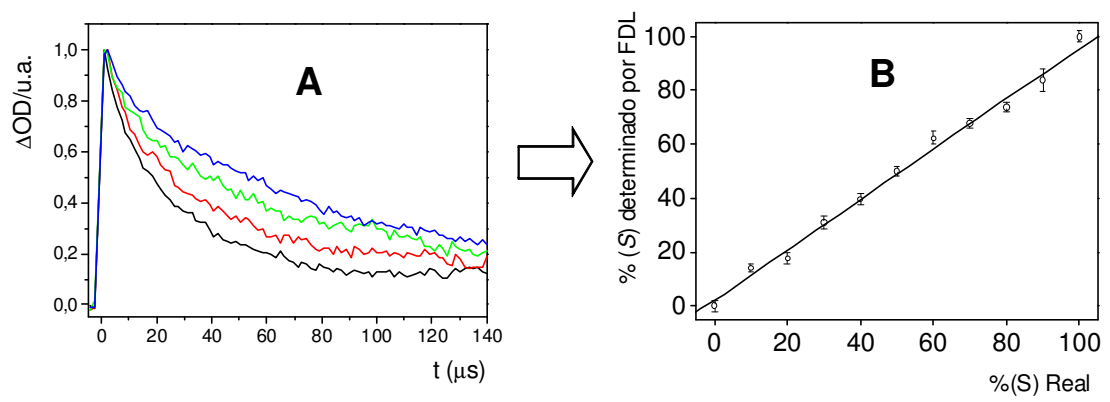

Figura 6.1. A: Curvas de desaparición $\left(\lambda_{\text {mon }}=360 \mathrm{~nm}\right)$ para varias mezclas $(S)$ FBPMe/(R)-FBPMe/ASH: 1:0:1 (negro), 0.7:0.3:1 (rojo), 0.3:0.7:1 (azul), y 0:1:1 (verde) tras FDL a $266 \mathrm{~nm}$. B: Valores de \% de enantiómero (S)- determinados por FDL frente a valores reales, junto con el ajuste lineal de los valores experimentales.

Se observa claramente que las curvas de desaparición se alargan con cantidades crecientes de (R)-FBPMe ya que los tiempos de via de triplete de este enantiómero son más largos. Para obtener ajustes precisos, se asumió que, para una mezcla FBPMe/ASH dada conteniendo ambos enantiómeros existen cuatro tipos diferentes de triplete, correspondientes a (R)- y (S)-FBPMe dentro de sitio I y sitio II. En estas condiciones no es factible que haya FBPMe libre en disolución. Así, la ley multiexponencial para ajustar la curva de desactivación vendría dada por ec. 1, en la cual $\tau^{\mathrm{S}}$ y y $\tau_{\text {|| }}^{\mathrm{S}}$ son los tiempos de vida de triplete de (S)-FBPMe en el sitio I y sitio II de ASH $\left(\tau^{\mathrm{S}}{ }_{\mid}=31.5 \mu \mathrm{s}, \tau^{\mathrm{S}}{ }_{||}=4.1\right.$ 
$\mu \mathrm{s})$, mientras que $\tau^{\mathrm{R}}{ }_{1}$ y $\tau^{\mathrm{R}}{ }_{\|}$son los valores correspondientes para el enantiómero $R\left(\tau^{R}{ }_{\mid}=157.6 \mu \mathrm{s}, y \tau^{R}{ }_{\|=16.6} \mu \mathrm{s}\right)$.

$$
\Delta O D=\Delta O D_{0}+A_{1}^{S} e^{\left(-t / \tau_{1}^{S}\right)}+A_{\|}^{S} e^{\left(-t / \tau_{\|}^{S}\right)}+A_{1}^{R} e^{\left(-t / \tau_{1}^{R}\right)}+A_{\|}^{R} e^{\left(-t / \tau_{\|}^{R}\right)} \quad(\text { ec. } 1)
$$

Asumiendo que las relaciones $A^{S}{ }_{\mid} / A^{S}$ y $A^{R}{ }_{l} / A^{R}$ permanecen constantes (70:30 y 68:32, respectivamente), ${ }^{15 a}$ el ajuste de cada curva de desactivación permitió obtener $A^{S}$, y $A^{R}$, y de ahí, utilizando la ec. 2, el porcentaje del enantiómero (S)-FBPMe.

$$
\% S=\frac{\left(A_{1}^{S}+A_{\|}^{S}\right) \times 100}{A_{1}^{S}+A_{\|}^{S}+A_{1}^{R}+A_{\|}^{R}} \quad \text { (ec. 2) }
$$

En la figura 6.1B se representan los valores de porcentaje de (S)-FBPMe determinados mediante FDL frente a los valores reales; la correlación entre ambos valores es satisfactoria y claramente valida la metodología propuesta.

Otra de las albúminas con una marcada estereoselectividad en la interacción con FBPMe es ASCe. Se realizó un minucioso estudio análogo con esta proteína y se obtuvieron resultados también satisfactorios, aunque en este caso los parámetros fueron diferentes

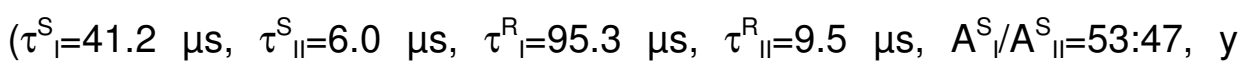
$\left.A^{R}{ }_{\mid} / A^{R}{ }_{\|=}=75: 25\right)$. 

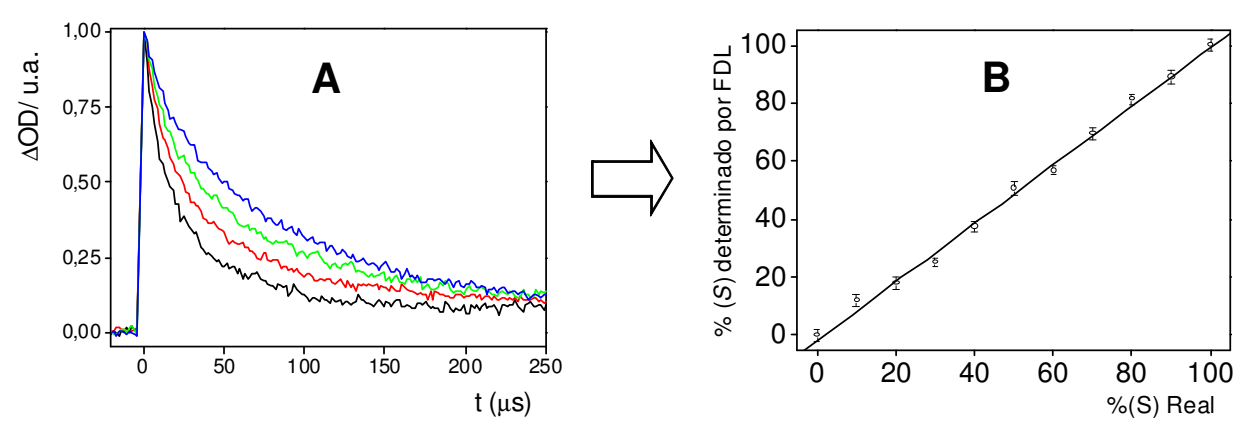

Figura 6.2. A: Curvas de desactivación $\left(\lambda_{\operatorname{mon}}=360 \mathrm{~nm}\right)$ para varias mezclas $(S)$ FBPMe/(R)-FBPMe/ASCe: 1:0:1 (negro), 0.8:0.2:1 (rojo), 0.4:0.6:1 (azul), y 0:1:1 (verde) tras FDL a $266 \mathrm{~nm}$. B: Valores de porcentaje de (S)-FBPMe determinados por FDL frente a valores reales, junto con el ajuste lineal de los valores experimentales.

En la Figura $6.2 \mathrm{~A}$ se muestran algunas de las curvas de desaparición; en 6.2B se representan los porcentajes de (S)-FBPMe obtenidos con FDL frente a los valores reales de la composición enantiomérica para los sistemas.

El requisito para aplicar esta metodología de modo satisfactorioes una discriminación quiral en los tiempos de vida de triplete de los complejos fármaco-AS, que no siempre se da en todos los sistemas. Por ejemplo, los tiempos de vida de triplete de FBP en

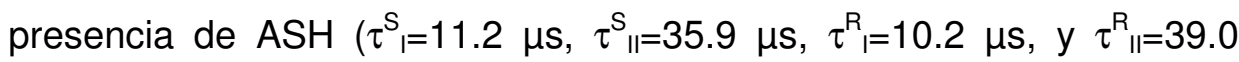
$\mu \mathrm{s})^{(15 b)}$ o ASCe $\left(\tau^{\mathrm{S}}=6.5 \mu \mathrm{s}, \tau^{\mathrm{S}}{ }_{||}=44.5 \mu \mathrm{s}, \tau^{\mathrm{R}}=6.8 \mu \mathrm{s}, \mathrm{y} \tau^{\mathrm{R}}{ }_{||}=45.0 \mu \mathrm{s}\right)$ no son suficientemente diferentes para que los valores obtenidos para los porcentajes de los dos enantiómeros no sean suficientemente precisos. En la Figura 6.3 se muestran las curvas de desaparición para mezclas 1:1 de (R)- y (S)-FBP con ASH y ASCe. 

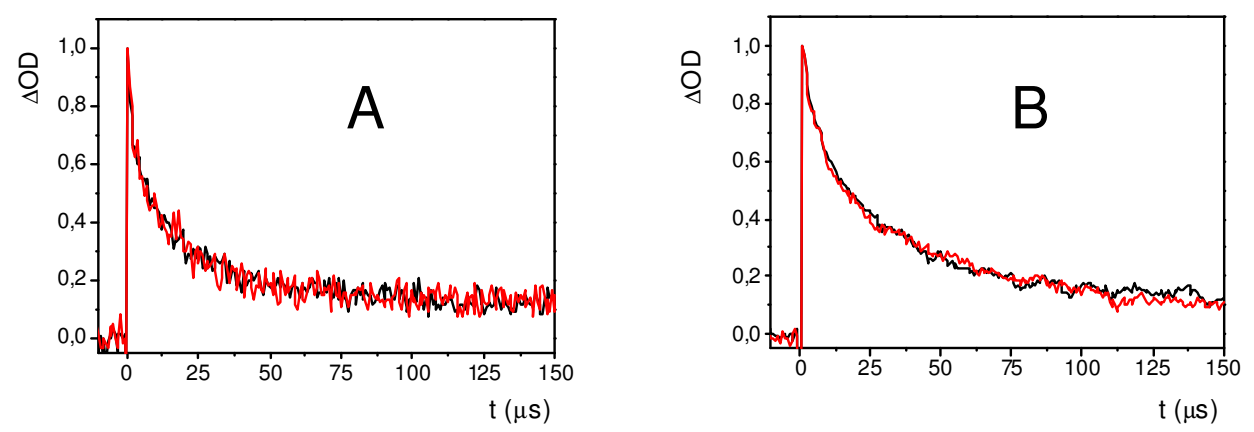

Figura 6.3. Curvas de desaparición $\left(\lambda_{\text {mon }}=360 \mathrm{~nm}\right.$ ) para mezclas FBP/ASH $1: 1$ (A) y FBP/ASCe 1:1 (B) tras FDL a 266 nm. R-FBP (negro), S-FBP (rojo).

Sin embargo, incluso en ese caso, el problema se puede solventar eligiendo una proteína para la cual los tiempos de vida de triplete de los dos enantiómeros sean lo suficientemente distintos. Así, para FBP, la albúmina sérica bovina (ASB) es un selector quiral apropiado. Dentro de esta proteína se observa una clara estereodiferenciación para (S)- y (R)-FBP en ambos sitios de unión

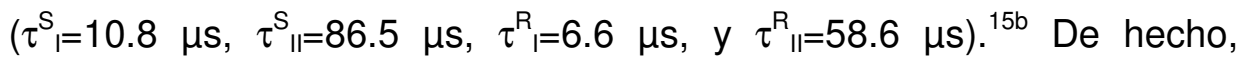
cuando se procesaron las cinéticas obtenidas en presencia de ASB con diferentes relaciones (S)-FBP/(R)-FBP de la forma habitual, se encontró una buena correlación entre los valores obtenidos con FDL y la composición enantiomérica real (Figura 6.4). 


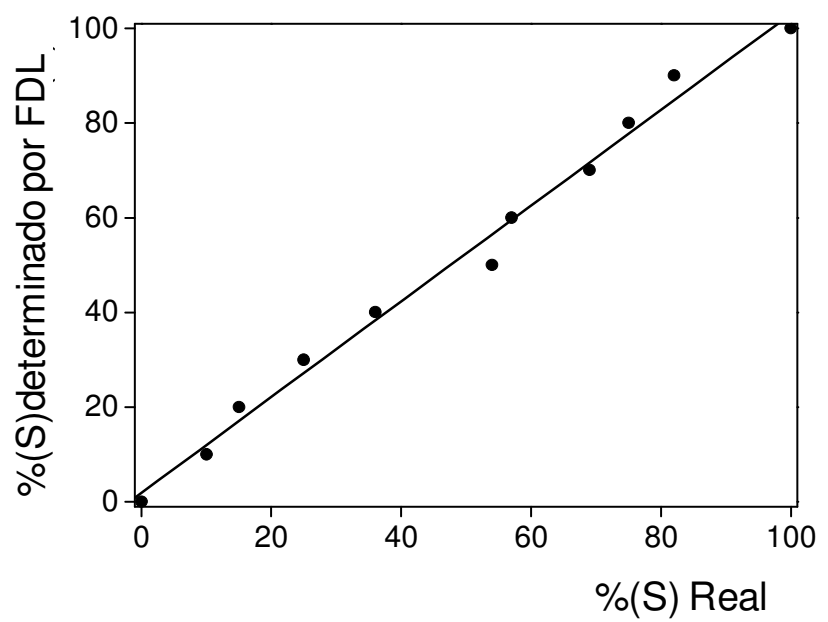

Figura 6.4. Valores determinados por FDL frente a valores reales de S-FBP en presencia de ASB, junto con el ajuste lineal de los valores experimentales.

La estereodiferenciación en las interacciones del estado excitado triplete entre analitos quirales y proteínas debe ser, en principio, un fenómeno general. Por ello, se realizó un experimento similar utilizando otro fármaco quiral pero con una estructura diferente, como es el caso del Naproxeno (NPX) (figura 6.5).<smiles>COc1ccc2cc(C(C)C(=O)O)ccc2c1</smiles>

Figura 6.5. Estructura química del NPX. 
Se prepararon mezclas NPX/ASH y tras someterlas a FDL se encontraron los siguientes tiempos de vida para (R)- y (S)-NPX en los sitios I y II de ASH: $\tau_{\mathrm{I}}^{\mathrm{S}}=8.5 \mu \mathrm{s}, \tau_{\mathrm{II}}^{\mathrm{S}}=31.6 \mu \mathrm{s}, \tau_{\mathrm{I}}^{\mathrm{R}}=7.5 \mu \mathrm{s}, \tau^{\mathrm{R}}{ }_{\mathrm{II}}=25.4 \mu \mathrm{s}$.

Con estos valores y las relaciones de los factores preexponenciales obtenidos del ajuste $\left(A_{1}{ }^{S} / A_{\|}{ }^{S}=0.333\right.$ y $A_{l}{ }^{R} / A_{\|}{ }^{R}=$ 0.370 ) también se obtuvo una buena correlación entre los valores reales y los determinados por FDL (figura 6.6).

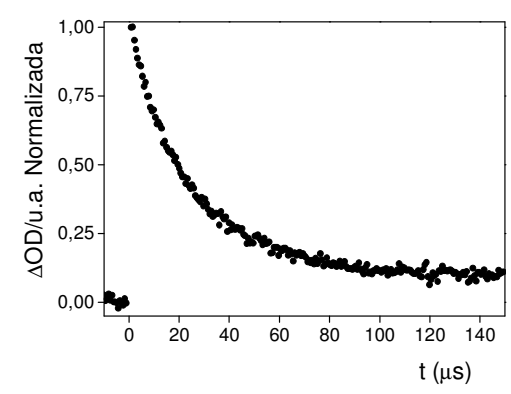

\begin{tabular}{|c|c|}
\hline Real & Determinados por FDL \\
\hline 70 & 67 \\
\hline 50 & 51 \\
\hline 40 & 42 \\
\hline
\end{tabular}

Figura 6.6. FDL $\left(\lambda_{\mathrm{exc}}=266 \mathrm{~nm}\right)$ de $(S)-\mathrm{NPX} /(R)-\mathrm{NPX} / \mathrm{HSA}$ con relación molar 0.5:0.5:1. Curva de desaparición normalizada obtenida a $420 \mathrm{~nm}$. La concentración total de NPX fue de $4 \cdot 10^{-5} \mathrm{M}$. Los porcentajes determinados por FDL $v s$ los reales de (S)NPX fueron comparados para tres mezclas $(S) /(R)$ (tabla de la derecha).

Para demostrar la viabilidad de la técnica se compararon las curvas de desaparición de los dos enantiómeros con la obtenida con el fármaco racémico (figura 6.7) 


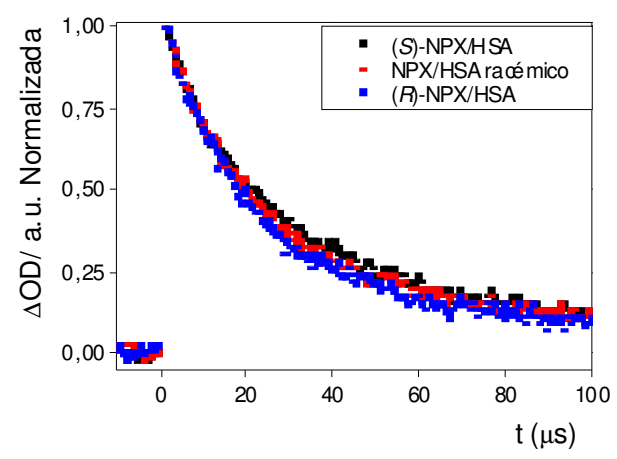

Figura 6.7. Curvas de desaparición de (S)- y (R)-NPX/HSA comparadas con la del racémico.

y se concluye que la técnica es viable para una amplia gama de compuestos quirales.

Como principales ventajas de este método frente a otros más tradicionales como pueden ser RMN o polarimetría. Podríamos destacar la tolerancia a impurezas y la sensibilidad.

Respecto a la tolerancia a impurezas, en principio podría pensarse que un método tan sensible tendría poca tolerancia a las mismas. Para examinar esta posibilidad se procedió a realizar el mismo experimento de FDL usando pastillas comerciales de Froben $^{\circledR}$, en las que el contenido de principio activo (FBP racémico) es el $25 \%$ del contenido total de la pastilla $(200 \mathrm{mg})$. Entre los excipientes se encuentran gran variedad de compuestos que podrían interferir en la medida de FDL como son los azúcares, ceras, etc. (figura 6.8). 


\section{FROBEN ${ }^{\circledR} 50$, grageas}

Flurbiprofeno

\section{COMPOSICIÓN por gragea:}

Flurbiprofeno

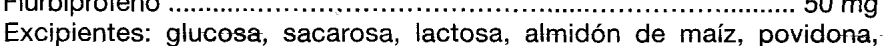

estearato de magnésio, ácido esteárico, talco, dióxido de titanio ( $\mathrm{E}$ -

171), barniz de sandáraca, cera carnauba, sílice coloidal y tinta negra

(E-172), c.s.

Figura 6.8. Fragmento del prospecto del fármaco Froben ${ }^{\circledR}$ donde se muestra la composición de cada gragea.

Se preparó una disolución con el comprimido comercial de Froben ${ }^{\circledR}$ y se sometió a FDL siguiendo el procedimiento anteriormente descrito. Paralelamente, se realizó el mismo experimento con FBP racémico y se observó como las curvas de desaparición obtenidas en ambos experimentos eran prácticamente idénticas (Figura 6.9).

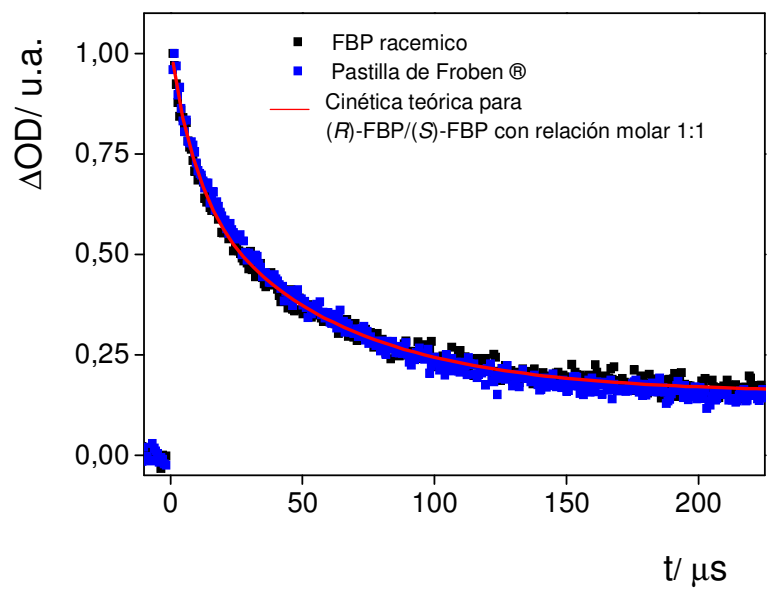

Figura 6.9. Cinética del FBP racémico comercial (negro) y de la pastilla de Froben ${ }^{\circledR}$ (azul), además, curva de desaparición teórica para una mezcla racémica de (R)- y (S)-FBP (rojo). 
Por otro lado, se prepararon disoluciones de Froben $^{\circledR}$ y de FBP comercial, y se analizaron por $\mathrm{RMN}-{ }^{1} \mathrm{H}$. Así, se disolvió un comprimido de Froben ${ }^{\circledR}$ en $80 \mathrm{ml}$ de $\mathrm{CH}_{3} \mathrm{OH}$, se filtró, y el disolvente se evaporó a vacio consiguiendo un polvo blanco. Entonces, $10 \mathrm{mg}$ de ese sólido se disolvieron en $\mathrm{CD}_{3} \mathrm{OD}(0.7 \mathrm{ml})$ y se realizó un espectro de $\mathrm{RMN}-{ }^{1} \mathrm{H}$.

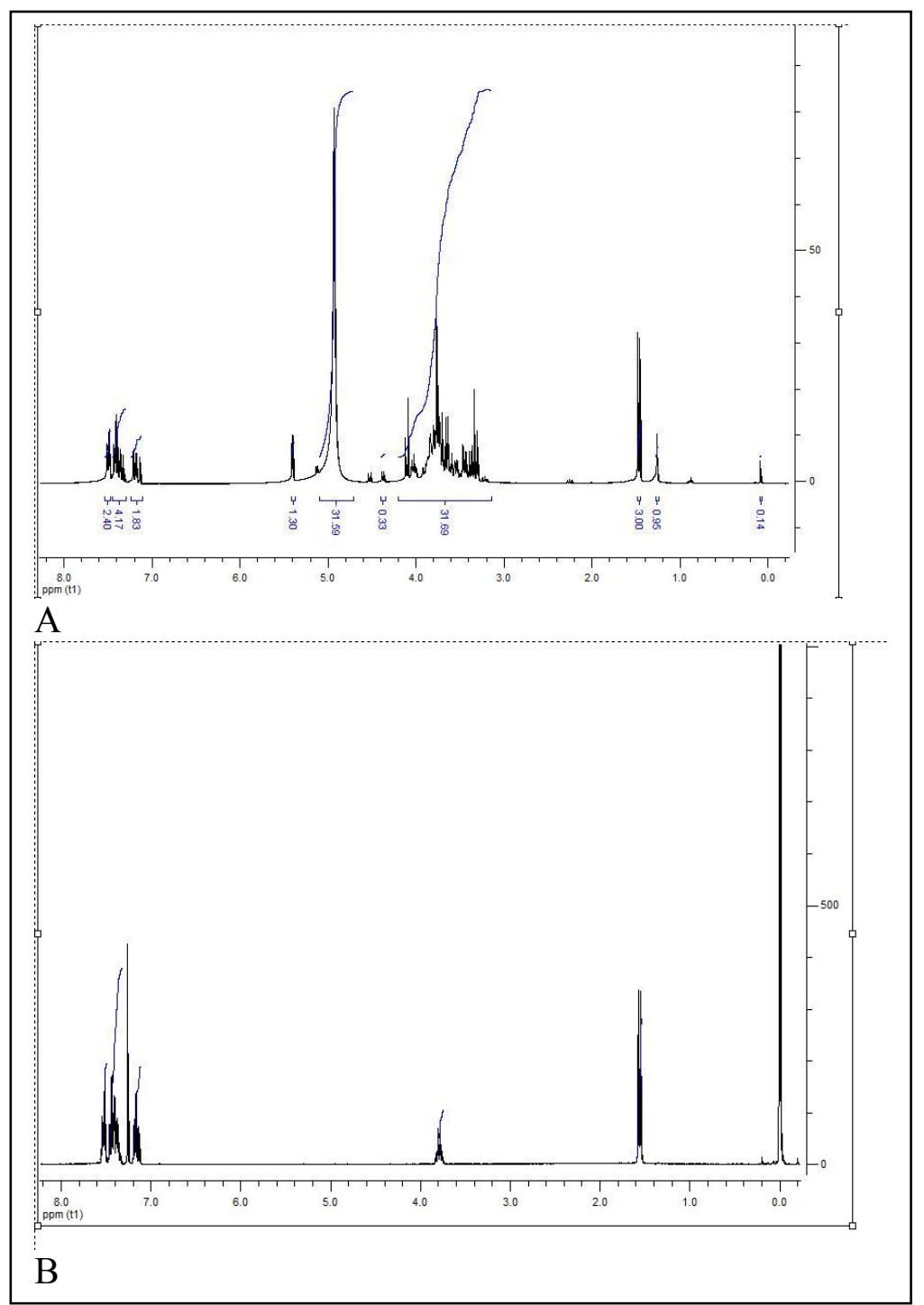

Figura 6.10. Espectros de ${ }^{1} \mathrm{H}-\mathrm{RMN} 300 \mathrm{MHz}$ de la pastilla de Froben $^{\circledR}(\mathrm{A})$, y de FBP puro (B). 
Como patrón, con FBP puro se siguió el mismo procedimiento. En la figura 6.10 se observa como en el espectro de Froben ${ }^{\circledR}$ (figura 6.10A) aparecen gran cantidad de señales correspondientes a los excipientes.

Otra de las ventajas de este método es la poca cantidad de muestra necesaria para el análisis (del orden de $\mu \mathrm{g}$ ). No todas las técnicas usadas en la actualidad para la determinación de excesos enantioméricos dan buenos resultados con tan poca cantidad de muestra. Como ejemplo, se realizaron análisis para el caso del FBP usando técnicas como polarimetría, RMN y HPLC, cuyos resultados se exponen a continuación.

Tabla 6.1. Rotación óptica (R.O.), desviación estandard $(\sigma)$ y \% de coeficiente de variación (C.V.) de mezclas conteniendo diferente porcentajes de $(S)$ - y $(R)$-FBP en MeCN con concentración total de $2.5 \times 10^{-5} \mathrm{M}$. ${ }^{a}$ Medidas realizadas en un polarímetro JASCO P-1030 con celda de cuarzo de $10 \mathrm{~cm}$ de cámino óptico.

\begin{tabular}{|c|c|c|c|}
\hline$\%(\boldsymbol{S})$-FBP & R.O. $^{\mathbf{a}}$ & $\boldsymbol{\sigma}$ & $\mathbf{C . V . \%}$ \\
\hline 100 & $-0,0031$ & 0,0048 & -152 \\
90 & $-0,0014$ & 0,0056 & -393 \\
80 & 0,0012 & 0,0031 & 260 \\
70 & $-0,0020$ & 0,0033 & -167 \\
60 & 0,0017 & 0,0034 & 198 \\
50 & $-0,0020$ & 0,0014 & -67 \\
40 & 0,0023 & 0,0014 & 62 \\
30 & 0,0035 & 0,0029 & 84 \\
20 & $-0,0010$ & 0,0045 & -446 \\
10 & $-0,0023$ & 0,0025 & 80 \\
0 & $-0,0026$ & 0,0026 & -102 \\
\hline
\end{tabular}


En la tabla 6.1 se muestran los resultados obtenidos con la técnica de polarimetría de los que se puede deducir que con cantidades tan pequeñas como las usadas con la técnica de FDL no se obtienen datos fiables de rotación óptica. Por tanto, la polarimetría no proporciona resultados precisos en el mismo rango de concentraciones que el método basado en FDL.

A continuación se llevaron a cabo experimentos de $\mathrm{RMN}-{ }^{1} \mathrm{H}$ con las mismas cantidades de FBP que las que se usan en los experimentos de FDL $\left(1 \times 10^{7} \mathrm{~mol}\right)$, obteniéndose el espectro de la figura 6.11 .

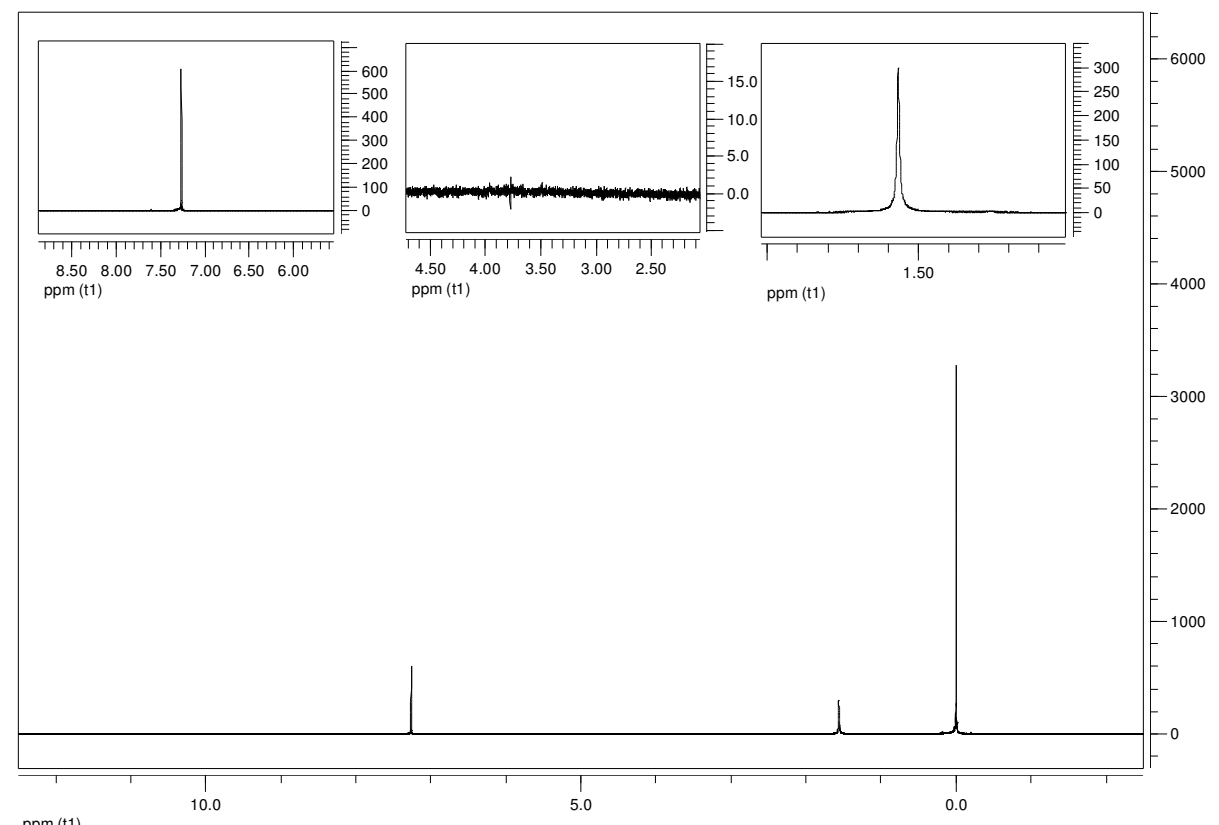

Figura 6.11. Espectro ${ }^{1} \mathrm{H}-\mathrm{RMN}(300 \mathrm{MHz})$ de la cantidad de FBP requerida para un experimento de FDL $\left(1 \times 10^{-7} \mathrm{~mol}\right)$ en $0.7 \mathrm{~mL}$ de $\mathrm{CDCl}_{3}$. No se detectaron señales del fármaco a estas concentraciones (ver ampliaciones).

No se detectó ninguna señal correspondiente al fármaco. Los recuadros internos de la figura 6.11 corresponden a ampliaciones de las zonas del espectro donde se esperarían encontrar las señales del FBP. 
Por último, se realizaron experimentos de cromatografía líquida de alta resolución para compararlos con la FDL. Se prepararon disoluciones conteniendo la misma cantidad de FBP requerida para un análisis por FDL $\left(1 \times 10^{-7} \mathrm{~mol}\right)$ en $300 \mu \mathrm{L}$ de tert-butil metil eter. Una alícuota de $200 \mu \mathrm{l}$ de esta disolución se inyectó en un sistema de HPLC (fase directa) dotado con una columna quiral (Kromasil 100 TBB $5 \mu \mathrm{m} 25$ $\mathrm{cm} \times 1 \mathrm{~cm}$ ). El eluyente empleado fue tert butil metil eter/hexano/ácido acético (60:40:0.1) con un flujo de $1.5 \mathrm{ml} / \mathrm{min}$. El sistema de detección usado fue un detector quiral (JASCO OR-1590). La técnica de HPLC, es la única de las utilizadas que proporciona resultados comparables a los obtenidos por FDL. Sin embargo, tiene como inconveniente un gasto de tiempo y disolvente muy superior al necesario para FDL, además de un tratamiento de la muestra más complicado.

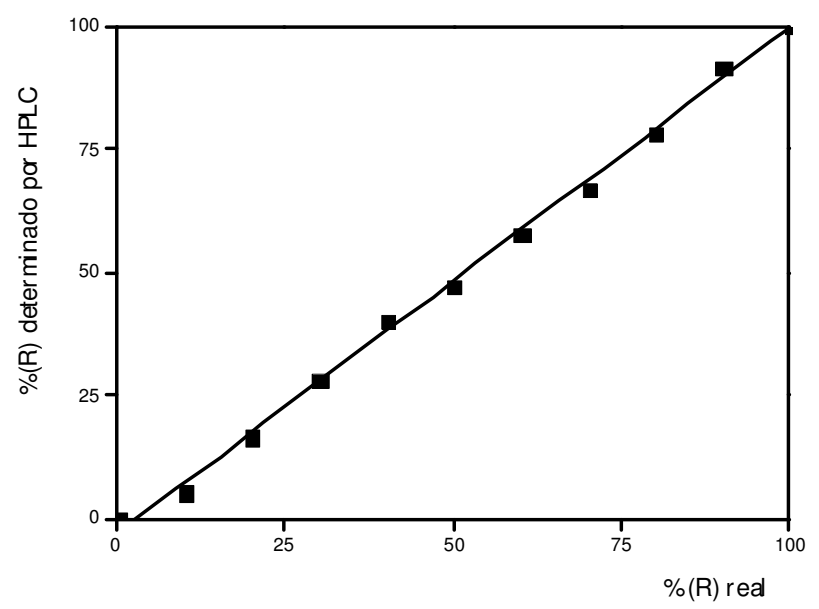

Figura 6.12. Composición de diferentes mezclas de $(S)$ - y $(R)$-FBP determinada por HPLC frente a los valores reales junto con la linea de ajuste de los puntos experimentales. 


\subsection{Conclusiones}

- Se ha presentado un nuevo método para la determinación directa de la composición enantiomérica basado en la espectroscopía de especies transitorias, explotando las diferencias en los tiempos de vida de triplete dentro de las albúminas séricas para reconocimiento quiral.

- El método es rápido y simple, ya que sólo necesita una medida por muestra para proporcionar resultados precisos.

- Es altamente sensible y apropiado para el análisis de cantidades pequeñas $(\mu \mathrm{g})$ de muestra.

- Como ventajas adicionales, evita la derivatización del sustrato así como la separación cromatográfica y no depende de la rotación específica del compuesto objetivo.

- A pesar de ser un método muy sensible es bastante tolerante a la presencia de impurezas. 


\subsection{Parte experimental}

\subsubsection{Materiales y disolventes}

Las albúminas séricas humana y bovina fueron adquiridas de Sigma. El (S)- y (R)-FBP y (S)- y (R)-NPX fueron adquiridos de Aldrich. Las disoluciones de PBS $0.01 \mathrm{M}(\mathrm{pH}=7.4)$ empleadas se obtuvieron por disolución de pastillas tampón fosfato adquiridas de Sigma en agua desionizada Milli-Q.

\subsubsection{General}

A continuación se exponen los detalles experimentales para una típica determinación de la composición enantiomérica de una muestra dada, en este caso la relación (S)-FBPMe/(R)-FBPMe/ASH 0.5:0.5:1.

Sobre una disolución de (S)-FBPMe en PBS $\left(10 \mathrm{ml}, 5 \times 10^{-5} \mathrm{M}\right)$ se adicionó otra de (R)-FBPMe (10 ml, $\left.5 \times 10^{-5} \mathrm{M}\right)$ y otra de ASH $(248 \mu \mathrm{l}$, $\left.2 \times 10^{-3}\right) .4 \mathrm{ml}$ de esa disolución se colocaron en una cubeta de cuarzo y se llevó a FDL (10 disparos a $360 \mathrm{~nm}$ ).

Para obtener una curva de desaparición precisa, este experimento se repitió al menos tres veces con muestra fresca; los tiempos de vida de triplete y los ajustes de las curvas de desactivación coincidieron dentro de los márgenes del error experimental (Figura 6.13) 


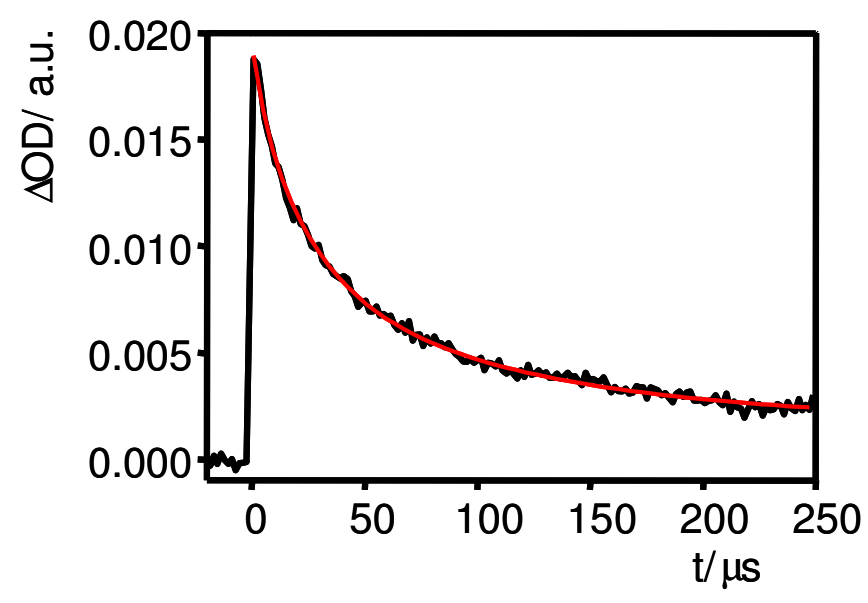

Figura 6.13. Fotólisis de destello laser $\left(\lambda_{\text {exc }}=266 \mathrm{~nm}\right)$ de $(S)$-FBPMe/(R)FBPMe/HSA a relación molar 0.5:0.5:1. La línea negra es la curva de desaparición obtenida a $360 \mathrm{~nm}$, mientras que la roja corresponde al ajuste exponencial (ec 1) de la curva. El procedimiento seguido para la determinación experimental de la composición enantiomérica se explica en el texto. 


\subsection{Referencias bibliográficas}

1. Finn, M. G. Chirality 2002, 14, 534-540.

2. Aboul-Enein H., Wainer I., The Impact of Stereochemistry on Drug Development and Use, John Wiley \& Sons, Inc., New York, USA, 1997; Norbert, N. N., Franco, P., Lindler, W. J. Chromatogr. A 2001, 906, 3-33.

3. a) Pirkle, W.H. Finn, J. M. J. Org. Chem. 1981, 46, 2935-2938; b) Y. Okamoto, E. Yashima, Angew. Chem. Int. Ed. 1998, 37, 1026.1043.

4. a) Edkins, T. J., Bobbit, D. R. Anal. Chem. 2001, 3, 488a; b) Tsukamoto, M. Kagan, H. B. Adv. Synt. Catal. 2002, 344, 453-463.

5. a) Guo, J. Wu, J. Siuzdak, G. Finn, M. G. Angew. Chem., Int. Ed. 1999, 38, 1755-1758; b) Reetz, M. T. Becker, M. H Klein, H.-W. Stöckigt, D.Angew. Chem., Int. Ed.. 1999, 38, 1758-1761; c) Markert, C. Pfaltz, A.Angew. Chem., Int. Ed. 2004, 43, 2498-2500.

6. a) Reetz, M. T. Kuhling, K. M. Deege, A.D Hinrichs, H. Belder, D. Angew. Chem., Int. Ed. 2000, 39, 3891-3893; b) Abato, P.; Seto, C. T. J. Am. Chem. Soc. 2001, 123, 9206-9207; c) van Delden, R. A. Feringa, B. L.Angew. Chem., Int. Ed. 2001, 40, 3198-3200; d) Taran, F. Gauchet, C. Mohar, B. Meunier, S. Valleix, A. Renard, P. Y Créminon, C. Grassi, J. Wagner, A. Mioskowski, C.Angew. Chem., Int. Ed. 2002, 41, 124-127; e) Li, L. Butikofer, B. Witholt, B. Angew. Chem., Int. Ed. 2004, 43, 1698-1702; f) Eelkema, R. van Delden, R. A. Feringa, B. L. Angew. Chem., Int. Ed. 2004, 43, 50135016; g) Dey, S. Karukurichi, K. R. Shen, W. Berkowitz, D. B J. Am. Chem. Soc. 2005, 127, 8610-8611; h) Mei, X.; Wolf, C. J. Am. Chem. Soc. 2006, 128, 13326-13327.

7. Reetz, M. T. Becker, M. H. Kuhling, K. M. Holtzwarth, A. Angew. Chem., Int. Ed. 1998, 37, 2647-2650. 
8. Ding, K. Ishii, A. Mikami, K. Angew. Chem., Int. Ed. 1999, 38, 497501.

9. a) Reetz, M. T. Kuhling, K. M. Deege, A. Hinrichs, H. Belder, D. Angew. Chem., Int. Ed. 2000, 97, 3891-3893; b) Blomberg, L. G. Wan, H. Electrophoresis 2000, 21, 1940-1952.

10. a) Yannoni, C. S. Acc. Chem. Res. 1982, 15, 201-208; b) Tekely, P. Gardiennet, C. Potrzebowski, M. J. Sebald, A. Reichert, D. Luz, Z. J. Chem. Phys. 2002, 116, 7607-7616; c) Potrzebowski, M. J. Tadeusiak, E. Misiura, K. Ciesielski, W. Bujacz, G. Tekely, P. Chem. Eur. J. 2002, 8, 5007-5011;d) Evans, M. A. Morken, J. P.J. Am. Chem. Soc. 2002, 124, 9020-9021.

11. a) James, T. D. Sandanayake, K. R. A. S. Shinkai, S. Nature 1995, 374, 345-347. b) Copeland, G. T. Miller, S. J. J. Am. Chem. Soc. 1999, 121, 4306-4307; c) Beer, G. Rurack, K. Daub, J.J. Chem. Soc., Chem. Commun. 2001, 1138-1139; d) Zhao, J. Fyles, T. M. James, T. D.Angew. Chem., Int. Ed. 2004, 43, 3461-3464; e) Pu L.Chem. Rev. 2004, 104, 1687-1716; f) Li, Z.-B. Lin, J. Qin, Y.-C. $\mathrm{Pu}$, L.Org. Lett. 2005, 7, 3441-3444.

12. a) Abato, P. T. Seto, C.J. Am. Chem. Soc. 2001, 123, 9206-9207; b) Taran, F. Gauchet, C. Mohar, B. Meunier, S. Valleix, A. Renard, P. Y. Creminon, C. Grassi, J. Wagner, A. Mioskowski, C. Angew. Chem., Int. Ed. 2002, 41, 124-127; c) Matsushita, M. Yoshida, K. Yamamoto, N. Wirsching, P. Lerner, R. A. Janda, K. D. Angew. Chem., Int. Ed. 2003, 42, 5984-5987; d) Hamberg, A. Lundgren, S. Penhoat, M. Moberg, C. Hult, K. J. Am. Chem. Soc. 2006, 128, 2234-2235.

13. a) Busch, K. W. Swamidoss, I. M. Fakayode, S. O. Busch, M. A. J. Am. Chem. Soc. 2003, 125, 1690-1691; b) Fakayode, S. O. Busch, M. A. Bellert, D. J. Busch, K. W. Analyst 2005, 130, 233-241; c) 
Busch, K. W. Swamidoss, I. M. Fakayode, S. O. Busch, M. A. J. Am. Chem. Soc. 2003, 125, 1690-1691.

14. a) Challa, V. K. Apinya, B. Ho, C. S. Chem. Commun. 2001, 297298; b) Abe, Y. Yasuoka, S. Shoji, T. Sugata, S. Hattori, K. Iwata, K. Suzuki, H. Anal. Sci. 2002, 18, 823-825; c) Hamblin, J. Abboyi, N. Lowe, M. P. Chem. Commun. 2005, 657-659; d) Singh, S. S. J. Mehta, J. Chromatogr. B. 2006, 834, 108-116; e) Hödl, H. Koidl, J. Schmid, M. G. Gübitz, G. Electrophoresis 2006, 27, 4755-4762; f) Martínez-Gómez, M. A. Sagrado, S. Villanueva-Camañas, R. M. Medina-Hernández, M.J. Anal. Chim. Acta. 2007, 582, 223-228.

15. a) Jiménez, M. C. Vayá, I. Miranda, M. A. J. Am. Chem. Soc. 2005, 127, 10134-10135; b) Vayá, I. Bueno, C. J. Jiménez, M. C. Miranda, M. A. ChemMedChem. 2006, 1, 1015-1020.

16. Bohne, C. Barra, M. Boch, R. Abuin, E. B. Scaiano, J. C. J. Photochem. Photobiol. A: Chem., 1992, 65, 249-265.

17. Jiménez, M. C. Miranda, M. A. Tormos, R. Vayá, I. Photochem. Photobiol. Sci. 2004, 3, 1038-1041.

18. Sudlow, G. Birkett, D. J. Wade, D. N. Mol. Pharmacol. 1976, 12, 1052-1061.

19. Peters, T. All About Albumins: Biochemistry Genetics and Medical Applications, Academic Press, San Diego, 1995. 



\subsection{Instrumentación general}

Los espectros de resonancia magnética nuclear de protón y carbono $\left(\mathrm{RMN}-{ }^{1} \mathrm{H}\right.$ y $\left.{ }^{13} \mathrm{C}\right)$ se registraron en un espectrómetro Varian Gemini de $300 \mathrm{MHz}$, utilizando como disolvente cloroformo o metanol deuterado. Los valores de desplazamiento químico $(\delta)$ están expresados en partes por millón (ppm), y son relativos a la señal del tetrametilsilano (TMS), escogido como referencia para el caso del cloroformo, mientras que en los espectros realizados en metanol deuterado, se usó como referencia la señal propia del metanol a 3.3 ppm. Los valores de las constantes de acoplamiento $(\mathcal{J})$ se indican en hercios $(\mathrm{Hz})$.

La determinación de la rotación óptica $\left([\alpha]_{\lambda}^{T}\right)$ de los compuestos se realizó haciendo uso de un polarímetro Jasco P-1030, cuya fuente de luz es de $\mathrm{Na}$ a $589 \mathrm{~nm}$. El valor de $[\alpha]_{\lambda}^{T}$ se determinó a una temperatura de $27^{\circ} \mathrm{C}$.

Para la cromatografía liquida de alta resolución (HPLC) se usó un equipo isocrático Waters modelo 6000A con detector de ultravioleta (UV/Vis), provisto de una columna semipreparativa de fase reversa. Se utilizó como eluyente acetonitrilo (de grado HPLC) y agua, la cual fue purificada con filtros de nylon de membrana (ref: A LBET-NY045-47-BL) ALBET.

\subsection{Instrumentación fotoquímica}

Los espectros de absorción ultravioleta-visible (UV-vis) se registraron en un espectrofotómetro Perkin Elmer Lambda 35. 
La técnica de fotólisis de destello láser (FDL) es una técnica de absorción resuelta en el tiempo, que consiste en la generación de especies excitadas mediante un haz excitador (láser pulsado de elevada intensidad) y en registrar la absorción de éstas mediante un haz analizador, en la región UV-vis con resolución temporal. En la Figura 7.1 se muestra de forma esquemática un sistema de FDL.

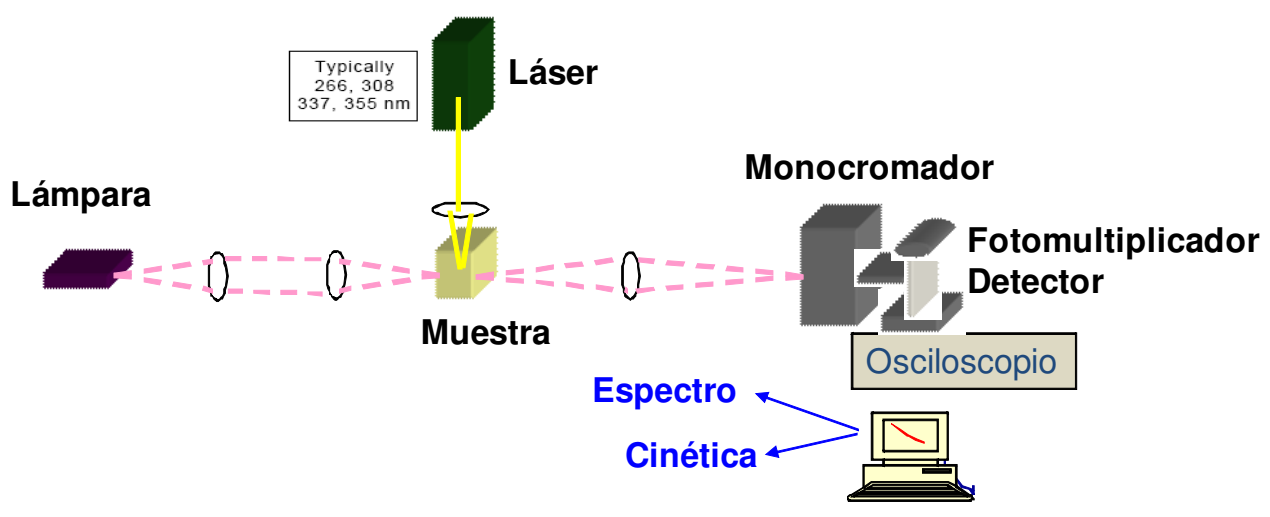

Figura 7.1. Esquema de un sistema de FDL.

Los componentes de un sistema de FDL son los siguientes:

- Haz excitador: láser pulsado, que puede ser de $\mathrm{XeF}, \mathrm{Nd}$, etc. En este caso se utilizó un sistema láser pulsado de Nd-YAG (Quantel Brilliant, de 266 ó $355 \mathrm{~nm}$ ).

- Haz analizador: se pueden utilizar distintos tipos de fuentes de radiación, como infrarrojo, UV-vis, etc, aunque el más común es el de UV-vis. En este caso se utilizó un detector UV-vis (lámpara de Xe).

- Sistema de detección: consta de un monocromador, con el que se puede seleccionar la longitud de onda deseada, y un fotomultiplicador, que detecta la señal a la longitud de onda deseada. 
De esta forma, el sistema es capaz de detectar la señal en función del tiempo y la longitud de onda seleccionada.

- Sistema de análisis de la señal: formado por un osciloscopio, que permite representar gráficamente la señal de voltaje en función del tiempo que llega al fotomultiplicador. El osciloscopio está conectado a un ordenador para el posterior almacenamiento y tratamiento de datos.

Aunque el sistema de fotólisis es un espectrofotómetro de un solo haz, se comporta como si fuese de doble haz, donde el de referencia y el de muestra se encuentran separados en el tiempo en lugar del espacio. Así pues, la señal que se observa tras FDL viene dada por la absorción de la muestra antes y después de ser irradiada con el pulso de láser. Ese cambio de absorción $(\Delta \mathrm{DO})$ viene dado por la ecuación 7.1.

$$
\Delta D O=-\log \left(I_{0} / I_{t}\right)
$$

donde $I_{0}$ es la intensidad del haz incidente antes de atravesar la muestra y $l_{t}$ es la intensidad del haz tras atravesar la muestra. La medida de $\Delta \mathrm{DO}$ en función del tiempo proporciona una traza que suele seguir una desactivación exponencial. El caso más sencillo se da cuando existe una única especie transitoria que se desactiva, bien de forma no radiante o por colisiones con el disolvente. En este caso, la señal obtenida sigue una ley de tipo monoexponencial, según la ecuación 7.2.

$$
\Delta D O=A e^{\left(-k_{D} \cdot t\right)}
$$

donde $\triangle D O$ es el cambio de absorbancia de la muestra, $A$ es el factor preexponencial, $t$ en el tiempo y $k_{D}$ es la constante de desactivación de 
la especie transitoria, que también se puede expresar como $\mathrm{k}_{D}=1 / \tau$, donde $\tau$ es el tiempo de vida de la especie transitoria.

La técnica de FDL permite estudiar tanto la desactivación cinética de la especie transitoria generada como la formación de nuevas especies. También se puede construir el espectro de absorción UV-vis de la especie transitoria generada, analizando las trazas resueltas en el tiempo a distintos valores de longitud de onda. El espectro obtenido resulta de la diferencia de la absortibidad molar de la muestra en el estado fundamental y de la especie transitoria formada después de la excitación. Este espectro es característico de aquellas longitudes de onda donde el estado fundamental es transparente.

El tipo de especies transitorias que se pueden detectar con esta técnica son estados excitados tripletes, radicales, radicales aniones 0 radicales cationes.

La técnica de FDL es muy útil para poder dilucidar mecanismos de reacción por el estudio de la evolución cinética de las especies transitorias formadas después de la excitación por láser. 



\section{Conclusiones}

Las interacciones entre FBP, FBPMe y FBPGluc con proteínas de diversas especies se pueden estudiar mediante una metodología basada en la espectroscopía de absorción de especies transitorias.

El FBP se une a dos sitios de ASCe y ASO, en ASC, ASP y ASR interviene un sólo sitio.

EI FBPGluc se une en menor grado que el fármaco de partida a todas las albúminas estudiadas en las que se observa un sólo tipo de microentorno.

En cuanto al FBPMe, se encontró una gran estereodiferenciación en su interacción con ASCe, ASP y ASR, no así en ASC y ASO.

En general, el tiempo de vida de triplete del isómero (R)- es mayor al del isómero (S)- dentro de las proteínas.

Se ha estudiado la actividad glucuronidasa de las albúminas séricas de distintas especies hacía el FBPGluc. En ASH, ASO y ASR se observa una considerable actividad glucuronidasa, además ed una gran estereoselectividad en el proceso ya que el isómero (S)- se degrada considerablemente más rápido que el (R)-. En ASP, ASCe y ASB se aprecia actividad glucuronidasa pero en menor grado. Además, el hecho de que a menor temperatura el proceso sea más lento, indica que la reacción enzimática está teniendo lugar. Por último, en ASC no se observa hidrólisis. Esto podría indicar que, a pesar de la similitud estructural con ASH (alrededor del 75\%), la configuración de la cavidad del sitio de unión de ASC, o bien las propiedades electrostáticas en dicha cavidad son muy diferentes a las encontradas en el rsto de albúminas.

Por otro lado se ha estudiado el grado de unión in situ de FBP, FBPMe y FBPGluc a dos proteínas transportadoras (ASH y AAG) 
presentes simultáneamente en el medio. De esta forma se ha conseguido determinar que, mientras FBP y FBPMe se unen a ambas proteínas, FBPGluc solo se una a ASH.

Por último se utilizo este método para la determinación directa de la composición de una mezcla enantiomérica. Así, se consiguió determinar la composición enantiomérica de diferentes mezclas de (S)y (R)-FBP y (S)- y (R)_FBPMe usando ASH, ASB y ASCe como selectores quirales.

Hemos establecido un método basado en la absorción de especies transitorias para diferentes aplicaciones de gran relevancia. Es un método con muchas ventajas entre las que cabe destacar su rápidez y simpeza, así como la ausencia de tratamiento previo de la muestra, lo que en el caso de proteínas, evita una posible alteración de su conformación que afectaría a la unión con sustratos. Además es sensible y apropiado para pequeñas cantidades $(\mu \mathrm{g})$ de muestra, aunque también es muy tolerante a la presencia de impurezas. 



\section{Resumen en castellano}

Las proteínas son macromoléculas muy abundantes en los organismos vivos que cumplen con diversas funciones vitales. En concreto, la importancia de las proteínas transportadoras como la albúmina sérica humana (ASH) y la alfa glicoproteína ácida (AAG) radica en que actúan como vehículo para la distribución de una amplia variedad de sustancias endógenas y exógenas en la sangre.

El flurbiprofeno (FBP) es un AINE de la familia de los ácidos 2arilpropiónicos ampliamente utilizado. Éste fármaco es transportado en sangre por ASH, aunque AAG también puede intervenir en el proceso. El ester metilico de FBP (FBPMe) es un profármaco que también interacciona con ambas proteínas. El principal metabolito del FBP es su glucurónido (FBPGluc) que, aunque en menor medida, también se une a las $\mathrm{ASH}$.

El estudio de la interacción fármaco/proteína es importante para conocer la biodistribución, el metabolismo, la eliminación y el efecto farmacológico del fármaco en el organismo. El número de técnicas utilizadas para la realización de este tipo de estudios es muy amplio y variado aunque presentan inconvenientes tales como falta de sensibilidad, reproducibilidad o un "work up" complicado. Recientemente se ha usado la técnica de fotólisis de destello láser para el estudio de sistemas fármaco/ASH, demostrando que el estado excitado triplete es muy sensible al medio y que, por tanto, puede ser utilizado como sonda de la unión fármaco-proteína.

Teniendo esto en cuenta, se propuso profundizar en el conocimiento de las interacciones fármaco-proteína, extendiendo el estudio a albúminas séricas de otras especies (usadas como modelo de 
ASH en ensayos con fármacos) así como a otras proteínas transportadoras como puede ser AAG.

En primer lugar, se llevo a cabo la síntesis del glucurónido del FBP (FBPGluc) y su posterior caracterización fotofísica dando lugar a propiedades muy similares a la del fármaco de partida.

Posteriormente, se realizó un estudio de interacción de FBP, FBPMe y FBPGluc con albúminas de diversas especies (conejo, perro, cerdo, oveja y rata) con el fin de detectar analogías y diferencias respecto a ASH. Esto se llevo a cabo con los dos enantiómeros de cada sustrato, para detectar una posible estereodiferenciación en el proceso. Analizando las curvas de desaparición obtenidas se dedujo que, efectivamente, existen diferencias en la unión del fármaco y sus derivados a las $\mathrm{ASs}$ respecto a $\mathrm{ASH}$, tanto en el número de sitios de unión, como en los valores de tiempo de vida de triplete del sustrato unido. En cuanto a la estereodiferenciación, se encontró que apenas ocurre en el caso del FBP, mientras que para el FBPMe si que se da en algunas albúminas (ASCe, ASP, ASR) y en el caso del FBPGluc hay algo de estereodiferenciación en todas las ASs.

A continuación se procedió a estudiar la actividad glucuronidasa de las diferentes albúminas sobre FBPGluc, aprovechando las diferencias en los tiempos de vida de triplete del metabolito respecto a FBP. Se observó que el proceso de hidrólisis tiene lugar a mayor velocidad dentro de la proteína y a temperatura fisiológica que en su ausencia o a temperaturas inferiores.

Como otra aplicación interesante de esta metodología, se procedió al estudio de interacción de cada sustrato con ASH y AAG presentes simultáneamente. De nuevo se realizó un análisis de regresión de las curvas de desactivación donde se obtuvieron 
resultados de ocupación de dichos sustratos en los sitios de unión de cada proteína.

Por último, utilizando la diferencia en los tiempos de vida de triplete de FBP y FBPMe en algunas ASs, se aplicó la metodología para determinar la composición enantiomérica de diferentes mezclas conteniendo (S)- y (R)-FBP o (S)- y (R)-FBPMe, usando las albúminas como selectores quirales y obteniendo excelentes resultados de correlación entre los valores determinados con nuestra metodología y las composiciones reales. 


\section{Resum en valencià}

Les proteïnes són macromolècules molt abundants en els organismes vius, que compleixen diverses funcions vitals. En concret, la importància de les proteïnes transportadores com l'albúmina sèrica humana $(A S H)$ i l'alfaglicoproteïna àcida (AAG) radica en el fet que actuen com a vehicle per a la distribució d'una àmplia varietat de substàncies endògenes $\mathrm{i}$ exògenes en la sang.

El flurbiprofèn (FBP) és un AINE de la família dels àcids 2arilpropiònics àmpliament utilitzat. Aquest fàrmac és transportat en la sang per l'ASH, encara que l'AAG també pot intervenir en el procés. L'ester metílic del FBP (FBPMe) és un profàrmac que també interacciona amb ambdues proteïnes. El principal metabòlit del FBP és el seu glucurònid (FBPGluc) que, encara que en menor mesura, també s'uneix a les ASH.

L'estudi de la interacció fàrmac-proteïna és important per conèixer la biodistribució, el metabolisme, l'eliminació i l'efecte farmacològic del fàrmac en l'organisme. El nombre de tècniques utilitzades per a la realització d'aquest tipus d'estudis és molt ampli i variat, encara que presenten inconvenients com ara la falta de sensibilitat, reproductibilitat o un work up complicat. Recentment s'ha usat la tècnica de fotòlisi de centelleig làser per a l'estudi dels sistemes fàrmac-ASH, i s'ha demostrat que l'estat excitat triplet és molt sensible al mitjà i que, per tant, pot ser utilitzat com a sonda de la unió fàrmacproteïna.

Tenint això en compte, es va proposar aprofundir en el coneixement de les interaccionis fàrmac-proteïna, estenent l'estudi a albúmines sèriques d'altres espècies (usades com a model d'ASH en 
assajos amb fàrmacs), així com a altres proteïnes transportadores com pot ser l'AAG.

En primer lloc, es du a terme la síntesi del glucurònid del FBP (FBPGluc) i la posterior caracterització fotofísica, que dóna lloc a propietats molt similars a la del fàrmac de partida.

Posteriorment, es va realitzar un estudi d'interacció de FBP, FBPMe i FBPGluc amb albúmines de diverses espècies (conill, gos, porc, ovella i rata), amb la finalitat de detectar analogies i diferències respecte a l'ASH. Això es va dur a terme amb els dos enantiòmers de cada substrat, per detectar una possible estereodiferenciació en el procés. Analitzant les corbes de desaparició obtingudes es va deduir que, efectivament, hi ha diferències en la unió del fàrmac $i$ els seus derivats a les ASs respecte a l'ASH, tant en el nombre de llocs d'unió, com en els valors de temps de vida de triplet del substrat unit. Quant a l'estereodiferenciació, es va trobar que amb prou feines ocorre en el cas del FBP, mentre que per al FBPMe sí que es dóna en algunes albúmines (ASCe, ASP, ASR) i, en el cas del FBPGluc, hi ha una mica d'estereodiferenciació en totes les ASs.

A continuació es va procedir a estudiar l'activitat glucuronidasa de les diferents albúmines sobre el FBPGluc, aprofitant les diferències en els temps de vida de triplet del metabòlit respecte al FBP. Es va observar que el procés d'hidròlisi té lloc a més velocitat dins de la proteïna i a temperatura fisiològica que en absència d'aquesta 0 a temperatures inferiors.

Com una altra aplicació interessant d'aquesta metodologia, es va procedir a l'estudi de la interacció de cada substrat amb l'ASH i l'AAG presents simultàniament. De nou es va realitzar una anàlisi de regressió de les corbes de desactivació, on es van obtenir resultats d'ocupació d'aquests substrats en els llocs d'unió de cada proteïna. 
Finalment, utilitzant la diferència en els temps de vida de triplet del FBP i FBPMe en algunes ASs, es va aplicar la metodologia per determinar la composició enantiomèrica de diferents barreges que contenen (S)- i (R)-FBP o (S)- i (R)-FBPMe, usant les albúmines com a selectors quirals i obtenint excel·lents resultats de correlació entre els valors determinats amb la nostra metodologia i les composicions reals. 


\section{Summary}

Proteins are macromolecules very abundant in living organisms, that are involved in various vital functions. In particular, transport proteins (such as HSA and AAG), serve as a vehicle for the distribution of a wide variety of endogenous and exogenous substances in blood.

Flurbiprofen (FBP) is a NSAID of the 2-arylpropiónic acid family. This drug is carried by $A S H$, although AAG may also be involved in the process. Methyl ester of FBP is a prodrug, which also interacts with both proteins. The major phase II metabolite of FBP is its glucuronide that, it also binds to HSA although to a lesser extent

The study of drug/protein interactions is important to understand the biodistribution, metabolism, disposal and pharmacological effect of drugs in the body. A number of techniques are available to address these issues. Recently laser flash photolysis has been used for this purpose, showing that the triplet excited states are very sensitive to the surrounding environment ; therefore, they can be used as a probes for the study of drug-protein binding.

With this background, the main goal of the present work is to extend the previous studies of this group to serum albumins of other species as well as to other transport proteins such as AAG.

Thus, the interaction of FBP, FBPMe and FBPGluc with albumins of various species (rabbit, dog, pigs, sheep and rat) was undertaken to establish comparisons with the case of HSA. This parallel experiments have been carried out with both enantiomers of each compound, to detect a possible stereodifferentiation in their interaction with the proteins. An appropiate analysis of the decays traces revealed significant species dependent differences in the binding of the drug or its 
derivatives to SAs, both in the number of binding sites, and in the triplet lifetimes within the protein.

The glucuronidase activity of different albumins on FBPGluc has also been investigated, taking advantage of the different triplet lifetimes of FBPGluc and FBP within the protein binding sites. An interesting observation is that hydrolysis takes actually place inside the protein, at physiological temperature.

Another interesting application of the methodology is the interaction of the substrates with HSA and AAG present simultaneously. A regression analysis of the decay traces, provides valuable information about the binding sites of both proteins.

In conclusion, a novel method for the straightforward determination of enantiomeric compositions is presented here. It is based on transient spectroscopy, exploiting the differences in triplet lifetimes within serum albumins for chiral recognition. The method is fast and simple, as it requires just one measurement per sample to provide accurate results. It is highly sensitive and is appropriate for analysis of minute $(\mu \mathrm{g})$ amounts. As further advantages, it avoids substrate derivatization as well as chromatographic separation and does not depend on the specific rotation on the target compound. All together, the above reasons make this LFP-based approach a very complementary tool to the existing techniques. 

- C. J. Bueno, I. Vayá, M.C. Jiménez, M. A. Miranda.

"Use of triplet excited states for the study of drug binding to human and bovine serum albumins". III Reunión de Químico Orgánica del Mediterráneo. Octubre 2006; Castellón. Poster.

- C. J. Bueno, I. Vayá, M.C. Jiménez,M. A. Miranda.

"Laser flash photolysis for the study of flurbiprofen binding to human and bovine serum albumins". II Jornadas ibéricas de fotoquímica. Julio 2007; Faro (Portugal). Poster.

- M.C. Jiménez, C. J. Bueno, I. Vayá, M. A. Miranda.

"Triplet Excited States as Reporters for the Binding of Drugs to Serum Albumins. Competition Studies on Human vs. Bovine Protein Occupancy". XXIII International conference on photochemistry. Julio 2007; Colonia (Alemania). Poster.

- C. J. Bueno, M.C. Jiménez, M. A. Miranda.

"Study of hydrolysis of acyl glucuronides in the presence of human serum albumin by transient absorption spectroscopy". XV Jornadas Hispano-Francesas de Química Orgánica. Junio 2008; Bousense (Francia). Presentación Oral.

- M.C. Jiménez, C. J. Bueno, I. Vayá, M. A. Miranda.

"Determination of enantiomeric composition by transient absorption spectroscopy in the presence of proteins". XV Jornadas Hispano-Francesas de Química Orgánica. Junio 2008; Bousense (Francia). Presentación oral.

- C. J. Bueno, M.C. Jiménez, M. A. Miranda.

"Laser flash photolysis on the glucuronidase activity of human serum albumin". XXII IUPAC Symposium on Photochemistry. Julio 2008; Goteborg (Suecia). Poster.

- I. Vayá, C. J. Bueno, M.C. Jiménez, M. A. Miranda.

"Determiantion of enantiomeric compositions by transient absorption spectroscopy within serum albumins". XXII IUPAC 
Symposium on Photochemistry. Julio 2008; Goteborg (Suecia). Poster.

- C. J. Bueno, M.C. Jiménez, M. A. Miranda.

"Transient absorption spectroscopy for the study of flurbiprofen interaction with binary serum albumin/alpha-1-acid glycoprotein systems". XXIV International Conference on Photochemistry. Julio 2009; Toledo (España). Poster.

- M.C. Jiménez, C. J. Bueno, I. Vayá, M. A. Miranda.

"Transient absorption spectroscopy of drugs derivatives within protein microenviroment". IX Congreso de Fotoquímica. Septiembre 2009; Bilbao (España). Presentación oral. 

- Vayá, Ignacio; Bueno, Carlos J.; Jiménez, M. Consuelo; Miranda, Miguel A. Determination of enantiomeric compositions by transient absorption spectroscopy using proteins as chiral selectors. Chemistry--A European Journal (2008), 14(36), 11284-11287. Language: English, Database: CAPLUS

- Bueno, Carlos J.; Jiménez, M. Consuelo; Miranda, Miguel A. In Situ Transient Spectroscopy for the Study of Glucuronidase Activity within Serum Albumin. Journal of Physical Chemistry B (2009), 113(19), 6861-6865. Language: English, Database: CAPLUS

\section{Otras publicaciones}

- Vayá, Ignacio; Bueno, Carlos J.; Jiménez, M. Consuelo; Miranda, Miguel A. Use of triplet excited states for the study of drug binding to human and bovine serum albumins. ChemMedChem (2006), 1(9), 1015-1020. Language: English, Database: CAPLUS

- Bueno, Carlos J.; Jiménez, M. Consuelo; Miranda, Miguel A. Determination of Drug Distribution in Binary Serum Albumin/Alpha-1-Acid Glycoprotein Systems using Transient Absorption Spectroscopy. Enviado

- Bueno, Carlos J.; Jiménez, M. Consuelo; Miranda, Miguel A. Glucuronidase activity of serum albumins of different species determinaed by LFP. En preparación. 